RFP-2061

February 1, 1974

\title{
CAUSES OF THE YIELD-POINT PHENOMENON \\ IN COMMERCIAL BERYLLIUM PRODUCTS
}

\author{
Dennis Roy Floyd
}

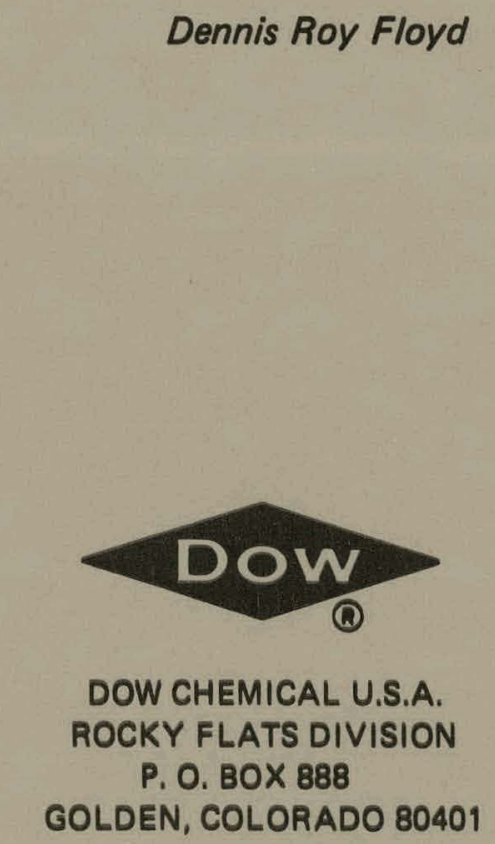

U. S. ATOMIC ENERGY COMMISSION CONTRACT AT(29:1)=1106 


\section{DISCLAIMER}

This report was prepared as an account of work sponsored by an agency of the United States Government. Neither the United States Government nor any agency Thereof, nor any of their employees, makes any warranty, express or implied, or assumes any legal liability or responsibility for the accuracy, completeness, or usefulness of any information, apparatus, product, or process disclosed, or represents that its use would not infringe privately owned rights. Reference herein to any specific commercial product, process, or service by trade name, trademark, manufacturer, or otherwise does not necessarily constitute or imply its endorsement, recommendation, or favoring by the United States Government or any agency thereof. The views and opinions of authors expressed herein do not necessarily state or reflect those of the United States Government or any agency thereof. 


\section{DISCLAIMER}

Portions of this document may be illegible in electronic image products. Images are produced from the best available original document. 
This report was prepared as an account of work sponsored by the United States Government. Neither the United States nor the United States Atomic Energy Commission, nor any of their employees, nor any of their contractors, subcontractors, or their employees, makes any warranty, expressed or implied, or assumes any legal liability or responsibility for the accuracy, completeness or usefulness of any information, apparatus, product or process disclosed, or represents that its use would not infringe privately owned rights.

Printed in the United States of America

Available from the

National Technical Information service

U. S. Department of Commerce

Springfield, Virginia 22151

Price: Printed Copy $\$ 4.00$ Microfiche $\$ 1.45$ 


\title{
CAUSES OF THE YIELD-POINT PHENOMENON IN COMMERCIAL BERYLLIUM PRODUCTS
}

\author{
Dennis Roy Floyd
}

Research and Ecology

GENERAL METALLURGY GROUP

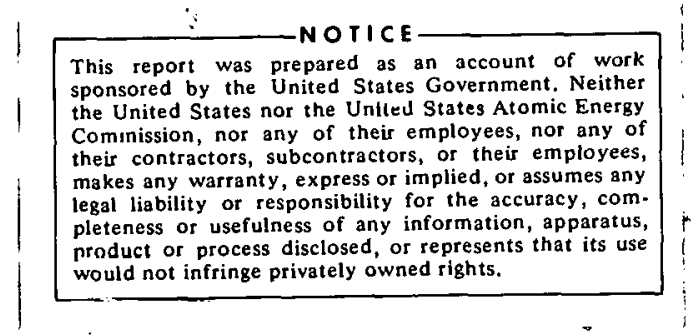

DOW CHEMICAL U.S.A.

ROCKY FLATS DIVISION

$$
\text { P. O. BOX } 888
$$

GOLDEN, COLORADO 80401

Prepared under Contract AT(29-1)-1106

for the

Albuquerque Operations Office

U. S. Atomic Energy Cómmission

\section{SUBJECT DESCRIPTORS}

Beryllium

Mechanical Properties

Metallurgy (Physical)

Yield Propertics

Yleld Point

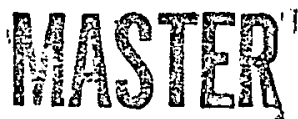




\section{ACKNOWLEDGMENTS}

The author gratefully acknowledges the aid of Dr. W. L. Bradley. who provided excellent advice and counsel throughout the course of this work; also Mr. R. H. Karlsson in providing the materials and encouraging the work on this project. Machining support was ably supplied by R. F. Biella and B. F. Duesterheck. W. W I eslie and A. D. Mille coordinated much of the experimental work. Metallography was provided by J. M. Capes and R. F. Hillyer and inlcroscopy bỹ A. W. Brewer. Chemical analyses are due to C. E. Caldwell. X-ray diffraction results are due to L. E. Bramlet. My thanks are extended to all of them. Special thanks are given to D. V. Miley, G. G. Gauger, and R. F. Brugger for their support and excellent work in mechanical testing. Other researchers in the field have made helpful contributions through their own work, and special appreciation is given S. H. Gelles at Battelle Columbus Laboratory and J. R. Hauber at Lawrence Livermore Laboratory. 


\section{CONTENTS}

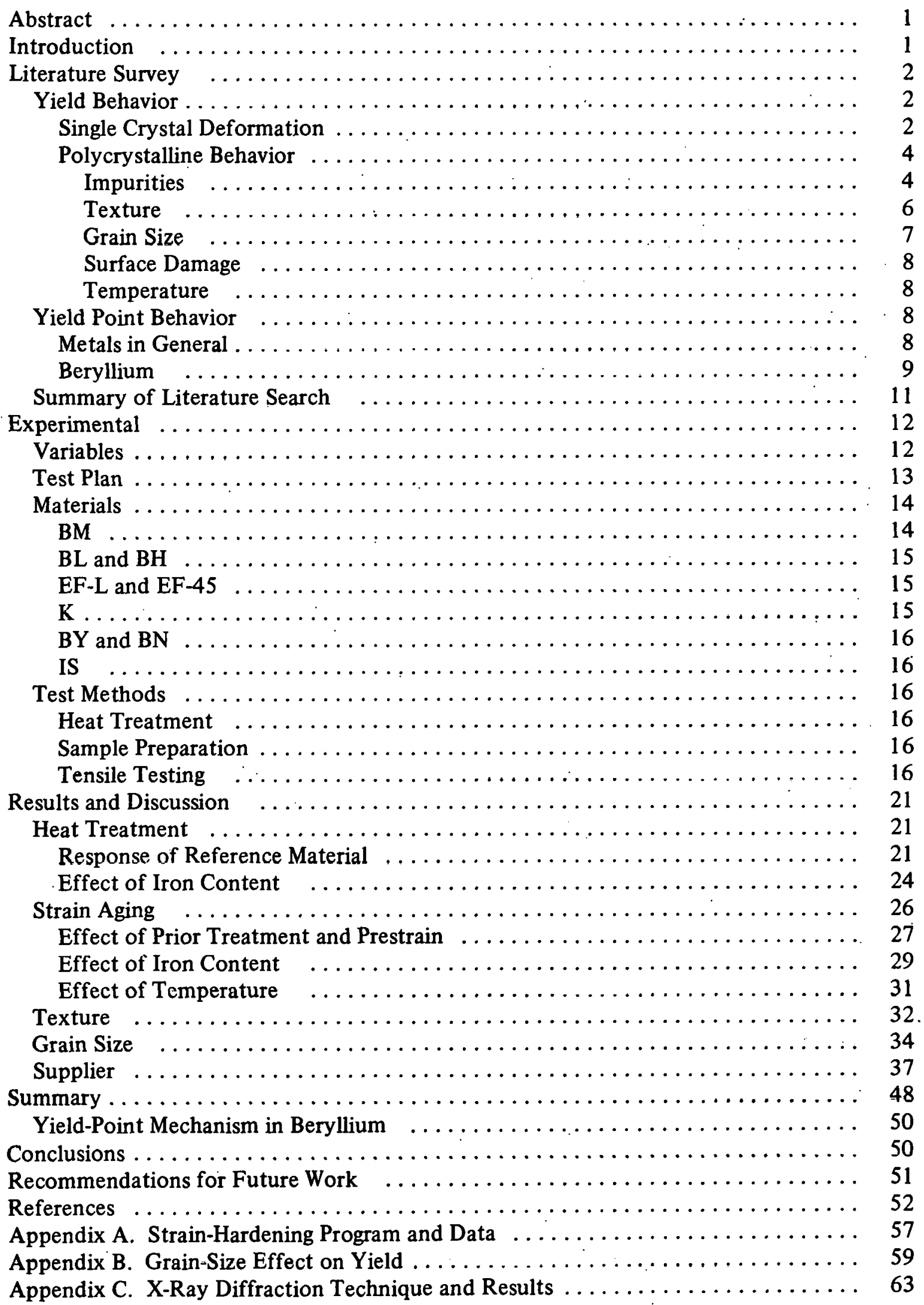




\section{LIST OF FIGURES}

1. Aging-Solutionizing Reactions in Beryllium $\ldots \ldots \ldots \ldots \ldots \ldots \ldots \ldots \ldots \ldots \ldots \ldots$

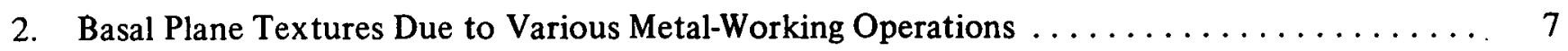

3. Key Features of the Yield Point Phenomenon for Mild Steel $\ldots \ldots \ldots \ldots \ldots \ldots \ldots \ldots$

4. Variables Controlling the Yield Behavior of Beryllium $\ldots \ldots \ldots \ldots \ldots \ldots \ldots \ldots \ldots \ldots \ldots$

5. Texture and Location of Tensile Bars in Extruded Flat $\ldots \ldots \ldots \ldots \ldots \ldots \ldots \ldots \ldots \ldots$

6. Photomicrographs of Materials Used in This Study $\ldots \ldots \ldots \ldots \ldots \ldots \ldots \ldots \ldots \ldots \ldots \ldots$

7. Tensile Bar Design for Hot-Pressed Materials $\ldots \ldots \ldots \ldots \ldots \ldots \ldots \ldots \ldots \ldots \ldots \ldots \ldots \ldots$

8. Tensile Bar Design for Ingot-Sheet Materials $\ldots \ldots \ldots \ldots \ldots \ldots \ldots \ldots \ldots \ldots \ldots \ldots \ldots . \ldots 21$

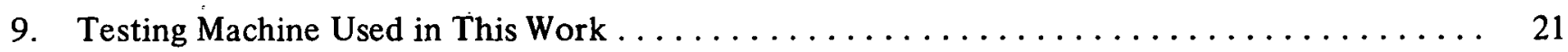

10. Gripping Mechanism for Tapered End Bars $\ldots \ldots \ldots \ldots \ldots \ldots \ldots \ldots \ldots \ldots \ldots \ldots \ldots \ldots$

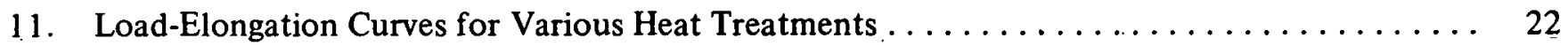

12. Solid-Solubility Limit for Iron in Beryllium $\ldots \ldots \ldots \ldots \ldots \ldots \ldots \ldots \ldots \ldots \ldots \ldots \ldots$

13. Plot Showing the Effect of

Solid-Solution Iron on the Yield Stress of Beryllium $\ldots \ldots \ldots \ldots \ldots \ldots \ldots \ldots \ldots$

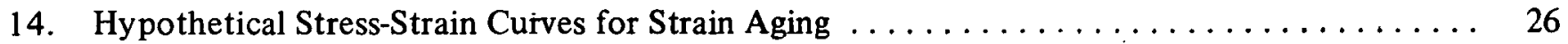

15. Load Extension Curves for $400{ }^{\circ} \mathrm{C}$ Strain-Aging Iron Alloys $\ldots \ldots \ldots \ldots \ldots \ldots \ldots$

16. Plot of Strain-Aging Parameter, $\Delta$, Versus Iron Content $\ldots \ldots \ldots \ldots \ldots \ldots \ldots \ldots \ldots \ldots$

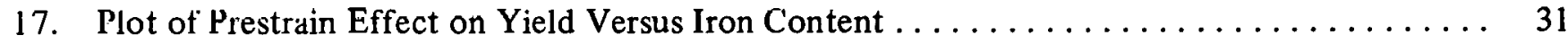

18. Load-Extension Curves for

BH Material Showing the Strain-Enhanced Precipitation Effect $\ldots \ldots \ldots \ldots \ldots \ldots \ldots$

19. Hall-Petch Plot of Grain Growth Data for BM and EF Material . . . . . . . . . .. 36

20. Load-Extension Curves for Ingot Sheet $\ldots \ldots \ldots \ldots \ldots \ldots \ldots \ldots \ldots \ldots \ldots \ldots \ldots \ldots$

21. Load-Extension Curves for Direct-Aging KBI Material $\ldots \ldots \ldots \ldots \ldots \ldots \ldots \ldots \ldots \ldots$

22. Photomicrographs of KBI Material Which Has a Strong Yield Drop $\ldots \ldots \ldots \ldots \ldots$

23. Load-Extension Curves of

EF-45 Material Showing Largest Yield Drop Found in This Study . . . . . . . . . . 47

1-B. Hall-Petch Plot for Two Hot-Pressed Materials $\ldots \ldots \ldots \ldots \ldots \ldots \ldots \ldots \ldots \ldots \ldots \ldots$

1-C. Complete X-Ray Diffraction Pattern of a Solid Beryllium Sample . . . . . . . . . .. 63

2-C. Partial X-Ray Diffraction Pattern of a Solid Beryllium Sample $\ldots \ldots \ldots \ldots \ldots \ldots \ldots$ 


\section{LIST OF TABLES}

1. Variables Studied to Determine

Their Effect on the Yield Behavior of Beryllium $\ldots \ldots \ldots \ldots \ldots \ldots \ldots \ldots \ldots \ldots \ldots \ldots$

2. Chemical Analyses of Materials Used in This Study $\ldots \ldots \ldots \ldots \ldots \ldots \ldots \ldots \ldots \ldots \ldots \ldots$

3. Tensile Data for BM Material in Various Heat-Treat Conditions $\ldots \ldots \ldots \ldots \ldots \ldots \ldots$

4. Tensile Data for Iron Alloys in Various Heat-Treat Conditions $\ldots \ldots \ldots \ldots \ldots \ldots \ldots \ldots$

5. Correction Factors for Determining Flow Stress $0.2 \%$ Beyond Unloading $\ldots \ldots \ldots \ldots$

6. Yield Stress Data for $400^{\circ} \mathrm{C}$ Strain Aging of BM Material $\ldots \ldots \ldots \ldots \ldots \ldots \ldots \ldots \ldots$

7. Yield Stress data for $400^{\circ} \mathrm{C}$ Strain Aging of Iron Alloys $\ldots \ldots \ldots \ldots \ldots \ldots \ldots \ldots \ldots \ldots$

8. Separation of Aging, Strain Aging, and Strain Effects for Iron Alloys Strain Aged at $400^{\circ} \mathrm{C} \ldots \ldots \ldots \ldots \ldots \ldots \ldots \ldots$

9. Confirmation of Strain-Induced Precipitation in the $\mathrm{BH}$ Material $\ldots \ldots \ldots \ldots \ldots \ldots \ldots$

10. Results of $760^{\circ} \mathrm{C}$ Strain Aging of the Iron Alloys $\ldots \ldots \ldots \ldots \ldots \ldots \ldots \ldots \ldots \ldots \ldots \ldots \ldots \ldots \ldots \ldots$

11. Effect of Heat Treatment on

Yield and Yield-Drop Behavior of Extruded Flat Material $\ldots \ldots \ldots \ldots \ldots \ldots \ldots \ldots$

12. Results of $400^{\circ} \mathrm{C}$ Strain Aging of Extruded Flat Material $\ldots \ldots \ldots \ldots \ldots \ldots \ldots \ldots \ldots \ldots$

13. Results of $760^{\circ} \mathrm{C}$ Strain Aging of Extruded Flat Material $\ldots \ldots \ldots \ldots \ldots \ldots \ldots \ldots \ldots$

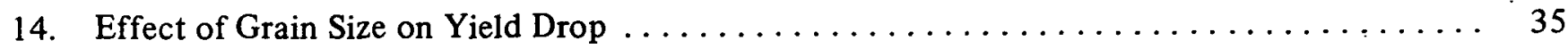

15. Effect of Supplier on Heat Treatment Results $\ldots \ldots \ldots \ldots \ldots \ldots \ldots \ldots \ldots \ldots \ldots \ldots$

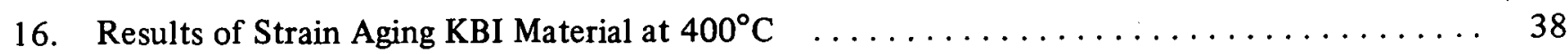

17. Results of Direct Aging Brush and Kawecki-Berylco Industries Material . . . . . . . . 38

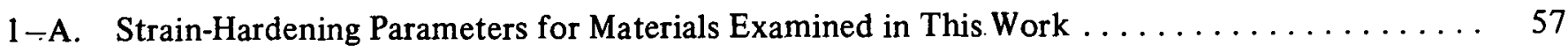

1-B. Grain Size and Yield Stress Data for Two Types of

Hot-Pressed Beryllium, BY and BN, Given Various Heat Treatments $\ldots \ldots \ldots \ldots \ldots .60$

1-C. Relative Intensity of $\mathrm{FeBe}_{11}$ and

$\mathrm{AlFeBe}_{4} \mathrm{X}$-Ray Diffraction Peaks as a Function of Heat Treatment $\ldots \ldots \ldots \ldots \ldots$ 


\section{EXPLANATIONS OF SYMBOLS AND TERMS USED IN THIS REPORT}

\section{Symbol}

or Term

A

Strair

train hardening coefficient, in the rela-

AGING Heat treatment designed to cause precipitation, always preceded by solutionizing unless otherwise stated

AR As-received condition

B A specific aging treatment: $650^{\circ} \mathrm{C}$ for 6 hours followed by a slow cool

BH Brush high-iron hot-pressed beryllium

BL Brush low-iron hot-pressed beryllium

BM Brush inedium-iron hot-pressed beryllium.

BN Brush no yield drop (AR) hot-pressed heryllium

BY Brush yield drop (AR) hot-pressed beryllium

BRUSH An abbreviation for the Brush-Wellman Co., Inc., Cleveland, Ohio

CRSS Critical Resolved Shear Stress

$\Delta$

$\Delta \sigma \quad$ The magnitude of the yield drop, defined as the difference between the upper and lower yield stress

EF Extruded flat, Brush hot-pressed and extruded material

EF-L Longitudinal test orientation, favoring prism slip

EF-45 Test orientation $45^{\circ}$ to longitudinal, favoring basal slip

$\epsilon \quad$ True plastic tensile strain in the strain hardening expression $\sigma=A \epsilon \mathrm{m}$

FAST Cooling rate used subsequent to soluCOOL tionizing treatments wherein tensile blanks are pulled out of furnace hot zone into cool air or flowing argon. Synonymous with rapid cool
Symbol

or Term

FLOW Descriptive term for the plastic portion

CURVE of the load-extension curve

FLOW The stress at any specified point on the

STRESS flow curve

$\mathrm{G}$ Grain growth anneal; $1150^{\circ} \mathrm{C}, 6$ hours, fast cool

GT Aging treatment subsequent to $\mathrm{G} ; 760^{\circ} \mathrm{C}$, 6 hours slow cool

HALL- A plot of yicld stress versus the inverse

PETCH square root of grain size

PLOT

i

IS

K KBI, hot-pressed beryllium

KBI An abbreviation for Kawecki-Berylco Industries, Hazelton, Pennsylvania

ksi Kilopounds per Square Inch

m Strain-hardening exponent, from the relationship $\sigma=A \epsilon \mathrm{m}$. Descriptive of the shape of the flow curve

MT Modified T-aging cyclc, where aging is done directly on material in the AR condition without first solutionizing

$\mathrm{OA} \quad$ An over-aging heat treatment; $1040^{\circ} \mathrm{C}$, 6 hours slow cool; to $760^{\circ} \mathrm{C}, 24$ hours, slow cool

$\cdot p$

Subscripted to yield data, means the flow curve has a horizontal "plateau"

ppm Parts per million, by weight

psi Pounds per square inch

RAPID Same as fast cool

COOL

RFD An abbreviation for the Rocky Flats

Division of Dow Chemical U.S.A., Golden, Colorado

$\mathrm{S}$

Solutionizing anneal; $1040^{\circ} \mathrm{C}, 6$ hours, rapid cool 
Symbol

or Term

$\begin{array}{ll}\text { SLOW } & \text { Programmed cooling rate of } 25^{\circ} \mathrm{C} \text { per } \\ \text { COOL } & \end{array}$

STD An abbreviation for standard deviation,

DEV - a statistical term indicative of degree of data scatter

STRAIN Aging preceded by room temperature

AGING pre-strain. Prior condition may be, but does not have to be, solutionized

$\sigma$

Stress. Load divided by original area except for strain-hardening computations

$\sigma_{1} \quad$ Yield stress

$\sigma_{2} \quad$ Flow stress at a given pre-strain

$\sigma_{2}^{\prime} \quad$ Yield stress after strain aging

$\mathbf{T}$

T-1 Same as T, except only 1 hour at $760^{\circ} \mathrm{C}$
Symbol or Term

TEM Transmission Electron Microscopy

$X$. At the end of the flow curve indicates sample fractured

y

Sub-scripted to yield data, indicates a yield drop is present in the flow curve(s)

YIELD Same as yield stress

YIELD A decrease in the stress required to

DROP sustain plastic flow during tensile loading, characterized by a "dip" in the flow curve

YIELD The presence of a discontinuity in the

POINT flow curve, such as a drop, plateau, or inflection; synonomous with yield drop

YIELD The stress present at $0.2 \%$ of fset 
RFP-2061 


\title{
CAUSES OF THE YIELD-POINT PHENOMENON IN COMMERCIAL BERYLLIUM PRODUCTS
}

\author{
Dennis Roy Floyd
}

\begin{abstract}
The purpose of this work is to characterize the yield point behavior of commercial beryllium materials and thereby pinpoint the responsible mechanism. The variables of iron content, texture, and grain size are studied as a function of solutionizing, aging, and strain-aging heat treatments. Yield effects are measured by room temperature tensile tests at constant strain rate.
\end{abstract}

Results show that the yield point commonly observed in commercial beryllium products is caused by precipitate pinning. Furthermore, precipitation is enhanced by pre-strain. The pre-strain can be introduced by elevated-temperature working, rapid cooling, or tensile elongation at room temperature. Aging is effective at temperatures between $400^{\circ} \mathrm{C}$ and $760^{\circ} \mathrm{C}$, depending on the type of pre-strain, iron content, and texture. Cottrell-type solute pinning is not observed, and the model described by Hahn for yield drops in body-centered cubic metals best explains these results.

Texture increases the likelihood of a yield point occurring. In the case of extruded-flat stock, texture causes a 3-fold increase in the amount of hardening accompanying the yield point when compared to hot-pressed block. Yield points appear on aging and strain-aging for orien tations favoring either prism or basal flow.

Fine grain size is a necessary condition for the occurrence of a yield point. A yield point can occur if: the average grain size is less than 10 microns, the microstructure is duplex and has a large number of grains less than 5 microns in size, a substructure exists with subgrains less than 5 microns in size. Grain-growth anneals can irreversibly eliminate a yield point.

Differences in the frequency of appearance of yield points can be explained by the above factors, and a strong yield point can be developed in material supplied by Brush and KBI by appropriate treatment.
The solid solution hardening effect of iron on yield stress is seen to be linear with a slope of $2.3 \mathrm{psi}$ per ppm in the range of iron from 640 to $5850 \mathrm{ppm}$. The grain-size effect, in the range from 8 microns to 45 microns, is seen to be linear for a Hall-Petch plot of yield stress versus inverse square root of grain size. The magnitude of the effect is $136 \mathrm{ksi}$ (microns) $)^{1 / 2}$, which is the slope of the plot.

The results of this work are obtained principally from about 150 room-temperature tensile tests of powder-source beryllium products. Heat treatments studied include solutionizing at $1040^{\circ} \mathrm{C}$; aging at $400^{\circ} \mathrm{C}, 650^{\circ} \mathrm{C}$, and $760^{\circ} \mathrm{C}$; and strain aging at $400^{\circ} \mathrm{C}$ and $760^{\circ} \mathrm{C}$. Commercially available, vacuum hot-pressed beryllium products with iron contents of $640,1750,2250$, and $5850 \mathrm{ppm}$ are given these heat treatments. Preferred crystallographic orientation is induced by extrusion of a rectangular cross section 3.75 -in. wide by 0.375 -in. thick at $870^{\circ} \mathrm{C}$. Grain size is altered by annealing at $1100^{\circ} \mathrm{C}$ and $1150^{\circ} \mathrm{C}$.

\section{INTRODUCTION}

Interest in this topic arose from the author's related work experience with the metal beryllium. A problem with beryllium cracking subsequent to welding was, at one point, thought to be associated with the occurrence of a yield point. A yield point is defined in this report to be a sudden decrease in load during tensile testing. Subsequent work revealed that not all cracked material had yield points, but a statistically significant percentage of the material had a high $0.2 \%$ off set yield stress. The apparent association between cracking and yield points was due to the high $0.2 \%$ offset yield stress normally present in materials having yield points.

Although the yield-point phenomenon is no longer thought to be the fundamental reason for that 
cracking problem, the investigation at the time showed that very little understanding of the phenomenon exists for beryllium. This work is therefore undertaken to help fill that gap. It is the objective of this study to determine the effect on the yield point phenomenon of those variables known to affect the yield behavior of beryllium. A further objective is to establish the micromechanism responsible for the phenomenon.

In the course of this work it became evident that, despite considerable effort aimed at understanding the factors controlling the yield stress in beryllium, serious gaps existed. Since a thorough understanding of yield is a necessary foundation for any study of the yield-point phenomenon, filling these gaps became essential to this work. Consequently, the contribution of this research falls in two areas:

1. Yield Phenomena - such as grain size, solubility, precipitation, recovery, and texture effects.

\section{Yield-point Phenomenon.}

The distinction between these is simply that the yield-point phenomenon is a special case of yield where the normal flow-curve is interrupted by a stress decrease.

This report is written for an audience that ranges from those who are quite familiar with beryllium metallurgy to those who have but a passing acquaintance with it. The results are presented in the order that the work was actually done. Extensive test results of a reference material are first analyzed statistically. The significance of changes in yield stress during the course of the study can then be assessed by comparison to the standard deviations found in this statistical analysis. Next the yield-point behavior of the reference material is examined as a function of heat treatment. The effect of iron content on yield and yield-point behavior is then presented. Strain-aging experiments are described and results for the iron alloys are presented to establish the yield-point mechanism. The influence of texture and grain size on the occurrence of yield points is next analyzed, and the effect of grain size on yield is included in Appendix B. Results of this work are applied to material from another supplier and a large yield point is induced in this product. Finally the results are summarized and a yield-point mechanism is proposed.

\section{LITERATURE SURVEY}

The yield-point phenomenon can only be understood if yield itself is first understood. A comprehensive review of the literature has revealed limited data concerning the yield-point behavior of beryllium, but it has disclosed most of the available information about yield behavior. A summary of these data is included in this section.

\section{Yield Behavior}

The greatest amount of research work aimed at understanding and improving the mechanical properties of beryllium was performed between 1955 and 1965 . The most significant work during that period was reported at three major conferences held in London, ${ }^{1}$ Philadelphia, ${ }^{2}$ and Grenoble. ${ }^{3}$ Because of the strategic uses of beryllium the most intensive work was sponsored by the governments of Great Britain, France, and the United States. Since no solution to the ductility problem resulted from these efforts, government support has been largely withdrawn. The limited funding that is available is being spent on specific, short-range applications and not on basic research. ${ }^{4}$ The information in this literature survey results principally from that 10 year period, 1955 to 1965 . The deformation characteristics of single crystals will be presented first to establish a foundation for the discussion, which follows, on polycrystalline behavior.

\section{Single Crystal Deformation}

The room-temperature, critical-resolved shear stress (CRSS) is lower for basal slip ( $2000 \mathrm{psi}$ ) than it is for prism slip $(\sim 10,000 \mathrm{psi})$ in commercially pure beryllium. ${ }^{5}$ This is anomalous, since the c/a ratio of beryllium (1.568) is less than ideal (1.633), suggesting that atoms in prism planes are more closely packed than in basal planes and therefore 
should flow more easily. The slip direction is the same for basal planes as it is for prism $-<11 \overline{2} 0\rangle$. There are no other active slip systems for beryllium at room temperature. Single crystal specimens, when loaded in compression along the c-axis so that there is no shear stress on either prism or basal planes, will strain elastically until a stress of about 300,000 psi is reached. At this stress level the sample literally explodes into many fragments with no measurable plastic flow having occurred. ${ }^{6}$

Beryllium single crystals fail by cleavage on the basal plane (0002), second order prism plane (11 $\overline{2} 0)$, or on the $(10 \overline{1} 2)$ twin plane. ${ }^{7}$ The basal-plane fracture mode is the most common and is thought to be best described by the Stroh bend-plane splitting mechanism. ${ }^{7}$ This occurs when dislocations resulting from non-uniform basal slip form a wall perpendicular to the basal plane, constructing a $(1 \overline{2} 0)$ low angle boundary or bend plane. This bend plane moves under applied stress and, when it encounters an obstacle, part of the plane moves ahead resulting in a "split" in the basal plane. This new crack propagates readily on the basal plane because there is no nonbasal slip mode available to blunt the crack. ${ }^{7}$

The ductility of single-crystal beryllium is also orientation dependent. Crystals oriented for basal slip will fail at about $8 \%$ strain, whereas crystals oriented for prism slip can be strained up to $35 \%$ prior to fracture. In prism slip, if the tensile axis is perpendicular to a set of primary prism planes $(10 \overline{10})$, the other two sets of primary prism planes $(1 \overline{100})$ and $(01 \overline{10})$ each form angles of $30^{\circ}$ with the tensile axis. Deformation will begin on one of the prism planes and continue until rotation occurs, decreasing the stress on the active slip plane. The rotation also increases the stress on the other prism plane and deformation commences on this plane. Eventually, the second plane rotates and deformation begins once again on the first plane. Slip continues alternately on one plane and then the other until the crystal necks down to a knife edge. This process is called duplex slip. A cylindrical single crystal looks like a crimped tube after necking in duplex slip. The diameter of the bar does not change in the direction of the c-axis because of the absence of slip systems in that direction.?
Increasing the test temperature for single crystals results in additional slip systems being activated. These include nonbasal systems such as $(10 \overline{1} 1)$ $<11 \overline{2} 0\rangle,(10 \overline{1} 1)<1 \overline{1} 01>$, and $(\overline{1} 014)<\overline{1} 120>^{8}$ Also, increasing the test temperature causes a decrease in the CRSS for prism slip from 10,000 psi at $25^{\circ} \mathrm{C}$ to 2,000 psi at $500^{\circ} \mathrm{C}$. The CRSS for basal slip remains unchanged in this temperature range, and so the deformation behavior becomes more isotropic at elevated temperatures than at room temperature. These factors combine to improve single crystal ductility at elevated temperature.

Purification has a pronounced effect upon singlecrystal behavior. Multi-pass, zone-refined material exhibits a CRSS for basal slip at room temperature of 200 psi, compared to 2000 psi for commercially pure material. ${ }^{9}$ These same materials have CRSS values for prism slip of 8,000 psi and $10,000 \mathrm{psi}$, respectively. This indicates that the impurity effects are more predominant in the basal plane, which is contrary to the prediction of Hanes, et al., that impurities are restricting prism slip in beryllium. ${ }^{7}$

The effect of alloy additions on single crystals was also studied by Kaufman and Aronin. ${ }^{9}$ Copper had the most pronounced effect; a 5 weight-percent addition increasing the CRSS for basal and prism slip to 8,000 psi and 12,000 psi, respectively. Since the original CRSS values were $200 \mathrm{psi}$ for basal slip and 8,000 psi for prism, the copper had a greater effect on basal slip and lowered the ratio of prism-to-basal CRSS from 40:1 to 1.5:1. Therefore, both purification and selective alloying can improve isotropy in single-crystal beryllium.

Recently published work by Averback has suggested that beryllium does not exhibit characteristic metallic bonding between atoms in the c-axis direction. ${ }^{10}$ The interatomic bonding for directions within the basal plane seems to be metallic. These conclusions were obtained by acoustical measurements of elastic constants and Compton-scattering experiments and seem to indicate that bonding in the direction of the $c$-axis is covalent. If true, this would help explain the high degree of anisotropy exhibited by single crystals. Some workers are beginning to analyze their results from the viewpoint of orientation-dependent interatomic bonding, 
and in at least one case confirm Averbach's work. ${ }^{11}$ Covalent bonding results in strong interatomic bonds and high melting points, such as a diamond. ${ }^{12}$ The elastic modulus of beryllium is higher along the c-axis, tending to support the theory of covalent bonding in that direction.

Twinning is an important characteristic of beryllium, since it can accomodate some of the strain which the absence of "c plus a" (or nonbasal) slip will not tolerate. Also twinning is associated with crack formation. The twinning plane is (10/2) which is a second-order pyramidal plane, and the twinning direction is (1011). For twinning to occur, geometric lattice restraints require contraction in the a-direction and dilation in the cdirection. This means that single crystals loaded in the c-direction will not twin in compression but can twin in tension if the stress is sufficiently high $\left(\sim 16,000\right.$ psi). ${ }^{7}$ Conversely, compression is required to induce twinning in crystals loaded in the adirection. ${ }^{13}$

\section{Polycrystalline Behavior}

The preceding discussion of single-crystal behavior should give the reader a strong indication of polycrystalline-beryllium properties. The anisotropy should carry over, especially in beryllium bodies having preferred orientation or texturing. The brittleness problem will persist because only four independent slip systems (three sets of prism planes and one set of basal planes) are available. Taylor has pointed out that five independent slip systems are necessary to ensure compatibility; this requirement arising from the observation that four independent strain measurements are needed to fully define the deformation of a volume element. ${ }^{14}$ Also, since slip with a nonbasal Burgers vector is not possible, blunting of crack tips by plastic flow will not be possible and ductility will be further reduced.

Yisld strength will probably be increased significantly over the observed CRSS values for single crystals. This is because, once flow commences at low stress values in grains with favorable basalplane orientations, the flow will cease at the boundary and not be continued in adjacent grains because of orientation differences. Deformation by prism slip occurs only at stresses five times as great as the stress required for basal slip. Therefore, high stress concentrations arc needed to activate slip in adjacent grains oriented for prism slip. Adjacent grains with no available slip systems will be stressed to very high values and may twin or crack. The net effect of these limitations on plastic flow should be to significantly increase the stress required to reach a given strain level (e.g., $0.2 \%$ ) and to limit ductility. Elevated temperatures should improve ductility by providing nonbasal slip modes and causing the CRSS for basal and prism slip to become more nearly equal. Alloying with copper may improve the anisotropy between CRSS for prism and basal slip. These effects are discussed in the following sections.

\section{Impurities}

As mentioned earlier, commercially pure beryllium is actually an alloy. Some of the naturally occurring impurities behave as alloying elements. The elements thought to be most significant in metallurgical reactions are iron, aluminum, and silicon. These elements are also present in the greatest concentrations; typically 800 to $1500 \mathrm{ppm}$ for iron, 300 to $1000 \mathrm{ppm}$ for aluminum, and 400 to $800 \mathrm{ppm}$ for silicon.

Iron is known to form two precipitates: a binary, $\mathrm{FeBe}_{11}$; and a ternary, $\mathrm{AlFeBe}$. The ternary precipitate was found by the French in 1960 to be an fcc compound and they also showed that the precipitate occurred in a fixed orientation to the beryllium lattice. ${ }^{15}$ The binary precipitate was found at about the same time, ${ }^{16}$ and was later shown to be $\mathrm{FeBe}_{11}$ and to have a hexagonal closepacked structure. ${ }^{17}$ The formulation of the ternary compound is due to Carrabine, ${ }^{18}$ who showed that iron could be replaced in the compound by any of the transition elements.

The aging-solutionizing reactions in beryllium have been characterized by Fraikor ${ }^{19}$ and are depicted in Figure 1. Heating above $900^{\circ} \mathrm{C}$ puts the transition elements in solid solution and the aluminum and silicon, which are insoluble, migrate to grain boundaries. The solutionized condition can be 


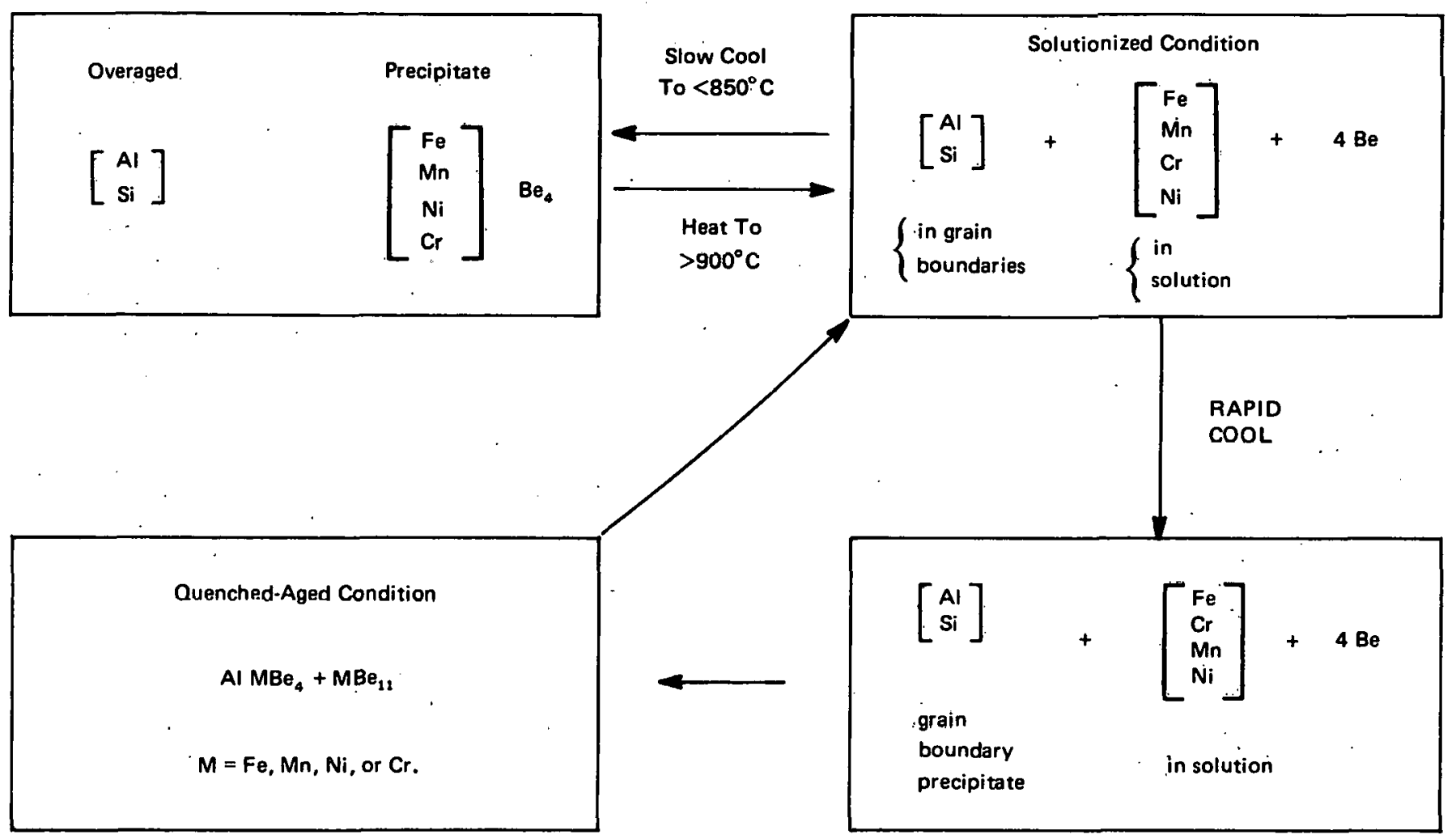

Figure 1. Aging-Solutionizing Reactions in Beryllium.

retained by quenching to room temperature, whereas precipitation of the ternary compound, $\mathrm{AlFeBe}_{4}$, occurs from very slow cooling from the solutionizing temperature. The binary precipitate can be made to occur by aging the solution-quenched material. Aging at $600^{\circ} \mathrm{C}$ promotes formation of the $\mathrm{FeBe}_{11}$ compound, whereas temperatures close to $800^{\circ} \mathrm{C}$ favor the presence of the ternary compound. ${ }^{16}$ The occurrence of the ternary precipitate at the higher temperature may be due in part to the improved mobility of the iron enabling it to diffuse to the grain boundaries where the aluminum is concentrated. Mobility of iron is also probably responsible for the predominance of the tcrnary phase resulting upon slow cooling from the high solutionizing temperature.

The solubility of iron in beryllium is obviously an important factor in these precipitation reactions. Unfortunately, not enough information is available to provide for a clear picture of these reactions. For example, British workers found that the solid solubility for iron in beryllium was much less than the solid solubility limits found by American and
French investigators. ${ }^{20-22}$ However, the differences appear to be due to the presence of aluminum in those materials having the lower solubility. Therefore, the presence of aluminum seems to severely reduce the solubility for iron in beryllium, and a ternary phase diagram is needed to fully understand these reactions. Such a diagram has not been developed.

Note that the stoichiometric atom ratio of iron-toaluminum in the compound $\mathrm{AlFeBe}_{4}$ is 1 to 1 . This means that the stoichiometric weight ratio is about 2.1 iron to 1 aluminum. Commercial beryllium alloys have iron-to-aluminum ratios ranging from 1 to 8 . Thus, in some cases there is an abundance of aluminum, probably to be found in grain boundaries, and in other cases an abundance of iron which could be present in solid solution in the matrix or as $\mathrm{FeBe}_{11}$ precipitates.

The role of aluminum in beryllium, in addition to its role in the ternary compound, includes improving sinterability during hot pressing and decreasing. elevated temperature ductility in service. Donze, 
et al., found that the interface energy of molten aluminum with solid beryllium was less than beryllium's grain boundary energy. ${ }^{23}$ This means that elemental aluminum, if present, will wet the grain boundaries at low temperature. This grain boundary aluminum was shown to be responsible for hot shortness or elevated temperature embrittlement above $500^{\circ} \mathrm{C},{ }^{24}$ and the presence of silicon with aluminum could cause a eutectic, lowering that temperature to $430^{\circ} \mathrm{C.}^{25}$ The fact that aluminum and silicon wet beryllium grains is also probably the reason for improved sinterability during the hot-pressing cycle.

The major impurity in beryllium is $\mathrm{BeO}$. Although its presence may affect the kinetics of the metallurgical reactions discussed above, $\mathrm{BeO}$ itself is not amenable to heat treatment. The same is true for carbon, which is present as stable $\mathrm{Be}_{2} \mathrm{C}$ at carbon concentrations of about $1000 \mathrm{ppm} .{ }^{26}$

The first comprehensive work on the effect of aging on mechanical properties was done by Mash in $1955 .^{27} \mathrm{He}$ observed the yield point phenomenon and serrated stress-strain curves, and showed that the yield point could be eliminated and made to return by heat treatment. He cautioned that the yield point could be an important factor in the metallurgy of beryllium, and he believed that more attention should be given to it.

Work on extruded beryllium rod demonstrates that slow cooling from $1100^{\circ} \mathrm{C}$ results in improved ductility over fast cooling ( $12.4 \%$ versus $2.5 \%$ tensile elongation at room temperature). ${ }^{16}$ However, aging the solution-quenched material at $600^{\circ} \mathrm{C}$, which promotes the binary precipitate, improves the ductility and ultimate tensile strength to the levels achieved by slow cooling.

Carrabine and his co-workers show that, for the same iron content ( $4300 \mathrm{ppm})$, room temperature yield and ultimate strength decrease with increasing aluminum content. ${ }^{28}$ More-recent work confirms these conclusions and also reveals that for a given aluminum content, increasing iron content increases the yield strength. The mechanism is thought to be solid solution hardening, the amount of iron in solution being a function of the aluminum content (since aluminum consumes iron to form
$\left.\mathrm{AlFeBe}_{4}\right)^{29}$ This study also shows decreasing ductility with increasing iron content. Neither study discusses the yield-point phenomenon nor mentions whether it occurred in testing.

Impurities have significant effects on elevated temperature properties, both of ingot-source and powder-source beryllium. One of the most celebrated effects is a minimum in the elongationtemperature curve occurring at about $600^{\circ} \mathrm{C}$. British work shows that this low ductility at $600^{\circ} \mathrm{C}$ is due to an aged and metastable condition $;{ }^{20}$ the precipitate later being identified as $\mathrm{FeBe}_{11}{ }^{16}$ Over-aging at temperaturcs above $575^{\circ} \mathrm{C}$ eliminates this minimum, causing an increase in tensile elongation from $10 \%$ to $40 \%$.

Aluminum has a deleterious effect on tensile properties above $450^{\circ} \mathrm{C}$, where it causes hot shortness in the beryllium. This condition is describer by Olds, and others. ${ }^{30}$ It occurs when the iron-toaluminum ratio is $<2$, resulting in free aluminum which wets the grain boundaries and is molten above $450^{\circ} \mathrm{C}$. Hot shortness can even oscur in beryllium having adequate iron to tie up the aluminum if the iron is in solution and formation of the ternary compound does not occur on cooling.

\section{$\underline{\text { Texture }}$}

As expected, certain metal-working operations produce a preferred crystallographic orientation in beryllium. ${ }^{26}$ Either unidirectional rolling or crossrolling tends to align basal planes into the plane of the sheet. Unidirectional rolling causes (1010) planes to lie transverse to the rolling direction and cross rolling (turning the plate $90^{\circ}$ after each pass) produces a random prism plane orientation. Extrusion tends to align basal planes in a direction transverse to the extrusion direction. Extrusion of rounds results in a random distribution of basalplane poles with respect to the extrusion axis, whereas extrusion of flats causes the basal plane poles to be concentrated at $70^{\circ}$ to $90^{\circ}$ to the extrusion axis. These texture conditions are sketched in Figure 2.

Not surprisingly, the mechanical properties of beryllium are strongly dependent upon crystallographic 


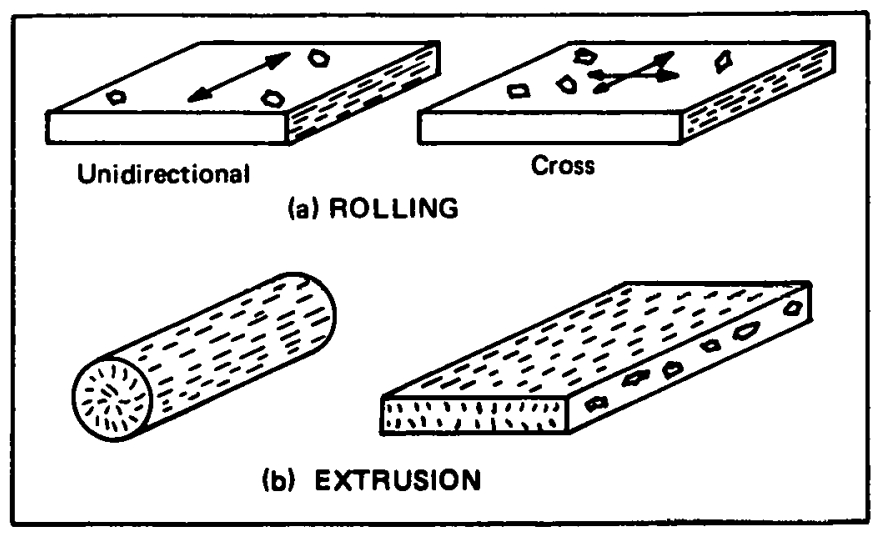

Figure 2. Basal Plane Traces as They Intersect the Geometric Limits of the Samples.

texture. Tensile elongations in the plane of crossrolled, powder-source sheet are typically 10 to $20 \%$ at room temperature, whereas the original hotpressed block exhibits only 1 to $4 \%$ tensile elongation at room temperature.

The basal-plane population in the plane of the cross-rolled sheet is about 10 times a random population that would be present in the hot-pressed block. All four slip systems are available for tensile deformation in the plane of the sheet, which accounts for the improved ductility. However, the ductility in the thickness direction is very low because there are no active slip systems present in this direction. Fenn measured the tensile fracture strain in the thickness direction to be $<0.02 \%{ }^{31}$ Additional evidence of this poor ductility is the low fracture strain in plane-strain bending at room temperature. For plane-strain conditions, the width strain is zero; therefore, from the constant volume requirement, axial plastic strain must equal thickness plastic strain. Thus the same material that exhibits 10 to $20 \%$ axial strain in tension fails in bending at less than $1 \%$ axial strain because less than $1 \%$ thickness strain can be achieved in bending. As bending occurs, very slight in-plane plastic strains are held compatible by very high elastic stresses in the thickness direction. Slip occurs on a few favorably oriented basal planes followed by bend-plane formation and, eventually, fracture by basal cleavage.

Tensile elongation of unidirectionally rolled beryllium sheet depends upon test direction in the plane of the sheet. The longitudinal axis is aligned for duplex slip, and fracture strains of $25 \%$ can be obtained. But the transverse direction results in flow on one set of prism planes, and elongations of $5 \%$ are common.

Tensile properties of extruded stock are best in the direction of the extrusion axis. Extruded flats also exhibit good properties through the thickness, but the width direction, containing basal planes, exhibits poor ductility. Any radial direction of an extruded round has a greater-than-random number of basal plane poles parallel to it, and thus radial ductility of round extrusions is poor.

Attempts have been made to produce isotropic beryllium by combinations of extrusion, upsetforging, and rolling. ${ }^{32,} 33$ Generally, even if isotropy has been achieved, the impact resistance of the resulting product is quite poor.

\section{Grain Size}

Numerous investigations have been conducted to improve the room temperature properties of beryllium by decreasing the grain size. ${ }^{34-38}$ Predictions that the ductile-brittle transition of beryllium could be lowered to room temperature by decreasing grain size spurred much interest in this direction. ${ }^{39}$ To date, the only products having grain sizes well under 10 microns have been of powder-metallurgy origin and have contained high concentrations of impurities that may be responsible for the disappointingly low room temperature ductilities observed. ${ }^{29}$ Recent Russian work with relatively pure ingot-source beryllium did result in material with a 15-micron grain size which had room temperature ductility of $7.5 \% .^{40}$ This is quite good for ingot-source beryllium.

Beryllium follows a Hall-Petch type relationship of yield strength increasing linearly with the Inverse square root of grain size. ${ }^{41,42}$ Ultimate tensile strength increases as the tensile elongation increases with decreasing grain size.

Recent work suggests that subgrain size, as resolved by transmission electron microscopy, is also an important material parameter. ${ }^{43,44}$ Since conventional polarized light microscopy is not effective in resolving substructure, transmission microscopy should be used to supplement low power metallography in investigations of grain size effects. 


\section{Surface Damage}

Beryllium performance and properties are strongly affected by surtace damage. ${ }^{45}$ This damage usually takes the form of mechanical twinning on machined surfaces caused by the forces of the machine tool on favorably oriented grains. Intersecting twins can act as crack-initiation sights; the damage can be removed effectively by either chemical milling or heat treating. Common industrial practice for structural applications is to remove between 0.002 and 0.003 inch from all surfaces after machining. A dramatic example of the importance of chemical milling to remove machine damage is seen in the work of Beitscher ${ }^{46}$ where tensile ductility at room temperature increased from $0.4 \%$ without chemical milling to $4.0 \%$ after chemical milling. Consequently, all beryllium test samples must be etched to remove machining damage, and all beryllium structures must be etched to ensure maximum service strength.

\section{Temperature}

As expected, increasing the test temperature results in increased tensile elongation. This is the result of decreasing CRSS for prism slip while the CRSS for basal slip remains about the same, thereby improving mechanical isotropy. Also, above $\sim 200^{\circ} \mathrm{C}$ nonbasal slip modes become available, satisfying the Taylor criterion and enabling blunting of crack tips.

Even at elevated temperature, fracture surfaces exhibit cleavage traces. The fracture mode changes from one of nearly all transgranular at room temperature to nearly all intergranular above about $500^{\circ} \mathrm{C} .47$ Impurity effects are more pronounced at elevated temperatures and, as mentioned above, are believed to be responsible for the ductility minimum observed at $600^{\circ} \mathrm{C}$.

Increasing temperature results in decreasing ultimate and yield strengths. A $540^{\circ} \mathrm{C}$ increase above room temperature results in about a $50 \%$ decrease in ultimate and a $35 \%$ decrease in yield strength. ${ }^{48}$ In the temperature range from $25^{\circ} \mathrm{C}$ to $355^{\circ} \mathrm{C}$, beryllium is said to follow the relationship $\sigma=\sigma_{0}+\mathrm{h} \epsilon^{1 / 2}$, where $\sigma=$ true stress, $\sigma_{0}=$ yield stress for $0 \%$ plastic strain, $\epsilon$, and $\mathrm{h}=$ slope of the $\sigma-\epsilon^{1 / 2}$ curve. $^{49}$ The $\sigma_{0}$ decreases from 60,000 psi at $25^{\circ} \mathrm{C}$ to 40,000 psi at $355^{\circ} \mathrm{C}$ and $\mathrm{h}$ decreases from 88,000 psi to 43,000 psi for the same temperatures, respectively,

One aspect that is commonly ignored, of the effect of temperature on beryllium properties, is the effect of heating or cooling rate on properties. Armstrong and Borch point out that because of beryllium's thermal expansion anisotropy and high modulus, differential thermal strains can produce local stresses between grains comparable to the bulk stresses that are necessary for yielding or fracture. ${ }^{50}$

\section{Yield Point Rehavior}

\section{Metals in General}

The most common example of a yield-point phenomenon is the negative slope of the stress-strain curve for mild steel that occurs at the onset of yielding. A sketch of such a curve is shown in Figure 3. A measure of the magnitude of the yieldpoint phenomenon is given by $\Delta \sigma$, which is the difference between the upper yield stress and the lower yield stress. Sometimes discrete upper and lower yield stresses are not observed, but a constant stress plateau is present. This is also considered a yield-point phenomenon; the plateau occurring as a deformation wave-front passes along

Figure 3. Key Features of the Yield Point Phenomenon for Mild Steel.

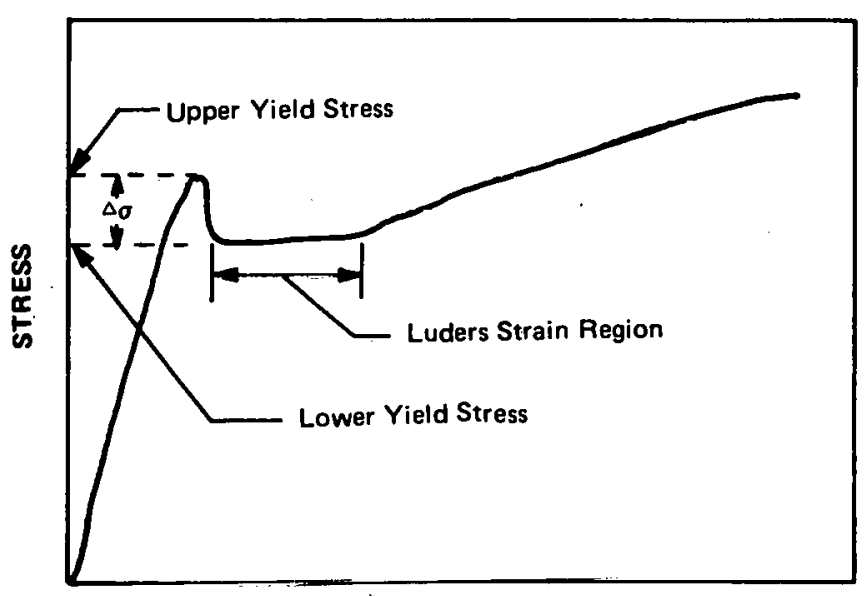

STRAIN 
the test bar gauge length. Such a wave-front is : called a Luders band and the amount of strain in the constant stress plateau is the Luders strain.

The mechanism for the presence of the upper yield strength is thought to be an interaction between dislocations and solute atoms that results in the need for higher stress to allow the dislocations to break away from the pinning solute atoms. ${ }^{51}$ In the case of steel, the pinning atoms are thought to be the interstitials-carbon and/or nitrogen. Rough calculations show that, for annealed iron, concentrations of $4 \times 10^{-8}$ are adequate, assuming every interstitial atom present is involved in the pinning process. Since the carbon concentration is more like $2 \times 10^{-3}$ only one in every 100,000 carbon atoms need be engaged in the pinning process. This mechanism is called Cottrell-locking.

An excellent book by Hall on the yield-point phenomenon has recently been published. ${ }^{52}$ It includes descriptions of several models for the yield-point phenomenon and data for most metal systems exhibiting the phenomenon. It makes the clear distinction between dislocation locking-which is responsible for the upper yield strength-and dislocation motion associated with the lower yield strength and Luders strain region. The Cottrelllocking model described, assumes that plastic flow commences when the dislocations break a way from their pinning atmospheres and cause Luders band formation and hence slip. More recent models, such as Suzuki locking and precipitation locking, do not require the pinned dislocations to be released, but rather account for plastic flow by new dislocations being formed at the upper yield stress. The Suzuki model involves a concentration difference betwecn the matrix and stacking-fault zone and postulates pinning of the dislocations comprising the stacking fault by precipitation within the fault. The precipitation arises from the concentration difference. The precipitation locking arises in systems that have decreasing solid solubility with decreasing temperature and where precipitation preferentially occurs at dislocations because of favorable energy states being there.

Although yield points are best known in low carbon steel, they also occur in other bcc metals such as vanadium, chromium, niobium, molybdenum,
- tantalum, and tungsten. They also occur in fec metals such as aluminum and its alloys, silver and its alloys, nickel, and thorium; and in hexagonal metals, such as cadmium, zinc, titanium, and magnesium.

In the case of hexagonal metals, yield points are most often noted in single crystals upon strain aging and rarely appear in polycrystals. Absence of yield points in polycrystalline-hexagonal metals is purportedly the result of anisotropy induced cooling stresses which are similar to those predicted for beryllium by Armstrong and Borch. ${ }^{50}$ Magnesium$0.5 \mathrm{wt} \%$ Th alloy does show a yield point in polycrystalline form with similarities to the yield point in mild steel. Polycrystalline titanium also shows a yield point, but with both titanium and the magnesium alloy the phenomenon is only present in the temperature range between $100^{\circ} \mathrm{C}$ to $300^{\circ} \mathrm{C} .^{52}$ The absence of a yield point below $100^{\circ} \mathrm{C}$ is thought to be associated with the absence of pyramidal slip below this temperature. It is apparent that information is sparse on the yieldpoint phenomenon in hexagonal metals.

An important treatise on the yield-point phenomenon in bcc metals is credited to Hahn. ${ }^{53}$ Following the lead of Johnston and Gilman, who described the yield-point behavior of lithium fluoride, ${ }^{54} \mathrm{Hahn}$ postulates a mechanism involving permanent locking of once-glissile dislocations and generation of new dislocations at a high stress level. The mechanism requires a low mobile dislocation density and a high stress dependence for dislocation velocity. The low mobile dislocation density arises by pinning of glissile dislocations. At the upper yield stress new dislocations are generated at grain boundaries and second-phase particles. These dislocations flow at a lower stress than that required to generate them. This is the lower yield stress.

\section{Beryllium}

Perhaps the most significant result of reviewing the literature for information about the yield point in beryllium lies in the dearth of such data. Although Mash, as early as 1954, showed the presence of the phenomenon in commercial product, and commented 
on its significance relative to the brittle behavior of beryllium, very few authors have discussed it since. ${ }^{27}$ This is not to say that the yield point was absent in beryllium products that have been studied since then, but rather that the effect was ignored. Comprehensive reviews of beryllium metallurgy, as by Herman ${ }^{13}$ Beaver and Wilke, ${ }^{34}$ and Conrad and Perlmutter, ${ }^{55}$ make no mention of the yieldpoint phenomenon. Researchers working in closely related areas, with materials that may easily have manifested yield points, do not include such information in their summary reports. ${ }^{38,44-45,56-58}$ The lack of data may be the result of:

a. Material variations that prevent yield points.

b. Testing problems-such as pre-strain or a soft testing machine.

c. Investigators dismissing such data as trivial to their specific interests.

Whatever the reason for the absence of data, the fact that yield points can, and do, occur is reason enough to critically examine the circumstances affecting them. The problem occurs often enough to cause one vendor to devise a heat treatment to eliminate yield points. ${ }^{59}$ This heat treatment lowers the magnitude of yield drops but does not always eliminate them. ${ }^{60}$

Although many researchers have overlooked the yield point, some usetul information has been developed. In 1961, Wolff, et al., reported observing the yield point phenomenon in commercially pure beryllium powder that had been cold compacted and extruded to a 30:1 area reduction at $1070^{\circ} \mathrm{C} .{ }^{61}$ The powder contained 730 -ppm iron and 600-ppm aluminum. They note that a region of easy-glide strain (or Luders strain) is observed in the as-extruded condition, but is absent after air quenching from an $1100^{\circ} \mathrm{C}$ solutionizing temperature. The yield point can be made to reappear upon aging at $400^{\circ} \mathrm{C}$. One of three extruded rods from the same source powder did not show the yield point phenomenon. Careful examination reveals that the only difference between it and the material showing the yield point is grain size. The grain size is described as somewhat larger in the rod that did not exhibit yield points. This same study includes experiments on strain aging and the kinetics of yield-point return. A Cottrell-locking mechanism is proposed and an activation energy for the time-temperature combination required to return a yield point is determined as $48,000 \mathrm{cal} / \mathrm{g}$-mole. This corresponds to the activation energy for diffusion of iron in beryllium, which suggests that iron is the solid solution element diffusing to and pinning dislocations.

Bennett has observed the yield-point phenomenon in extruded rod made from commercially pure powder (680 ppm iron, $550 \mathrm{ppm}$ aluminum). ${ }^{62}$ He also postulates a Cottrell-locking model, and observes maximum, elevated-temperature ductility occurring when strong yield points $(\Delta \sigma=10 \%$ of $0.2 \%$ offset yield strength) are present. He notes a nil-ductility problem in some samples tested in the range $100^{\circ} \mathrm{C}$ to $300^{\circ} \mathrm{C}$, and observes that this problem can be eliminated by water quenching from $900^{\circ} \mathrm{C}$. He does not associate yield points with cooling rates, but does point out how the yield-point phenomenon can be the trigger for a brittle fracture mechanism.

More recently, Lindholm and Yeakley report yield points in both hot-pressed and hot-pressed- and extruded powder-source beryllium. ${ }^{48}$ Although not concerned with the physical metallurgy involved, they do publish their stress-strain curves taken as a function of temperature, strain-rate, and orientation. The following observations can be inferred from their data:

a. Extruded material exhibits a stronger yield point (stronger, i.e., greater $\Delta \sigma$ ) than as-hotpressed material.

b. The $\Delta \sigma$ increases with increasing temperature up to the maximum test temperature of $540^{\circ} \mathrm{C}$.

c. The $\Delta \sigma$ increases with increasing strain rate in the range $10^{-3}$ to $10 \mathrm{sec}^{-1}$.

d. Tests in the direction transverse to the pressing axis exhibit stronger yield points than do tests in the longitudinal direction, for hot-pressed beryllium.

The material used in the study contained 1200-ppm iron and 700-ppm aluminum. 
During 1971, Gelles et al. found yield points in numerous commercial grade, powder-sourceberyllium pressings. ${ }^{63}$. These unpublished studies prompt the following observations:

a. Yield points appear in many as-hot-pressed commercial products. The yield points are consistently stronger in the material supplied by Brush than by Kawecki-Berylco, Inc. (KBI). Yield points are seldom observed in hotpressed products containing low levels of $\mathrm{BeO}$, iron, and aluminum.

b. Yield points can be eliminated by water quenching tensile coupons from abôve $370^{\circ} \mathrm{C}$, regardless of time at temperature. Quenching from below $370^{\circ} \mathrm{C}$ is not effective.

c. Maximum $\Delta \sigma$ appears to occur at a $260^{\circ} \mathrm{C}$ test temperature.

d. The yield point, once eliminated by quenching, can be made to return by slow cooling from $780^{\circ} \mathrm{C}$.

e. Isostatic pressurization of tensile coupons to 100,000 psi lowers the $\Delta \sigma$, whereas pressurization to 300,000 psi completely eliminates it.

f. Materials exhibiting yield points also produce serrated stress-strain curves at temperatures around $500^{\circ} \mathrm{C}$.

g. Dislocation densities in materials having yield points are lower than in materials not having yield points.

h. Hot-pressed beryllium containing low $\mathrm{BeO}$, iron, and aluminum impurity levels can be made to exhibit a yield point by annealing at $1040^{\circ} \mathrm{C}$ followed by a slow cool to room temperature.

i. Ingot sheet exhibits a yield point only in a recovery-annealed condition, never in a fully recrystallized condition.

A nivire cumplete discussion of this behavior has recently been made available by Gelles. ${ }^{64,65}$

\section{Summary of Literature Search}

The mechanical behavior of beryllium is dictated largely by its hexagonal close-packed crystal structure (hcp). Only four slip systems exist for beryllium, all with slip directions in the basal plane. Slip occurs on the basal plane at a critical resolved shear stress (CRSS) which is only about $20 \%$ of the CRSS for prism slip. Unfortunately, beryllium also cleaves on the basal plane, and any nonuniform deformation introduces dislocations of like sign that combine to form bend planes.

These bend planes can promote basal cleavage when they are moving under applied stress fields, meet an obstacle, and part of the bend plane continues to move while part remains behind on the obstacle (Stroh mechanism).

Commerically pure beryllium behaves as an alloy, exhibiting solutionizing, àging, and over-aging reactions. Some of the impurities, principally iron, aluminum, and silicon, act as alloying elements.

The iron can be retained in solid solution or precipitate as $\mathrm{FeBe}_{11}$ or $\mathrm{AlFeBe} e_{4}$. Aluminum and silicon are insoluble in beryllium and form a low melting eutectic which wets the grain boundaries and causes hot shortness above $\sim 450^{\circ} \mathrm{C}$.

Since there are no slip directions out of the basal plane the ductility of polycrystalline-beryllium products is anisotropic, depending upon the degree of crystallographic texture present. Rolled sheet, for example, exhibits ductilities of 10 to $20 \%$ in the plane of the sheet because most basal planes are oriented parallel to the plane of the sheet, but the ductility through the thickness is about $0.05 \%$.

The research effort on beryllium has been intensive in the past 15 years, spurred on by the great potential for this metal if the brittleness problem can be eliminated.

Despite the abundance of literature on beryllium, little information is available on the yield-point phenomenon. It seems certain that beryllium products have always displayed such behavior but for some reason the phenomenon escaped the attention of most .researchers. This is surprising hecause the yield-point phenomenon may be one of the causes for the brittleness problem, and 
certainly contributes to the lack of reproducibility of ductility and yield slrength.

The small amount of data available on the yieldpoint phenomenon in beryllium does not provide a clear picture of the mechanism. One series of experiments indicates that a Cottrell mechanism involving pinning by solute atoms is active, whereas another tends to support a precipitate-pinning mechanism.

The effect of grain size is not known, and only sparse data exist on the effect of test temperature and strain rate. Crystallographic texture seems to affect the yield-point behavior. This infers that one of the two dislocation types (basal or prism) may be preferentially pinned. Also, if the mechanism involves precipitation, the precipitate may occur on a certain habit plane and tend to inhibit dislocation motion on this plane.

\section{EXPERIMENTAL}

Included in this section of the report are the details of the experimental work such as tensile bar designs, chemical analyses, and metallography. The test plan followed in the experimental program is also included. Initially, however, it is necessary to examine the variables which govern the yield behavior and how they regulate the test plan.

\section{Variables}

The diagram in Figure 4 depicts sohematically the variables associated with the yield behavior of beryllium. The primary dependent variables are inset within a tensile bar in the figure because these variables control yield. Throughout the entire study only room temperature tensile tests

Figure 4. Variables Controlling the Yield Behavior of Beryllium. Dependent variables are shown inset within a schematic tensile bar. Solid lines indicate the more direct effects. Dashed lines indicate less direct effects.

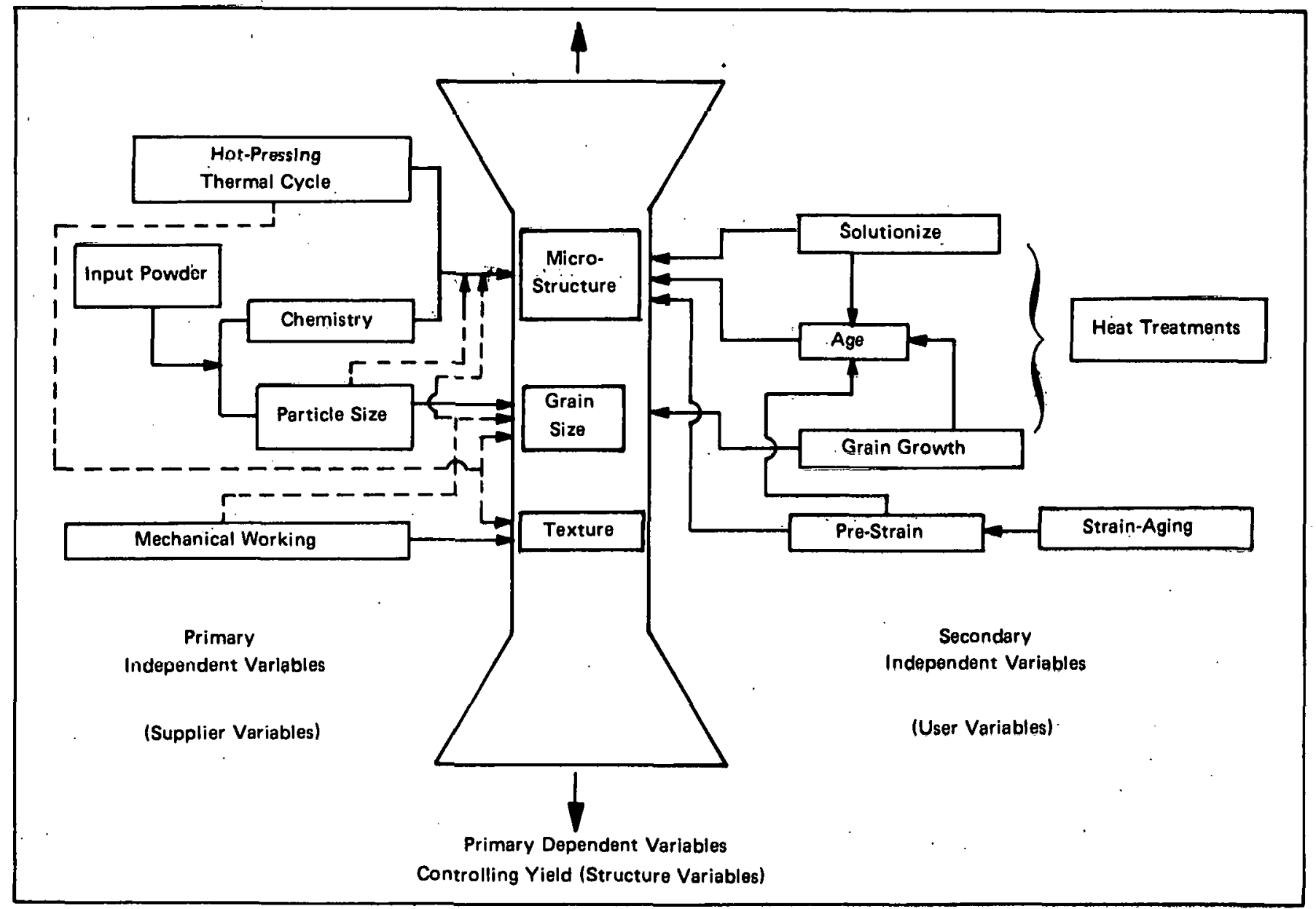


at a constant strain rate are used to measure yield behavior. Such variables as test temperature, strain rate, and stress state are not included in Figure 4 because they are not varied in the testing. They certainly have an effect on yield behavior.

The primary dependent variables represent effects occurring at three different levels internal to the structure of the metal. The first, microstructure, is concerned with processes at the atomic level, such as solute atom concentration and distribution, dislocation structure, and precipitates. The second, grain size, refers to the average size of the grains in the metal; and the third, texture, refers to the effect produced by large numbers of these grains having a common crystallographic orientation. These variables are considered primary because they directly control yield, and they are considered dependent because they are in turn controlled by certain other independent variables.

These independent variables are shown outside of the tensile bar in Figure 4. Those on the left are considered primary independent variables because they can be controlled independently during the manufacturing steps. The solid arrows indicate which structure variable is most strongly affected by a given independent variable, and the dashed arrows show which other dependent variables are also affected.

Once the material is made, the number of things that can be done to alter the yield behavior of the metal becomes quite restricted, as indicated on the right side of the figure. These variables are labeled as secondary because their effects are evidenced after the manufacturing variables are set. There are two things that can be done at this point to alter the yicld behavior of the metal in question. One is to heat treat it and the other is to strainage it. Heat treatments are normally considered relative to their effect on the impurity, iron, and as such are labeled "solutionizing" when the iron is put into solid solution and "aging" when iron is precipitated from solid solution. Aging is normally preceded by a solutionizing treatment, but in strainaging it is preceded by plastic strain. The solid arrows in Figure 4 indicate this sequence. The major effect of the heat treatments is on the microstructure. The grain growth heat treatment is basically a solution-anneal, but conducted at a temperature high enough to cause grain growth. The arrows on the right side in Figure 4 also show that both solutionizing and pre-straining will affect the microstructure (hence yield) without an intermediate aging treatment. The converse is not likely. Aging, unless preceded by solutionizing or pre-straining, will not affect the microstructure.

\section{Test Plan}

To develop an understanding of how the structure variables in Figure 4 control the yield behavior and the yield point of beryllium, a combination of user and supplier variables are studied. These variables are listed in Table 1. Three different iron levels, $640 \mathrm{ppm}, 1750 \mathrm{ppm}$, and $5800 \mathrm{ppm}$, constitute the main levels for the chemistry variable. Aluminum and silicon are held constant at $\sim 400$ ppm each, and $\mathrm{BeO}$ content is about 1 to $1.5 \%$ except for ingot sheet which is about $200 \mathrm{ppm}$.

The fabrication method allows for analysis of the texture effect. The hot-pressed material should

Table 1. Variables Studied to Determine Their Effect on the Yield Behavior of Beryllium.

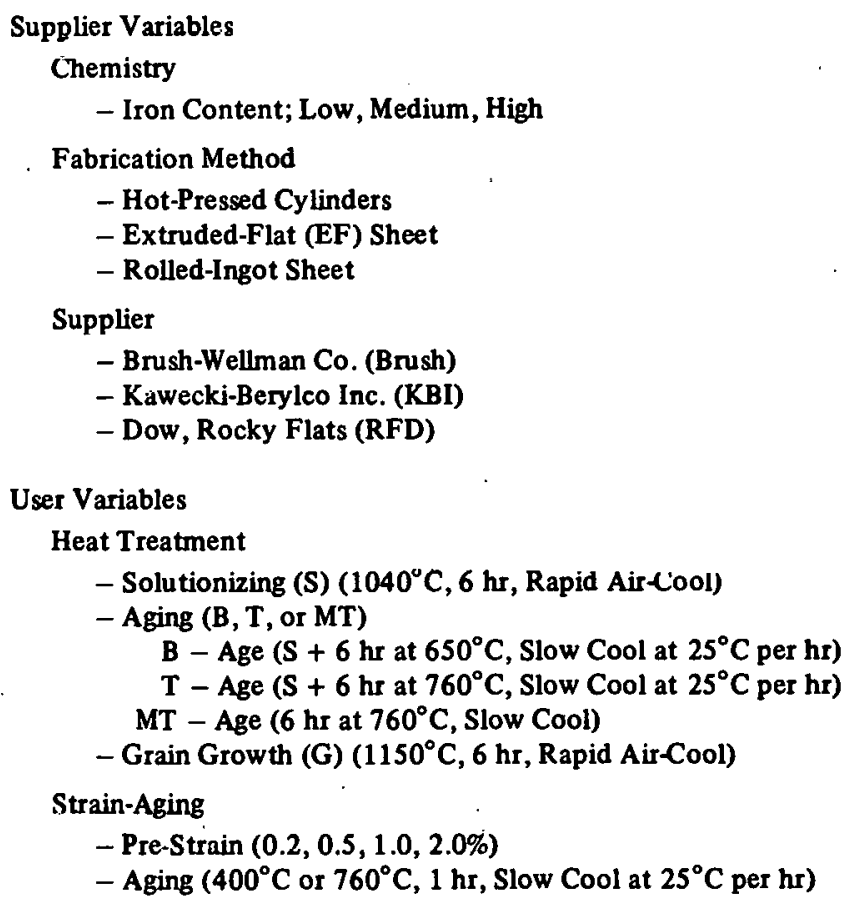


have a rather uniform, isotropic texture, whereas the extruded flat should have a perferred orientation similar to that depicted in Figure 5. Tensile bars oriented relative to the extrusion axis in the longitudinal $(\mathrm{L})$ and $45^{\circ}(45)$ directions allow for study of prism and basal flow, respectively. This is because the resolved shear stress is maximum on planes $45^{\circ}$ to the tensile axis. For the longitudinal orientation the prism planes are at $45^{\circ}$ to the tensile axis and, since relatively few basal planes are similarly oriented, flow occurs primarily by prism slip. On the other hand, the basal planes are situated $45^{\circ}$ to the tensile axis for the EF-45 bars and so basal flow should be favored. The rolled-ingot sheet is not included for texture purposes but rather to study grain size effects. If a sheet can be made with a sufficiently fine grain size to exhibit a yield drop, then grain growth can be obtained at relatively low temperatures to see if an upper limit of grain size exists.

Figure 5. (a) Schematic View of an Extruded Slab Showing Basal Plane Intersections with Slab Faces and Orientations of Tensile Samples. (b) View in the Width Direction Showing How Prism Faces are Orlented at Angles Approaching $45^{\circ}$ to the Tensile Axis. (c) View Transverse to the Tensile Axis of Specimen C, Showing that the Basal Planes Tend to be $45^{\circ}$ to the Tensile Axis.



The manufacturers themselves constitute a significant supplier variable. That the source of supply affects yield behavior is evident from the following observation. The percentage of material exhibiting a yield point, compared to the total material made by a supplier, varies from a significant fraction for Brush material, to a minor fraction for KBI material, to almost zero for Rocky Flats material. Including each supplier's material in this study enables us to compare the conditions that cause and eliminate yield points for these materials.

The yield response of the various materials to heat treatment is a major part of this study. Nearly all the materials are tested in the as-received, solutionized, $650^{\circ} \mathrm{C}$ aged, and $760^{\circ} \mathrm{C}$ aged conditions of heat treatment. Additionally, the $\mathrm{BM}$ and $\mathrm{EF}$ materials are tested in the $G$ condition and the $G$ plus $\mathrm{T}$ condition.

Finally, the test plan includes observing the strainaging response of most of the preceding materials in most of the conditions of heat treatment. A factor of ten range in pre-strain is included and the two strain-aging temperatures listed in Table 1 comprise the extremes of the reported range of aging temperatures.

\section{Materials}

Eight different materials are used in this work. The chemical analyses of these materials are listed in Table 2, and a description of each material is given below. The materials are referred to by the symbol defined in this section and throughout the report.

\section{BM}

This stands for Brush, medium-iron content. This material is used as a standard or reference material and is included in every experiment. It is typical of commercially available, hot-pressed beryllium and it exhibits a yield drop in the as-received condition. The vendor designation of this material is 7075-ser. 11. The details of fabrication are not known, but the hot pressing was at least 12 -in. diameter by 24-in. long. The portion used in this work is a 
Table 2. Chemical Analyses of Materials Used. Total beryllium content is determined by the difference method, iron and aluminum determined by atomic absorption, BeO by neutron activation of solid samples, carbon and nitrogen by wet-chemical methods, and the remainder by spectrographic analyses. Data are given in ppm by weight, except beryllium and BeO which are given in percent by weight.

\begin{tabular}{|c|c|c|c|c|c|c|c|c|}
\hline Element & BL & BM & BH & $\mathbf{K}$ & EF & IS & BN & BY \\
\hline $\mathrm{Be}, \%$ & 98.45 & 98.49 & 97.78 & 97.79 & 98.07 & 99.27 & 98.54 & 97.94 \\
\hline $\mathrm{BeO}, \%$ & 1.17 & 0.84 & 1.36 & 1.57 & 1.43 & 0.023 & 1.20 & 1.62 \\
\hline $\mathbf{F e}$ & 640 & 1750 & 5800 & 2200 & 1520 & 1450 & 930 & 1410 \\
\hline Al & 370 & 440 & 370 & 560 & 370 & 850 & 400 & 800 \\
\hline Si & 300 & 330 & 360 & 580 & 330 & 590 & 350 & .350 \\
\hline$c$ & 880 & 1400 & 1100 & 1180 & 1220 & 650 & 500 & 1070 \\
\hline $\mathbf{N}$ & 250 & 440 & 280 & 270 & 380 & - & 230 & 320 \\
\hline Mn & 120 & 90 & 90 & 580 & 90 & $40^{\circ}$ & 80 & .90 \\
\hline $\mathrm{Ni}$ & 90 & 120 & 90 & 140 & 130 & 130 & - & - \\
\hline $\mathrm{Ca}$ & $<30$ & $<30$ & $<30$ & $<30$ & $<30$ & $<30$ & - & - \\
\hline Cd & $<10$ & $<10$ & $<10$ & $<10$ & $<10$ & $<10$ & - & - \\
\hline Co & $<10$ & $<10$ & $<10$ & $<10$ & $<10$ & $<10$ & - & - \\
\hline $\mathrm{Cr}$ & 60 & 60. & $<20$ & 80 & 80 & $100^{\circ}$ & - & - \\
\hline $\mathrm{Cu}$ & 50 & 80 & 30 & 80 & 100 & 80 & - & $\cdot-$ \\
\hline $\mathrm{Mg}$ & 160 & 400 & 340 & 130 & 80 & $<10$ & 110 & 350 \\
\hline Mo & $<30$ & $<30$ & $<30$ & $<30$ & $<30$ & $<30$ & - & - \\
\hline $\mathbf{P b}$ & $<10$ & $<10$ & $<10$ & $<10$ & $<10$ & $<10$ & - & $\cdot-$ \\
\hline $\mathrm{Ti}$ & 140 & 80 & 40 & 140 & 130 & 180 & - & - \\
\hline $\mathbf{Z n}_{\mathbf{n}}$ & $<10$ & $<10$ & $<10$ & $<10$ & $<10$ & $<10$ & - & - \\
\hline
\end{tabular}

12-in.-diameter slab, $1 / 2$-in. thick, taken near the center of the hot pressing.

\section{$\mathrm{BL}$ and $\mathrm{BH}$}

This is Brush, low- and high-iron content, hotpressed beryllium. One 3.25-in. diameter by 2 -in.high cylinder was made for each iron level, and the vendor designation is: Lot No. $1778(\mathrm{BL})$ and $1779(\mathrm{BH})$. These are laboratory pressings rather than production pressings and they are used to study the effect of iron on yield.

\section{EF-L and EF-45}

This refers to extruded flat stock, tested longitudinally and $45^{\circ}$ to the extrusion axis. It is also Brush material, extruded at $870^{\circ} \mathrm{C}$ with a $13: 1$ area reduction and air-cooled. The extrusion crosssection is $0.375 \mathrm{in}$. by $3.75 \mathrm{in}$. and it is 10 feet long.
$\mathbf{K}$

This is $\mathrm{KBI}$ material from pressing $666-\mathrm{K}$. It is included in the study to help characterize commercially available beryllium. The original hot pressing was 19.2 inches in diameter by 31 in. long, weighing 607 pounds. The input powder was a blend of equal amounts of virgin powder and recycle powder. Hot pressing was done at a nominal temperature of $1040^{\circ} \mathrm{C}$, although one portion of the pressing reached only about $1010^{\circ} \mathrm{C}$. The pressing was held at $1040^{\circ} \mathrm{C}$ for 9 hours under 1000 psi axial pressure and was cooled under load to $540^{\circ} \mathrm{C}$ in the furnace in 21 hours, whereupon it was removed to a cooling tent and cooled to $50^{\circ} \mathrm{C}$. The tensile yield in the hotter portion of the pressing was $37,500 \mathrm{psi}$. It was $44,000 \mathrm{psi}$ in the cooler portion. The exact location of the material tested in this study is uncertain, but the cooler region is suspected. 


\section{$B Y$ and $B N$}

These symbols stand for Brush material, having a yield-drop (BY), and having no yield-drop (BN), in the as-received condition. Yield is $\sim 50,000 \mathrm{psi}$ and $\sim 30,000 \mathrm{psi}$, respectively, and the material is used for grain growth studies. Vendor designations are $8486-2318(\mathrm{BY})$ and $8492-2333(\mathrm{BN})$, and the materials come from large production-size hot pressings.

IS

'l'his is Ingot-Sheet beryllium which is the product of a redundant-forging and rolling operation applied to a 3 -in. by 3 -in. by 10 -in. cast billet. It is intended for grain-growth studies.

A representative microstructure of each of the above materials is given in Figure 6. The bright specks seen in most of the photomicrographs are enlarged etch pits around localized impurities, and are not characteristic of the structure. They should be ignored. The microstructure of those materials given grain growth anneals at $1150^{\circ} \mathrm{C}$ are also contained in Figure 6 for comparison.

\section{Test Methods}

There are three areas of experimental work important to this study: heat treatment, sample preparation, and tensile testing. The procedures used for each are described below.

\section{Heat Treatment}

Only two furnaces are used in this program. Both are horizontal tube furnaces made by Lindberg, one a vacuum furnace, the other containing a constant flow of gettered, high purity argon. The argon atmosphere furnace is used for the graingrowth heat treatments and the vacuum furnace for all other heat treatments. Temperatures are maintained within $\pm 5^{\circ} \mathrm{C}$. Two cooling rates are used; fast and slow. Fast-cooling consists of moving the samples out of the hot zone of the furnace and exposing them to air or argon flow. The slow cooling-rate is $25^{\circ} \mathrm{C}$ per hour which is maintained by Data-Track* controllers coupled into the furnace power supply.

Except for the strain aging heat treatments, the heat treat coupons are cylinders or square prisms about 0.200 in. larger than the dimensions of the tensile bars. This is to protect against chemistry changes resulting from the heat treatment as well as warpage. The strain-aging coupons are of course tensile bars, but warpage or chemical changes are less likely at the lower temperatures involved in strain-aging heat treatments.

\section{Sample Preparation}

Tensile bars are first removed from the bulk material by band-sawing. They are machined to the configuration shown in Figure 7 by a schedule of gradually decreasing depths of cut as prescribed for beryllium testing. ${ }^{66}$ A spring-loaded center is used to ensure that the axial force applied to hold the bar during machining is not great enough to eliminate the yield drop by pre-straining. Once machined, the bars are chemically milled by submersion in a solution of $2 \% \mathrm{HF}, 45 \% \mathrm{HNO}_{3}$, and remainder de-ionized water. A minimum of $0.005 \mathrm{in}$. is removed from all surfaces. The ingotsheet tensile-bar design is given in Figure 8. The machining and chemical-milling practice is the same as for the round bars, except that the edges are mill-cut and the rolled surfaces are not machined.

\section{Tensile Testing}

Tensile tests are conducted in accordance with ASTM standard E-8 and Materials Advisory Board, Beryllium Committee recommended procedures. ${ }^{66,67}$ Tests are conducted on the $20,000 \mathrm{lb}$ Instron machine shown in Figure 9, using a 1000-lb load cell. A constant cross-head speed is used so that the strain rate in the elastic range is 0.003 to 0.007 per minute. Since a rather stiff testing machine is required to observe the sudden load drop associated with yield point behavior, ${ }^{68}$ a series of maraging

\footnotetext{
*Trade name for product of R. I. Controls, a division of Research Inc., Minneapolis, Minnesota.
} 
Figures 6a-6m. Photomicrographs Showing the Grain Structure of the Materials Used in this Report. All photos are polarized light views taken at a magnification of $300 \mathrm{X}$. Average grain sizes, determined by the intercept method, are listed with each material. Unless otherwise specified, the materials are shown in the as-received condition. The small white specks in each photomicrograph are etch pits at impurity sites.

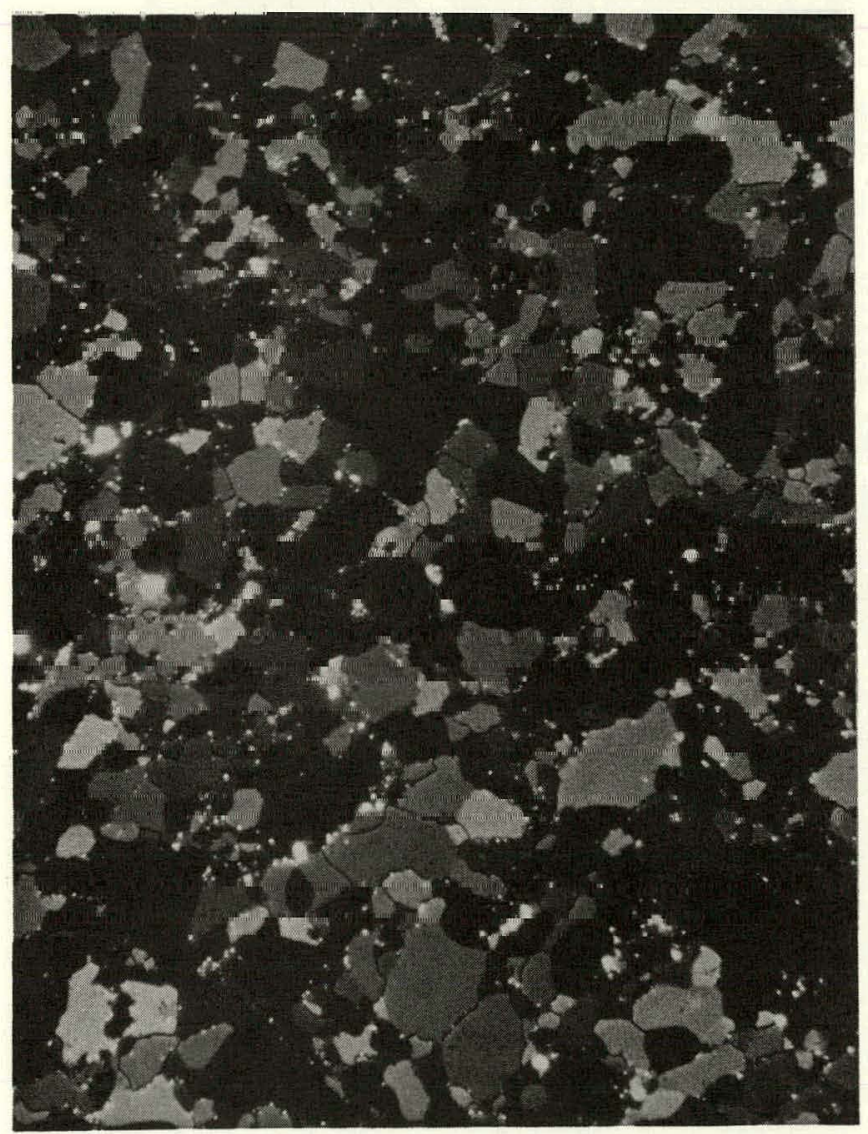

Figure 6a. Brush, low-iron material (BL). Average grain size: 12 microns.

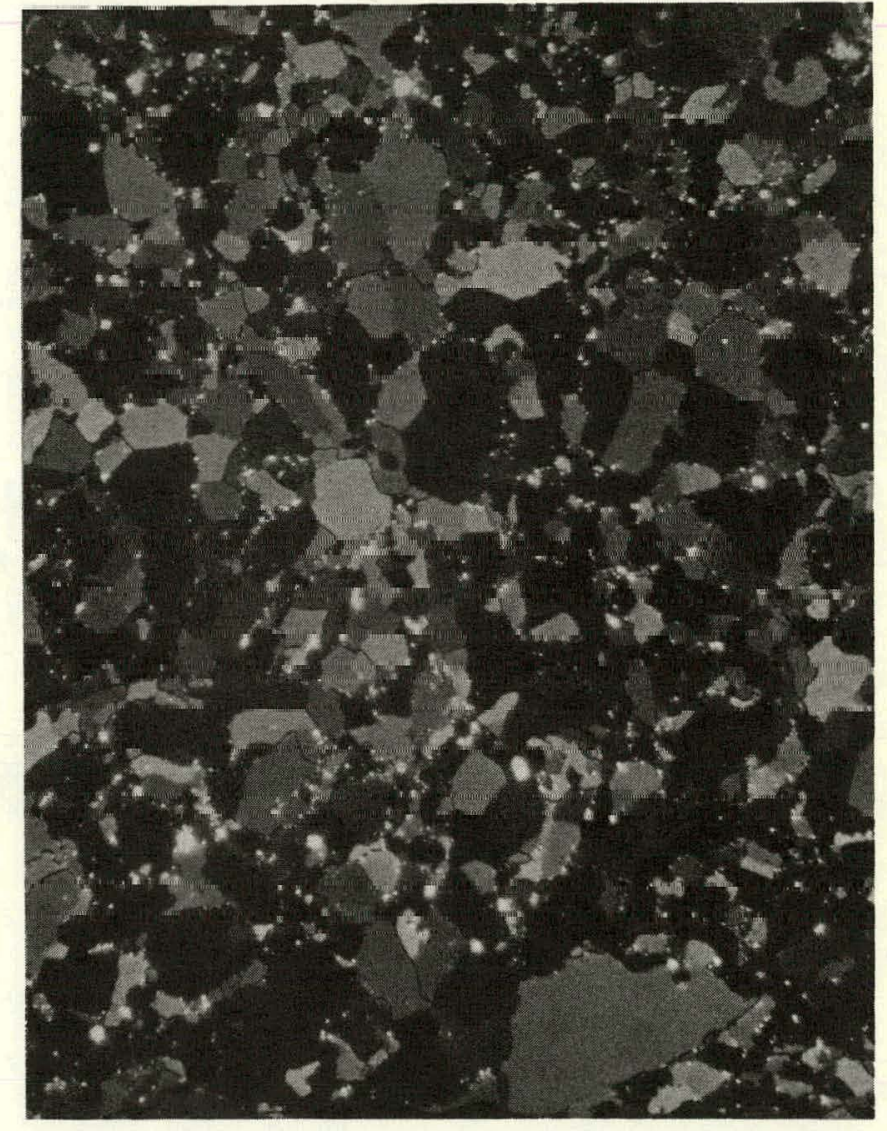

Figure 6b. Brush, high-iron material (BH). Average grain size: 10 microns. 


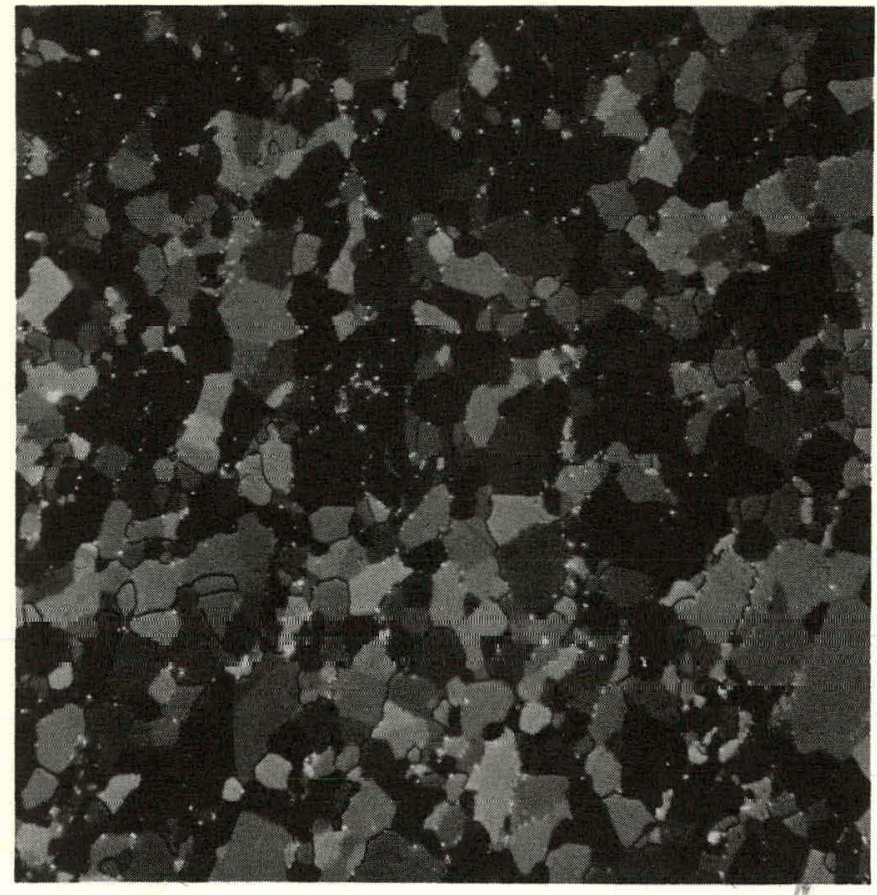

Figure 6c. Brush, medium-iron material (BM). Average grain size: 8.5 microns. Note the wide range in grain sizes in this material.

Figure 6d. BM material given a grain growth treatment at $1150^{\circ} \mathrm{C}$ for 6 hours. Average grain size: 14.6 microns. Note that the finer grains have grown preferentially and therefore the microstructure is more uniform than as-hot-pressed (Figure 6-c).

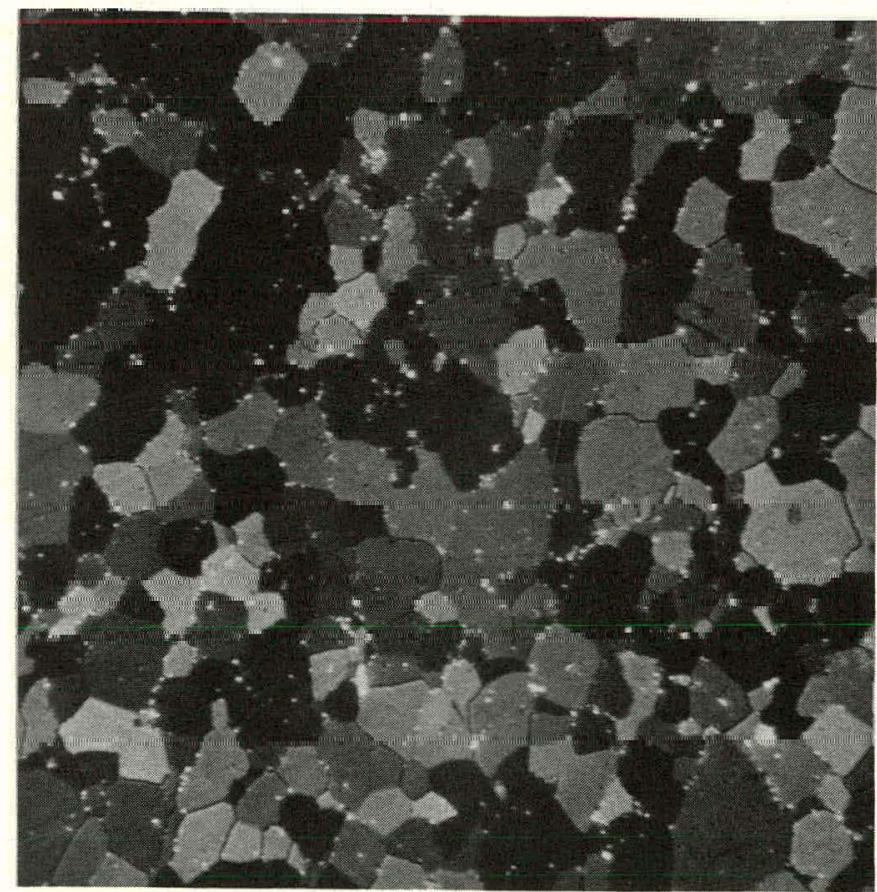

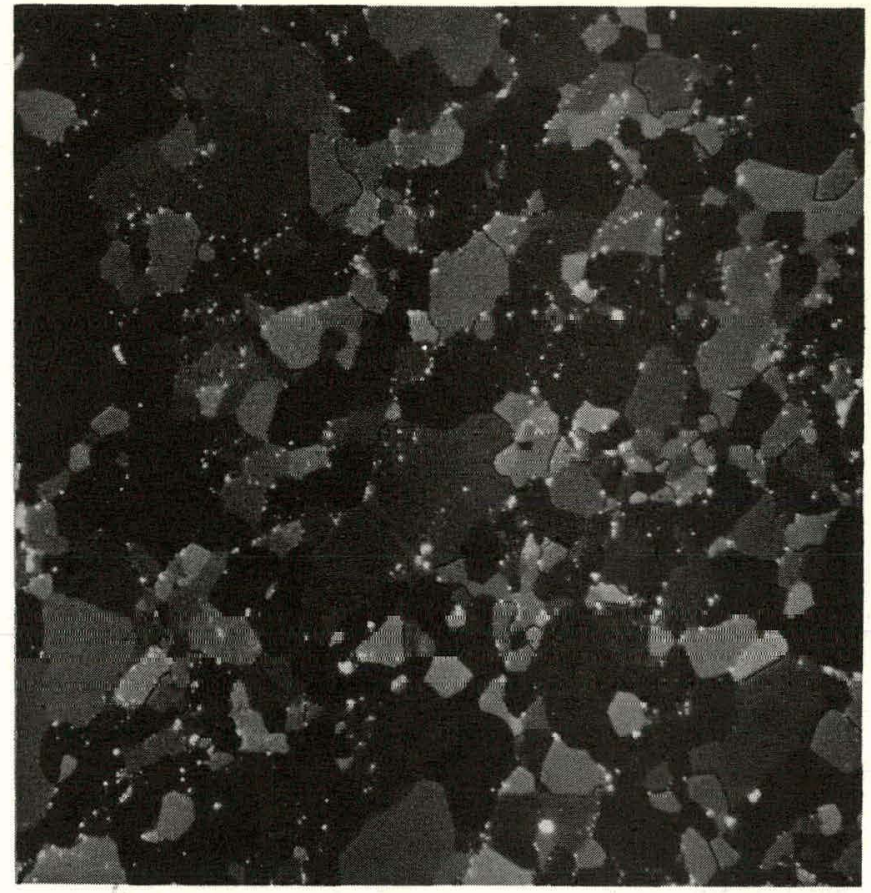

Figure 6e. Kawecki-Berylco Industries Material (K). Average grain size: 10 microns.

Figure 6f. Ingot-Source Beryllium (IS). Average grain size: 18 microns. Despite a 1 hour, $760^{\circ} \mathrm{C}$ heat treatment, the microstructure is not recrystallized. The various shades of gray within the larger grains indicate the presence of bend planes or low-angle sub-boundaries.

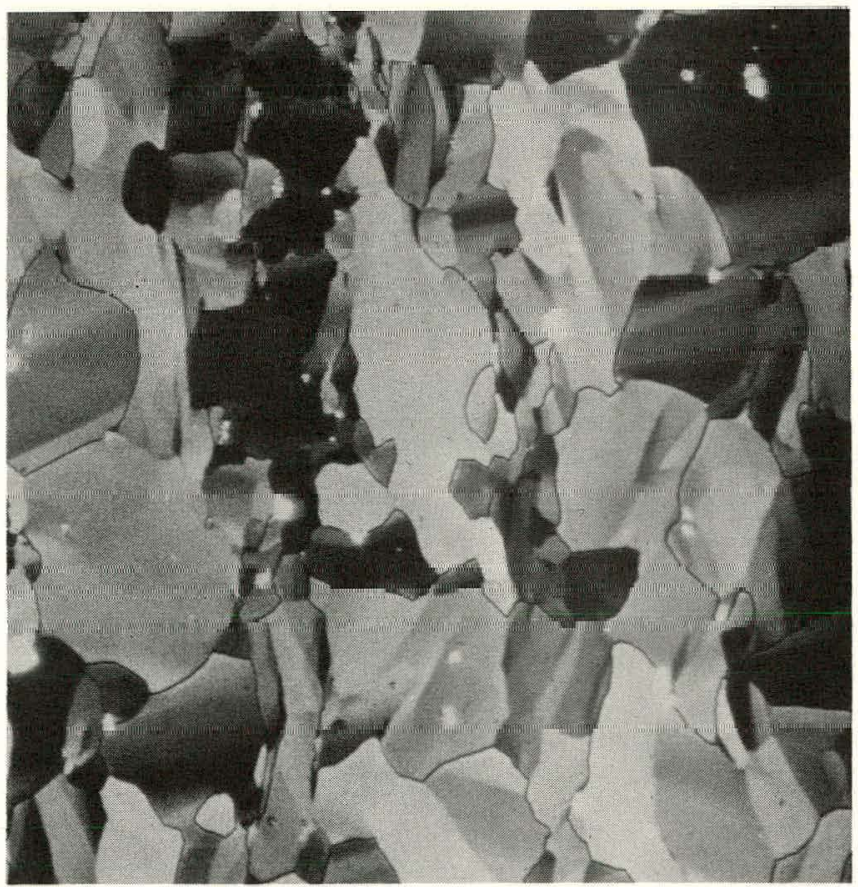




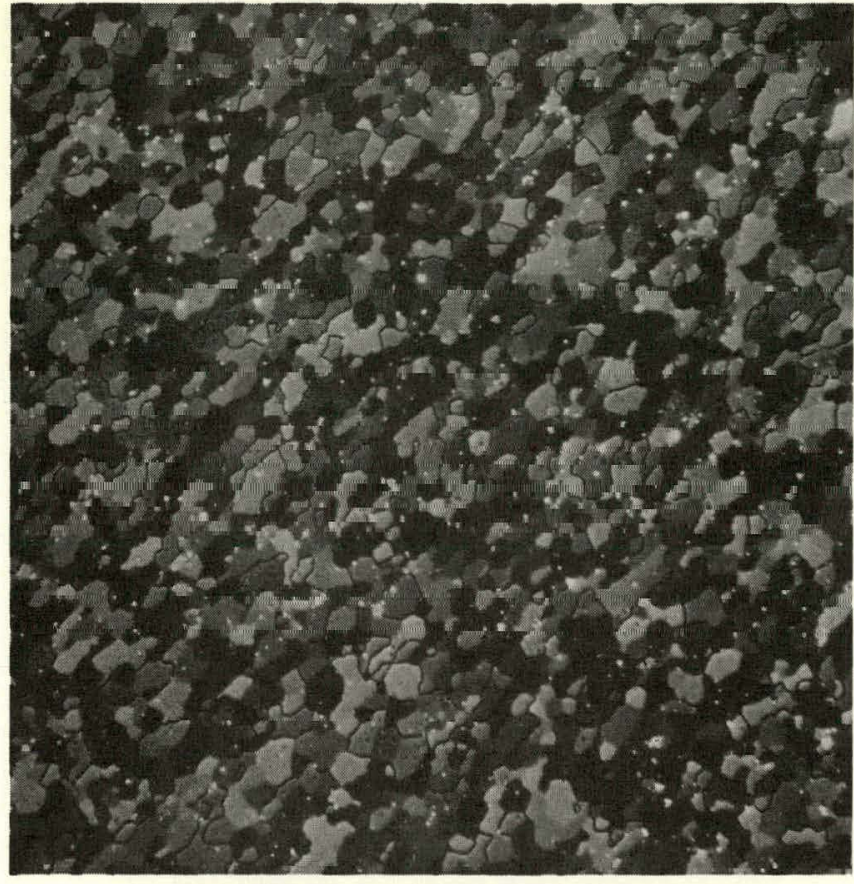

Figure 6g. Extruded flat, longitudinal orientation (EF-L). Average grain size: 6.1 microns.

Figure 6h. Extruded Flat, $45^{\circ}$ Orientation (EF-45). Average grain size: 8.1 microns.

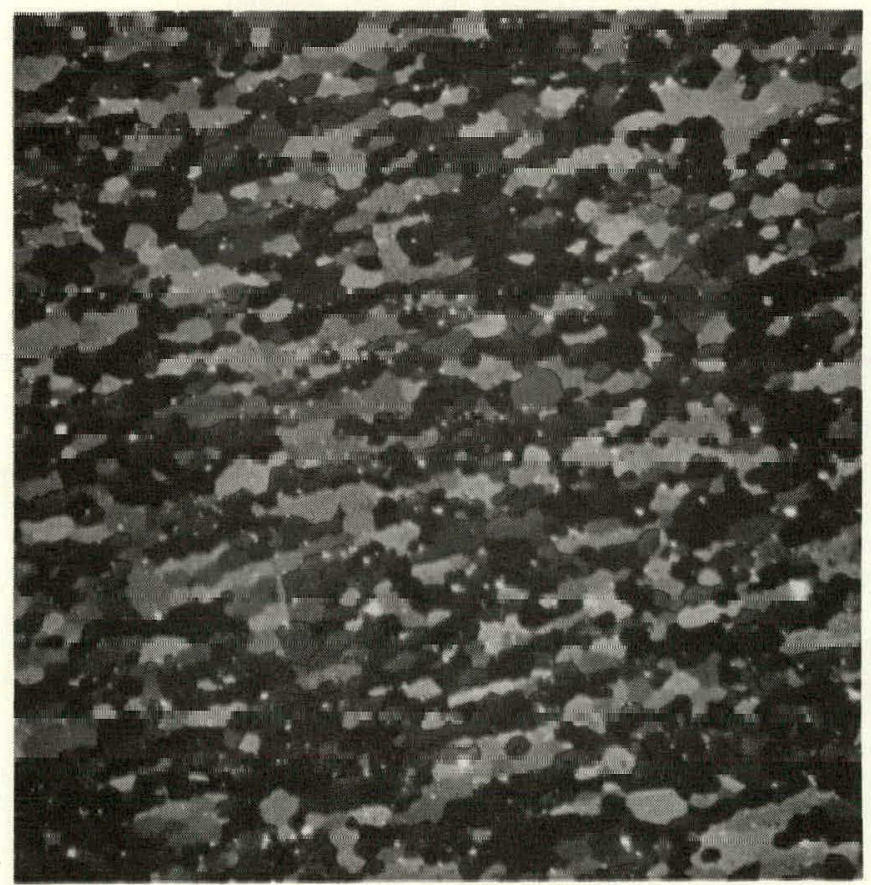

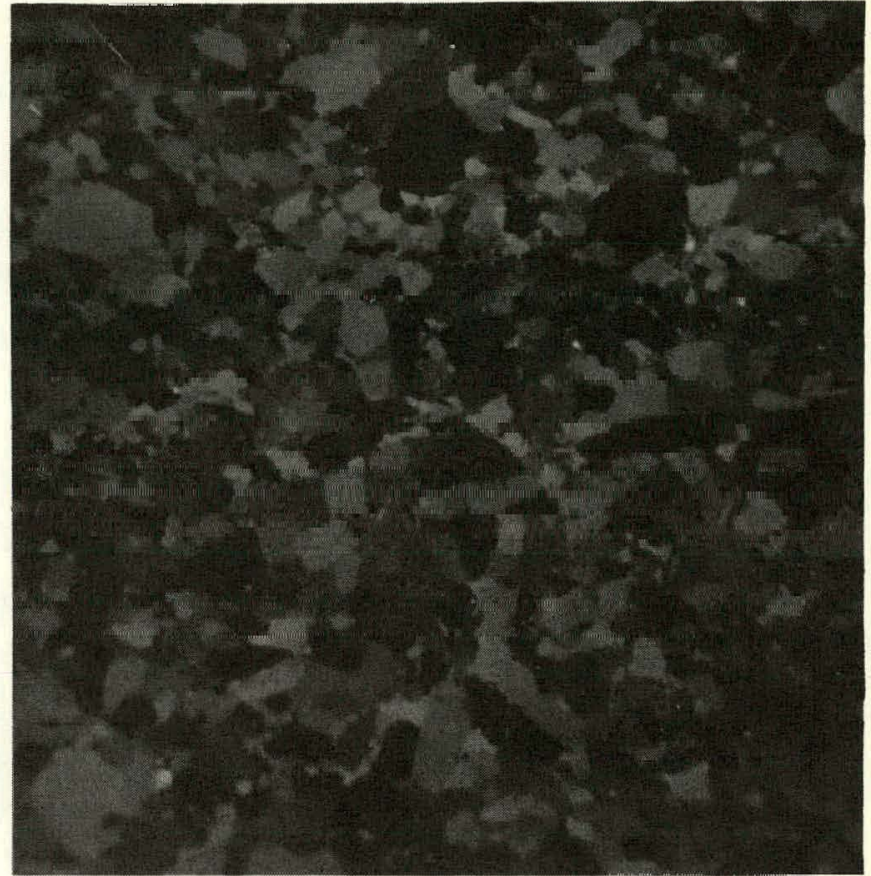

Figure 6i. EF-45 After 6 Hours at $1150^{\circ} \mathrm{C}$. Average grain size: 11.5 microns. Note the uniform grain size.

Figure 6j. Brush Material Showing Yield Drop as HotPressed (BY). Average grain size: 10 microns.

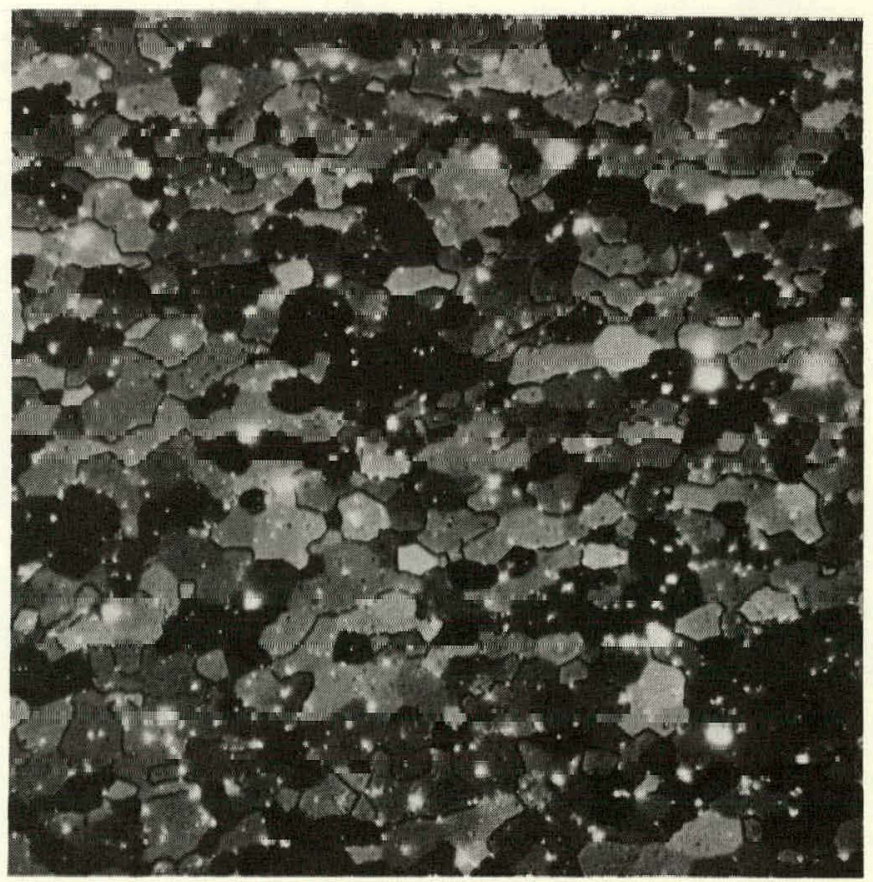




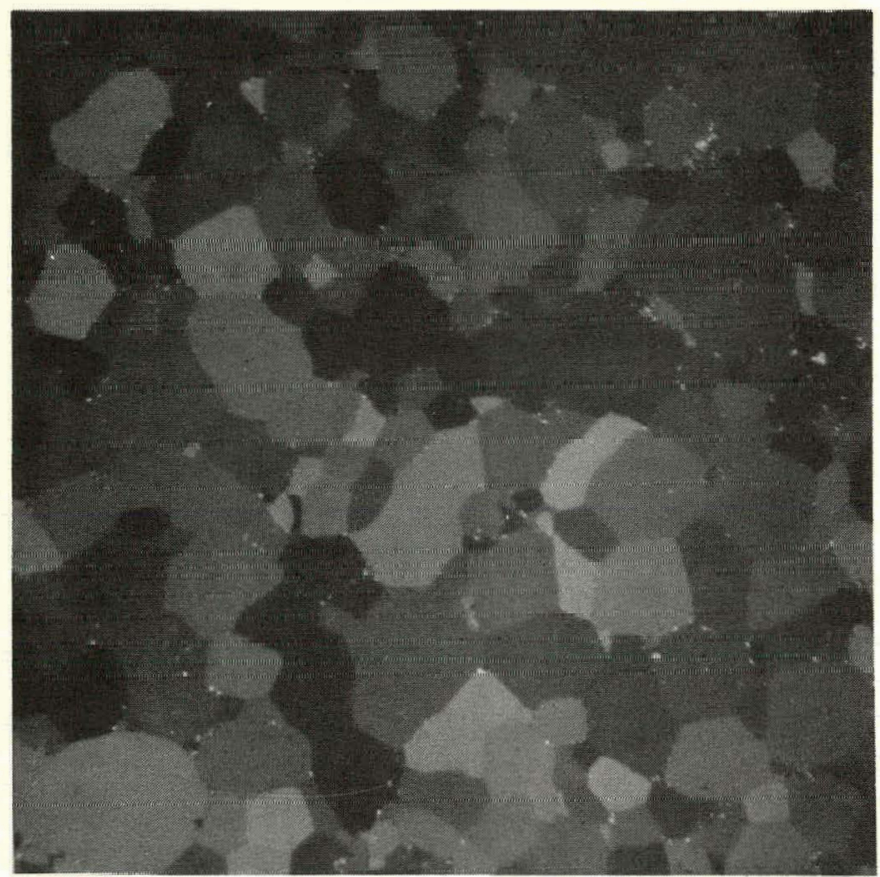

Figure $6 \mathrm{k}$. BY Material After 6 Hours at $1150^{\circ} \mathrm{C}$. Average grain size: 25 microns.

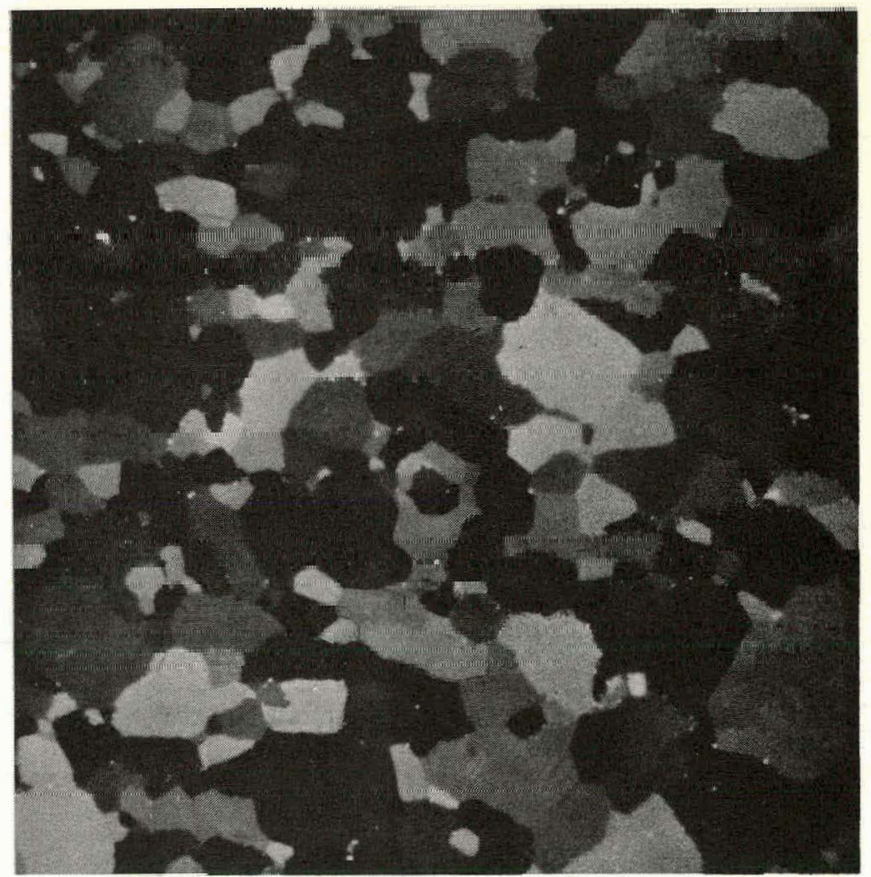

Figure 6I. Brush Material Having no Yield Drop as HotPressed (BN). Average grain size: 20 microns.

Figure $6 \mathrm{~m}$. BN Material After 6 Hours at $1150^{\circ} \mathrm{C}$. Average grain size: 45 microns.

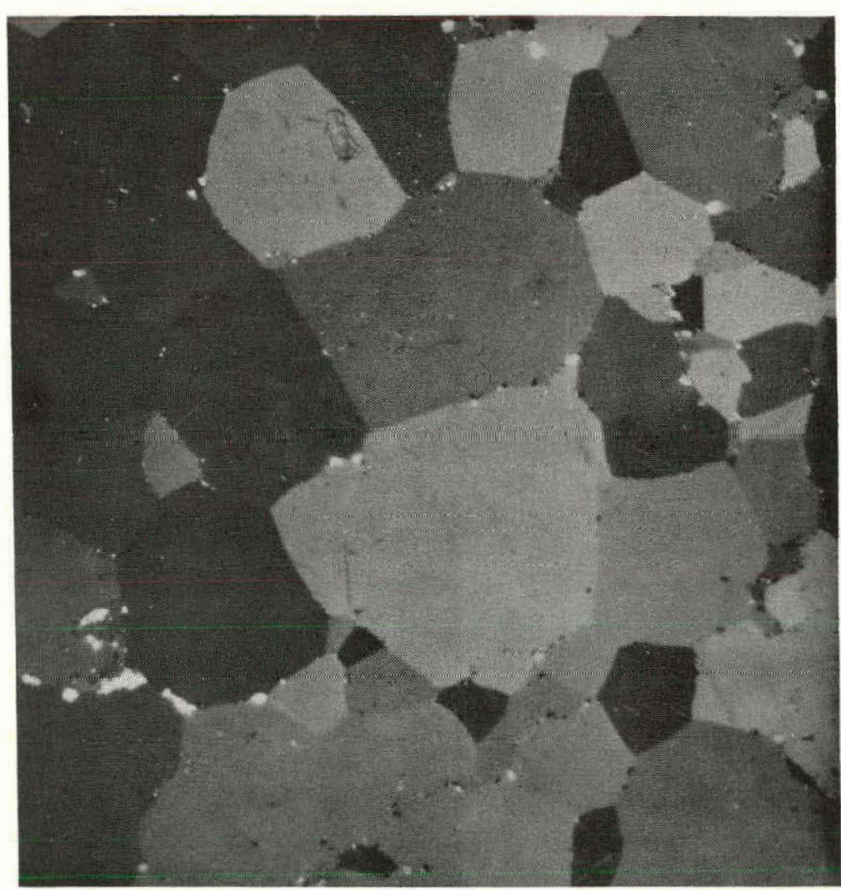




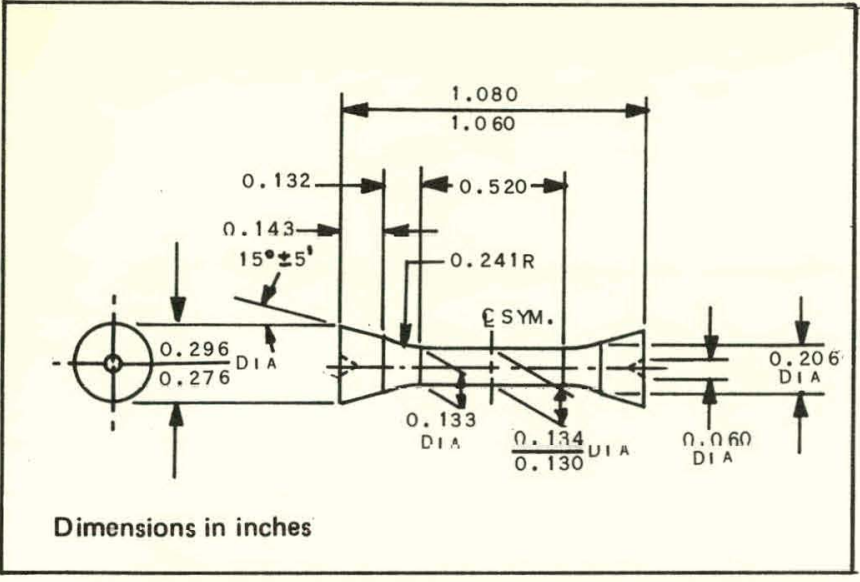

Figure 7. Tapered-End Tensile Bar Design Used for Testing All Powder-Source Materials in This Report.

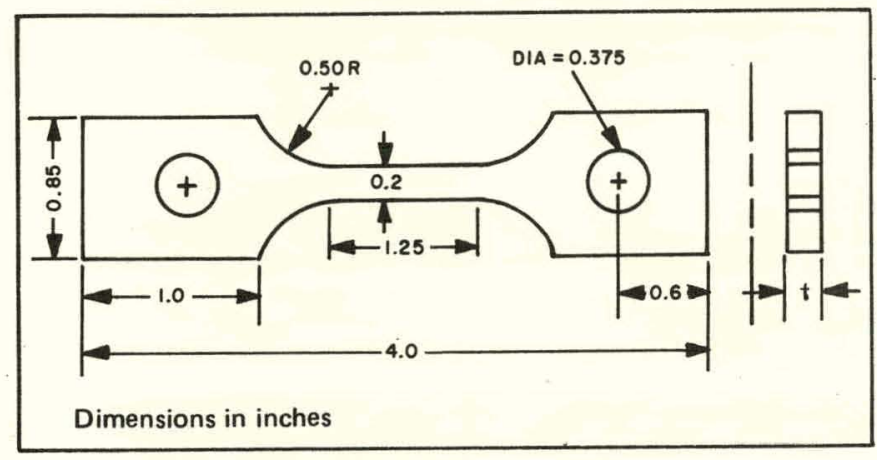

Figure 8. Pin-Loaded Flat Tensile Bar for Testing Beryllium Sheet. (The $t$ is sheet thickness minus 0.006 inch.)

steel tensile bars of the same type as shown in Figure 7 are used to test the machine compliance. This enables use of the same extensometer, grips, and load cell as are used for the beryllium testing. These tests show that the machine compliance is $2 \times 10^{-5}$ inch deflection per pound of force applied. This is considered to be sufficiently stiff in comparison to similar machines that are used to measure yield drops in beryllium. ${ }^{65}$ The gripping mechanism is shown in Figure 10. Strains are measured by the 0.5 -in.-gauge-length extensometer shown.

\section{RESULTS AND DISCUSSION}

Because of numerous data presented in this section, a discussion follows each topic. This section

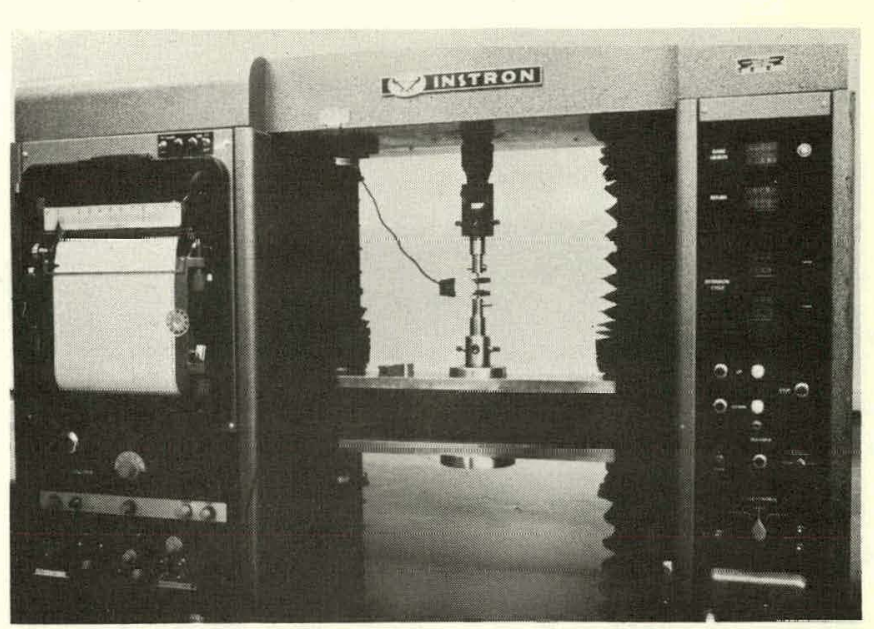

Figure 9. The Testing Machine Used in This Work.

discusses the effects of five variables on the yield point behavior of beryllium. Referring to Figure 4, the first two variables, heat treatment and strain aging, control the dependent variable microstructure. The next two, texture and grain size, are themselves dependent variables. The final variable, the source of supply (supplier), is an independent variable used to study whether the yield-point mechanism established for one material-source will apply to another.

\section{Heat Treatment}

\section{Response of Reference Material}

The BM material is chosen for this study because it exhibits a yield drop in the as-received condition. The circumstances which eliminate and return that yield drop are of special interest, for they should help clarify the yield point mechanism. Others, working with material taken from this same hot pressing, have shown that water quenching from any temperature above $370^{\circ} \mathrm{C}$ removes the yield drop, and aging at $760^{\circ} \mathrm{C}$ followed by slow cooling returns it.

The load-extension curves showing the effect of heat treatment on the BM material are plotted in Figure 11. The as-received material shows a modest yield drop that is completely eliminated by the solutionizing anneal. A slight inflection in 


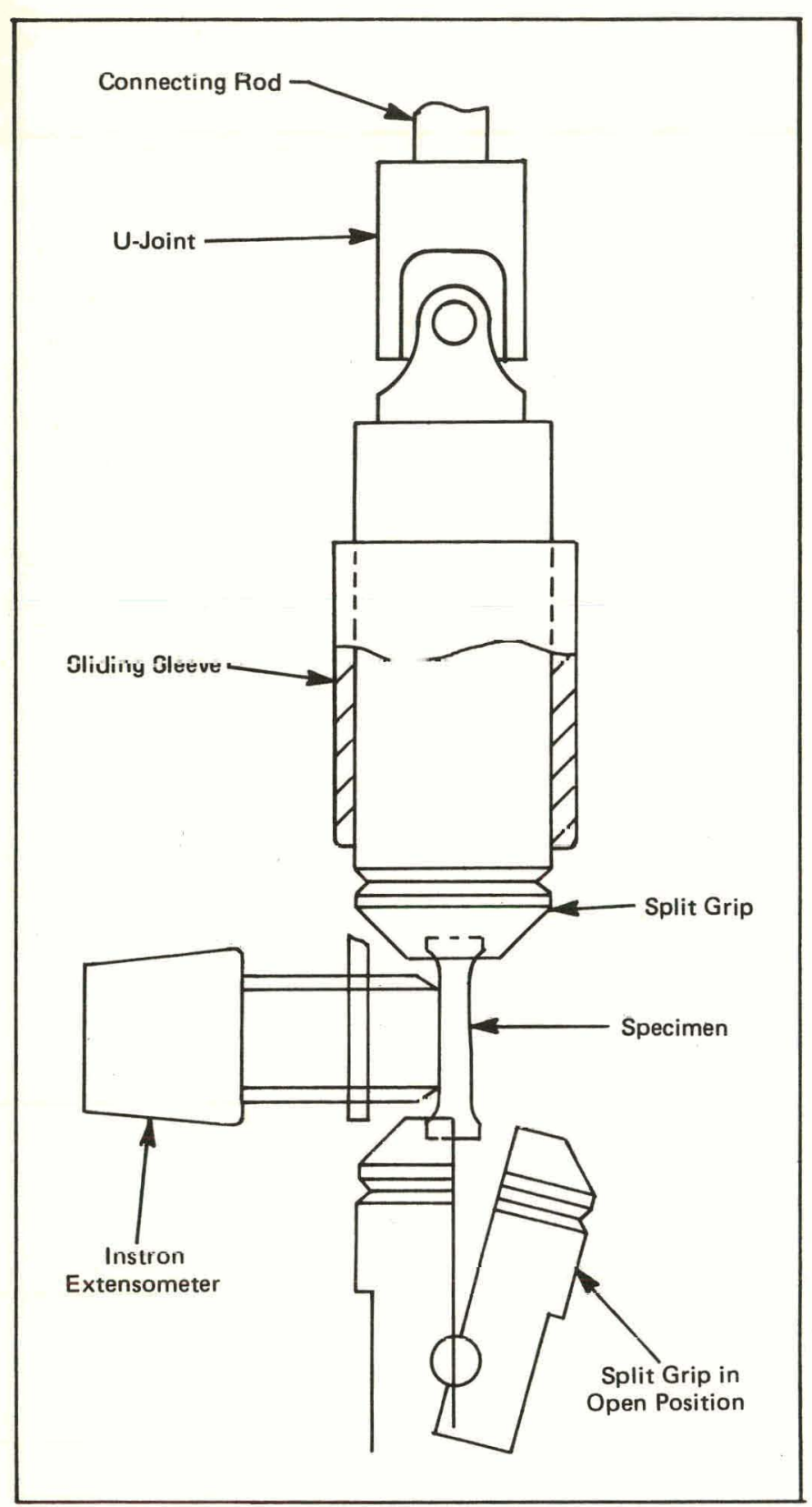

Figure 10. The Gripping Mechanism Used to Test TaperedEnd Tensile Bars. The U-Joint ensures good axiality of loading.

the flow curve does exist for the $\mathrm{S}$ condition, but is absent in the grain-growth condition $(G)$, which is basically another solutionizing treatment. Aging at $650^{\circ} \mathrm{C}$ causes no noticeable change in the flow curve from the S-condition, but there is a slight decrease in yield stress. The yield data for all conditions of heat treatment are summarized in Table 3. The aforementioned decrease can be seen

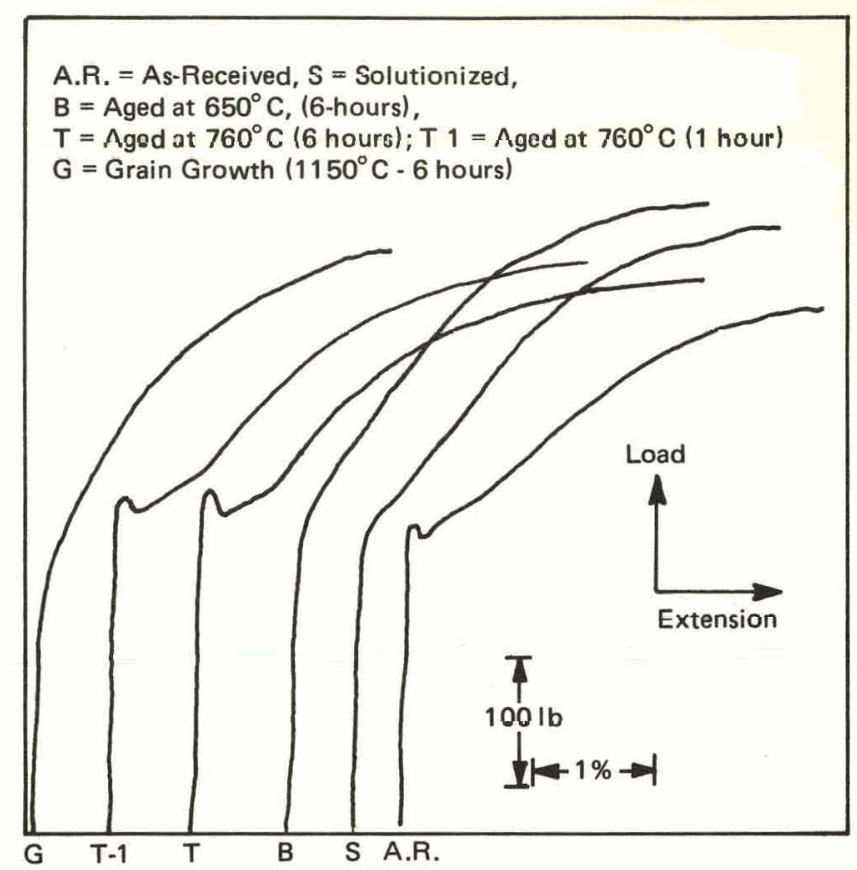

Figure 11. Comparison of Load-Extension Curves for Each of the Six Material Conditions Tested in this Phase of the Work. The curves were traced directly from the testing machine recorder charts and no effort was made to control the relative positions of the yield coordinates.

in this table to be from an average of $41.8 \mathrm{ksi}$ to an average of $39.6 \mathrm{ks}$. Although this decrease is only $2.2 \mathrm{ksi}$, it is significant because the one-sigma standard deviations are $0.5 \mathrm{ksi}$ and $0.7 \mathrm{ksi}$ for the two conditions ( $\mathrm{S}$ and $\mathrm{B}$ ) being compared. In this work a difference is considered significant if its magnitude is more than two standard deviations.

Referring to Figure 11, note that the two aging conditions at $760^{\circ} \mathrm{C}(\mathrm{T}$ and $\mathrm{T}-1)$ both cause a return of the yield drop; the 6-hour treatment causing the greater drop. The dala scaller for $\Delta \sigma$ is rather high, therefore the difference in $\Delta \sigma$ between the T and T-1 conditions cannot be considered significant. Also evident in Figure 11 is a characteristic inflection in the flow curves for the $\mathrm{T}$ and $\mathrm{T}-1$ conditions at about $0.5 \%$ strain. This feature is common to materials having a yield drop. If because of testing difficulties, a material that should exhibit a yield drop does not, then the inflection can serve as a double check. 
Table 3. Summary of Room Temperature Tensile Data for Brush, Medium-Iron, Hot-Pressed Beryllium in Various Conditions of Heat Treatment. Data are averages for the number of tests shown. The number of tests is shown in paren theses.

\begin{tabular}{|c|c|c|c|c|c|c|c|}
\hline & & \multicolumn{2}{|c|}{ Heat-Treat Condition } & \multirow[b]{2}{*}{ Aged $650^{\circ} \mathrm{C}$} & \multirow{2}{*}{$\begin{array}{c}\text { Aged } 760^{\circ} \mathrm{C} \\
(6 \mathrm{hr})\end{array}$} & \multirow{2}{*}{$\begin{array}{c}\text { Aged } 760^{\circ} \mathrm{C} \\
(1 \mathrm{hr}) \\
\end{array}$} & \multirow{2}{*}{$\begin{array}{c}\text { Grain Growth } \\
1150^{\circ} \mathrm{C} \\
\end{array}$} \\
\hline & & As-Received & Solutionized & & & & \\
\hline & & $\overline{\Lambda R}(3)$ & $S(10)$ & $B(8)$ & $T(8)$ & $T-1(2)$ & G (3) \\
\hline Yield Stress (ksi) & $\begin{array}{l}\text { Mean } \\
\text { Std Dev } \\
\text { Range }\end{array}$ & $\begin{array}{c}46.9 \\
- \\
46.3-48.0\end{array}$ & $\begin{array}{c}41.8 \\
0.5 \\
40.8-42.5\end{array}$ & $\begin{array}{c}39.6 \\
0.7 \\
38.7-40.4\end{array}$ & $\begin{array}{c}41.3 \\
0.7 \\
40.4-42.5\end{array}$ & $\begin{array}{c}43.6 \\
- \\
42.6-44.6\end{array}$ & $\begin{array}{c}33.0 \\
- \\
32.5-33.7\end{array}$ \\
\hline Yield Drop $\Delta \sigma(\mathrm{ksi})$ & $\begin{array}{l}\text { Mean } \\
\text { Std Dev } \\
\text { Range }\end{array}$ & $\begin{array}{l}0.3 \\
- \\
0-0.8\end{array}$ & $\begin{array}{l}- \\
-\end{array}$ & - & $\begin{array}{l}1.6 \\
- \\
0-3.0\end{array}$ & $\begin{array}{c}0.7 \\
-\overline{-} \\
0.2-1.2\end{array}$ & - \\
\hline
\end{tabular}

It is also evident from the shape of the flow curves in Figure 11 that the strain-hardening behavior varies as a function of heat treatment. The curves for the two solutionized conditions ( $S$ and $G$ ) and the B-aged condition exhibit a greater slope at any stress than the curves for the as-received and Taged materials. These qualitative observations can be reduced to quantitative observations by calculating the strain hardening coefficient, $m$, in the generalized stress-strain relationship $\sigma=A \epsilon \mathrm{m}$. Here " $\sigma$ " is the true stress for a plastic strain " $\epsilon$ ". A BASIC program for rapid computation of the constants that fit this expression is given in Appendix A, along with data for all material studied in this report.

In Table 3 the yield stress in the T-aged condition about equals that in the solutionized condition. This is contrary to expectations from the literature, where iron is considered a solid-solution hardener so that precipitation should cause a decrease in yield strength. ${ }^{29}$ But the data for aged material in Table 3 show that a yield drop is present. This yield drop does not mean that there is a decrease in the lower yield stress compared to the solutionized condition but rather an increase in the upper yield stress.

Therefore precipitation, which should occur in this heat treatment, appears to be pinning once mobile dislocations thereby causing an increase in yield. This increase is greater than the simultaneous decrease caused by removal of iron from solid solution. The data in Table 3 provide the first indication that the yield point mechanism is one of precipitate-pinning. If the yield-point mechanism were one of solute-pinning, the solutionized condition should provide the best circumstance to produce a yield drop because the amount of solute is a maximum in this condition. But a yield drop is not seen in the solutionized condition and it is seen in the aged condition for the BM material in Table 3. This, of course, tends to support a precipitate-pinning mechanism. However, considering that rapid cooling eliminates the yielddrop, and that rapid cooling is essential to retaining the solutionized condition, the absence of a yield drop in the solutionizing condition may simply be the result of the quenching effect. It has been postulated by this author and others ${ }^{65,} 69,70$ that the mechanism by which quenching eliminates the yield drop is through the introduction of glissile dislocations around second-phase particles such as $\mathrm{BeO}$ or $\mathrm{Be}_{2} \mathrm{C}$, or at grain boundaries caused by anisotropy. The data in Table 3 show that aging subsequent to solutionizing results in yield drops. Although it is reasonably certain that precipitation is occurring at the aging temperature, it might be argued that the real effect of the thermal treatment is to enable the solute atoms to migrate and pin dislocations. The precipitate in such a case may or may not contribute to the pinning. It is not possible at this point to state which mechanism is correct. The following information concerning the low- and high-iron alloys should help clarify this question. 
Table 4. Yield Stress in ksi as a Function of Initial Heat Treat Condition for Low (BL), Medium (BM), and High (BH) Iron Materials. Data are averages of three tests and all materials were heat treated together.

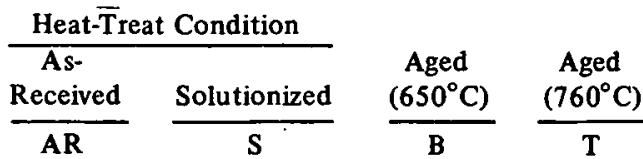

\begin{tabular}{ccccc}
$\begin{array}{c}\mathrm{BL} \\
(640 \mathrm{ppm})^{*}\end{array}$ & 36.9 & 37.4 & 35.9 & 35.9 \\
$\begin{array}{c}\mathrm{BM} \\
(1750 \mathrm{ppm})\end{array}$ & 44.7 & 43.2 & 43.9 & 45.3 \\
$\begin{array}{c}\mathrm{BH} \\
(5800 \mathrm{ppm})\end{array}$ & 46.6 & 51.8 & 45.8 & 42.8 \\
\hline
\end{tabular}

*Fe content

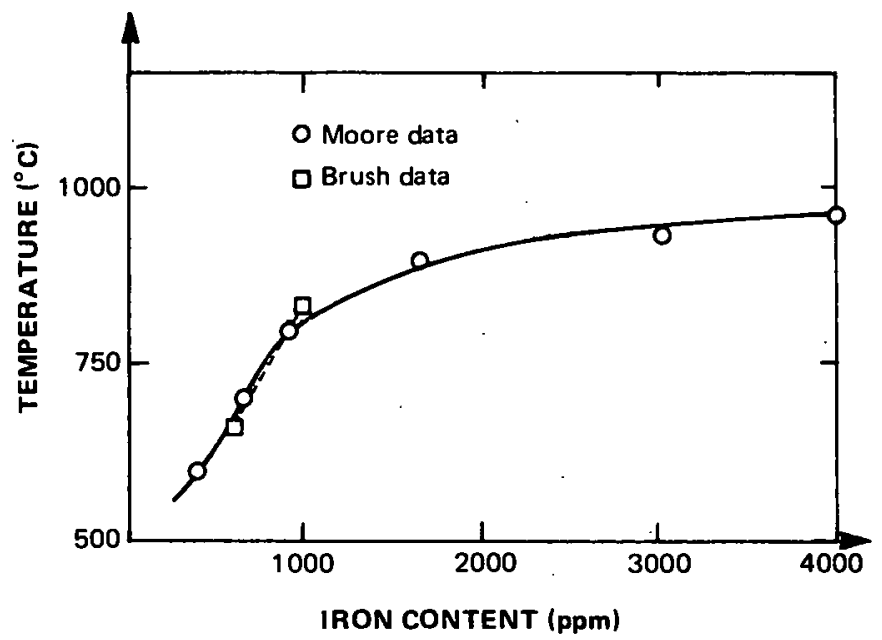

Figure 12. Curves Describing the Solid-Solubility Limit for Iron in Beryllium.

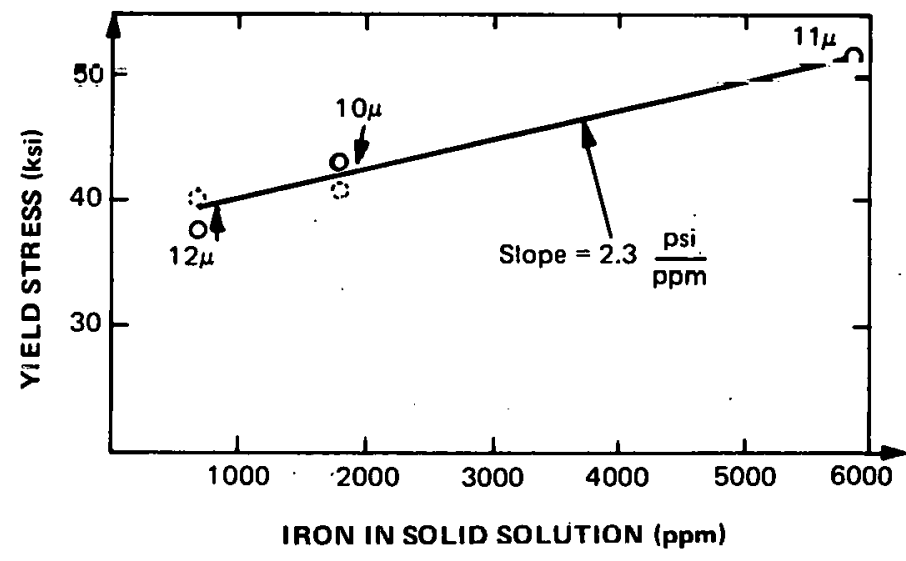

Figure 13. Dependence of Yield on Solid-Solution Iron. Arrows show the direction the data points would move if grain size were taken in to account.

anneal followed by a rapid air cool. The differing amount of irnn in solid snlution is largely respon= sible for the different yield values for these materials in the S-condition. These yield values, given in Table 4, are plotted in Figure 13. Other factors that might influence these yield data are $\mathrm{BeO}$ content, grain size, and texture. The texture in these materials is unknown, although the BL and $\mathrm{BH}$ materials are known to be fabricated in a laboratory press and the BM material comes from production equipment. The $\mathrm{BeO}$ contents also differ, but this factor is probably not as significant as the grain size differences that can be found in Figure 6. The BH material has a grain size of 11 
microns, and the grain sizes for the BL and BM materials are 12 and 10 microns, respectively. If these data could be adjusted to a mean grain size of 11 microns then the data points in Figure 13 would move toward the median line as shown.* The slope of this line, indicative of the solid solution hardening effect, is $2.3 \mathrm{psi}$ per $\mathrm{ppm}$.

It is interesting to check the aging conditions to see if the amount of softening that occurs when iron is removed from solid solution is commensurate with the amount of hardening predicted above. The standard deviations for yield data are about $0.8 \mathrm{ksi}$, so the $1.5 \mathrm{ksi}$ decrease that can be seen for the aged conditions of the BL material in Table 4 must be considered insignificant. In fact, it is apparent from the four data points in Table 4 that the BL material is not affected by heat treatment. This suggests that the equilibrium solubility limit for the $\mathrm{B}$ and $\mathrm{T}$ aging treatments is somewhere above $640 \mathrm{ppm}$. Lacking a better estimate for the $\mathrm{BM}$ and $\mathrm{BH}$ materials, it is assumed that $640 \mathrm{ppm}$ is also their equilibrium solubility limit as a result of the slow cooling used. The difference between the $\mathrm{B}$ and $\mathrm{T}$ aging conditions for either the $\mathrm{BM}$ or the $\mathrm{BH}$ material will therefore not be in the amount of iron precipitated, but in the form and distribution of the iron. The higher aging temperature $\left(760^{\circ} \mathrm{C}-\right.$ $\mathrm{T}$ condition) should result in larger precipitate particles and, because of diffusion of iron to the aluminum in the grain boundaries, possibly favoring the ternary precipitate: $\mathrm{AlFeBe}_{4}$. The lower aging temperature $\left(650^{\circ} \mathrm{C}-\mathrm{B}\right.$ condition $)$ should result in finer precipitates and precipitation in the matrix of the binary precipitate $\mathrm{FeBe}_{11}$. Some of each type of precipitate can be expected for either aging condition, so the major difference must be precipitate size. The assumption that both conditions will achieve the same solubility limit seems reasonable because of the slow-cooling cycle used $\left(25^{\circ} \mathrm{C}\right.$ per hour).

The data in Table 4 show that the net effect of aging BM material is to harden it. The data in Figure 13 suggest that a decrease in yield stress owing to removal of iron from solid solution should have been observed. The magnitude of this decrease should be 2.3 psi per ppm times the

\footnotetext{
*BL would move up $1500 \mathrm{psi}, \mathrm{BM}$ down $2000 \mathrm{psi}$ using the $136 \mathrm{ksi}-\mu^{1 / 2} \mathrm{G}$. S. effect from Appendix B.
}

difference between $1750 \mathrm{ppm}$ and $640 \mathrm{ppm}$, or about $2.5 \mathrm{ksi}$. Instead, an increase in yield of 0.7 ksi for the B condition and $1.9 \mathrm{ksi}$ for the $\mathrm{T}$ condition is seen. Thus the net hardening effect seems to be $3.2 \mathrm{ksi}$ and $4.4 \mathrm{ksi}$ for the B-and T-conditions, respectively.

Two mechanisms, therefore, are apparently operative for the BM material: (1) softening by removing iron from solid solution, and (2) hardening by precipitation. Furthermore, because yield drops develop, the precipitation is apparently hardening by pinning, as noted previously. It has been mentioned that the low iron material, which has about the same amount of iron in solid solution as the medium iron material, does not develop a yield drop on aging and, in fact, shows no significant change in yield for any heat-treat condition. If the yield-point mechanism were solute-pinning, an effect similar to that observed for the BM material should have been observed. This evidence lends further support to a precipitate-pinning mechanism and tends to rule out a solute-pinning mechanism.

The BH material in Table 4 does not exhibit a yield drop in any condition of heat treatment. Softening is observed on aging and the differences between the solutionized and aged conditions are large enough to be considered significant. Both the Band $T$-aging conditions would have the same magnitude of yield stress if no hardening accompanied precipitation, but the yield stress is $3.0 \mathrm{ksi}$ greater in the B-condition than in the $\mathrm{T}$-condition. This is not unexpected because the precipitates should be finer and more widely dispersed than in the $T$ condition. Again, two mechanisms are operativesof tening by removing iron from solid solution and hardening by precipitation. In this case, however, softening predominates; possibly because the precipitation is not effectively pinning mobile dislocations. The change in solid solution iron content on aging is $5800-640=5160 \mathrm{ppm}$. From the solid solution hardening effect of $2.3 \mathrm{psi}$ per ppm shown by Figure 13, a decrease in yield stress of about $12 \mathrm{ksi}$ should be expected. The observed decrease, in going from the S-condition to the Tcondition is, from Table 4, $9.0 \mathrm{ksi}$. It can be inferred that the yield stress in the T-condition is the net result of a $12 \mathrm{ksi}$ softening reaction and a $3 \mathrm{ksi}$ hardening reaction. The material in the $\mathrm{B}$ condition, from Table 4, shows a net decrease in 
yield of only $6 \mathrm{ksi}$, so the precipitate-hardening effect is $6 \mathrm{ksi}$. The difference between these two hardening effects, $3 \mathrm{ksi}$, is a measure of the effect of precipitate size and distribution.

The absence of a yield drop in the $\mathrm{BH}$ material must be considered as evidence contradictory to a precipitate-pinning mechanism. A relatively large quantity of iron is available for precipitation compared to the BM material. And yet, for the BH material, the effect of softening caused by removal of iron from solid solution $(\sim 12 \mathrm{ksi})$ exceeds the precipitate-hardening effects for both the B $(\sim 6$ ksi) and $T(\sim 3 \mathrm{ksi})$ conditions. The corresponding hardening effects of the BM material were 3.2 and $4.4 \mathrm{ksi}$. It seems reasonable that the greater amount of precipitate in the $\mathrm{BH}$ material should have caused a greater degree of hardening than these data show. A factor other than the amount of precipitate must be involved. The next variable to be discussed, strain aging, should help make that factor evident.

\section{Strain Aging}

To facilitate understanding of strain aging, it is useful to anticipate a few hypothetical strain-aging results. Suppose that a given tensile bar is placed into the grips of the testing apparatus and loading is begun at room temperature. The yield stress of this bar has been predetermined by a complex interaction of the key variables during the thermomechanical history of the material that the bar represents. It is now just a matter of increasing the applied stress until a plastic strain of $0.2 \%$ is reached to reveal this yield stress. Suppose that the stress is continuously increased beyond yield until a strain of $0.5 \%$ is reached, whereupon the load is removed. Now the preceding cycle becomes a part of the thermo-mechanical history of the bar; and, when reloaded, the bar will exhibit a new yield stress. We know that the difference between the new yield stress and the original one is due to the $0.5 \%$ strain cycle just applied, assuming all other variables are constant. Since the tests are done at room temperature it is reasonable to assume that no aging reactions occurred during the cycle, and so the reloading yield stress will simply reflect the strain hardening caused by the first cycle, and the new flow curve will blend into the extension of the previous curve as shown in Figure 14a. It is reasonable to expect that the second loading curve will return to the projection of the first flow curve by the time the $0.2 \%$ yield stress, $\sigma_{2}$, is reached.

Figure 14. Hypothetical Stress-Strain Curves Showing the Effect of Aging Prior to Reloading.

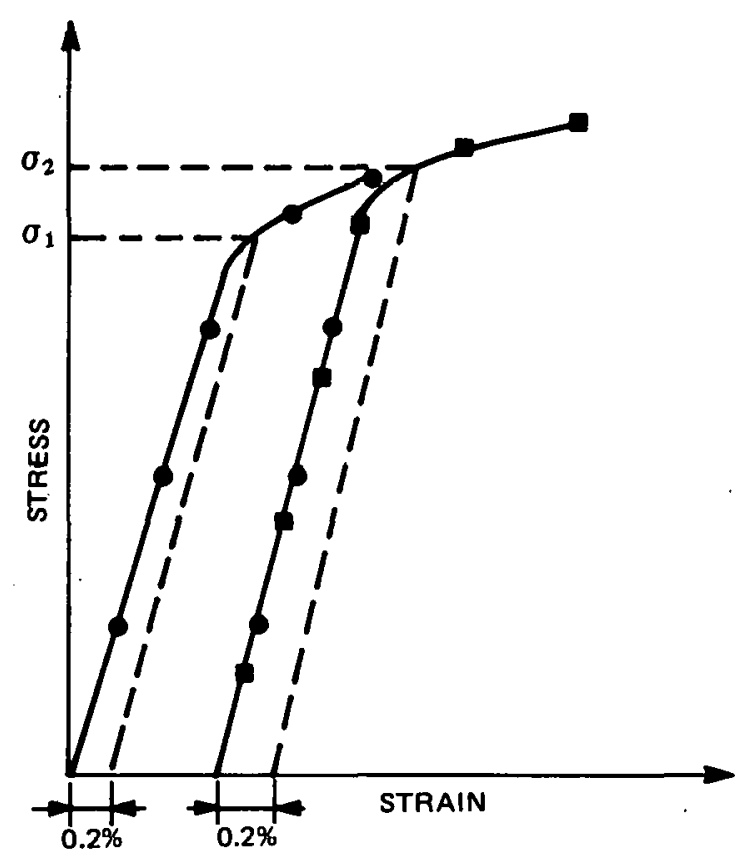

(a) Reload at $25^{\circ} \mathrm{C}$



(b) Aged at $400^{\circ} \mathrm{C}$, Reload at $26^{\circ} \mathrm{C}$. 
The difference $\sigma_{2}-\sigma_{1}$ is a measure of the strain hardening that occurred during the first $0.5 \%$ plastic extension.

Now suppose that after straining a new bar to $0.5 \%$ plastic strain and unloading it, an intermediate heat treatment at $400^{\circ} \mathrm{C}$ was introduced and followed by a slow cool to room temperature. One of three things will happen to the $0.2 \%$ yield stress when it is compared to the $\sigma_{2}$ value for the previous, unaged test: it will be higher, lower, or unchanged. These three possibilities arc depicted in Figure 14b, where the $0.2 \%$-offset yield strength will be higher $\left(\sigma_{2}^{\prime} \mathrm{H}\right)$, unchanged $\left(\sigma_{2}^{\prime} \mathrm{U}\right)$, or lower $\left(\sigma_{2}^{\prime} \mathrm{L}\right)$ than the reloaded yield strength, $\sigma_{2}$, shown in Figure 14a. Some type of hardening mechanism will have been operative in the aging cycle if the yield stress is higher. Conversely, if the yield stress is lower, a softening mechanism must have been operative. If the yield stress is unchanged, then either the aging had no effect or the hardening and softening mechanisms exactly balance.

Before proceeding to the experimental data it is worthwhile to speculate about likely mechanisms that might result from a $400^{\circ}$ aging treatment for hardening and softening. From earlier results it is evident that iron is a solid-solution hardener. Therefore, removing iron from solid solution by a precipitation-aging reaction can be considered a softening mechanism. Another softening mechanism could be a nct cffcct from dislocation rearrangement by recovery type mechanisms such as climb, and formation of loops. That such effects do occur at $400^{\circ} \mathrm{C}$ is evident from the recent results of Gelles and Peterson where considerable grain deformation of powder-source beryllium is observed in tensile tests at $250^{\circ} \mathrm{C}$ and $370^{\circ} \mathrm{C}$. ${ }^{65}$ Such deformation is characteristic of structures developed in creep by dislocation climb mechanisms or recovery-creep mechanisms. One possible hardening mechanism would be pinning of mobile dislocations by precipitation at $400^{\circ} \mathrm{C}$, or pinning by solute atoms owing to their enhanced mobility at $400^{\circ} \mathrm{C}$.

Another hardening mechanism could be the formation of coherent precipitates which must be sheared by mobile dislocations to allow general yielding. This mechanism, however, would presumably require a relatively large amount of precipitate to be effective if precipitation were random in the matrix.
Contained in this section of the report are data for the same three materials ( $\mathrm{BL}, \mathrm{BM}$, and $\mathrm{BH})$ that were studied in the previous section. Pre-strain levels of $0.2,0.5,1.0$, and $2.0 \%$ are used. Strainaging temperatures are $400^{\circ} \mathrm{C}$ and $760^{\circ} \mathrm{C}$ for times of one hour, followed by slow cooling. The three standard, heat-treat conditions from the previous section, solutionized (S) at $1040^{\circ} \mathrm{C}$, aged (B) at $650^{\circ} \mathrm{C}$, and aged $(\mathrm{T})$ at $760^{\circ} \mathrm{C}$, are used for heat treatments prior to strain aging to help establish the yield-point mechanism.

As discussed, room-temperature tensile testing is used to measure strain-aging effects. The difference between the $0.2 \%$-offset yield stress of the reloaded and aged material ( $\sigma_{2}^{\prime}$ in Figure $14 \mathrm{~b}$ ), and the $0.2 \%$ offset yield stress of the simply reloaded material $\left(\sigma_{2}\right.$ in Figure 14a) is the key measure. We shall define this difference by the symbol delta $(\Delta)$. l'o conserve samples, the $0.2 \%$-of fset yield stress of the reloaded, unaged material is determined from the maximum stress reached in pre-straining a given bar. This is done by adding the stress increase expected (as a result of strain hardening) for $0.2 \%$ additional strain. This bar is then aged and reloaded and the difference, $\Delta$, results from data taken from the same bar and is accordingly more accurate. The strain-hardening behavior varies significantly with material and initial heat treatment, but for a given set of these parameters the bar-to-bar variation is insignificant. Thus, a "calibration curve" for each material condition is obtained and used for determining the stress increase for $0.2 \%$ additional strain at the various strain levels studied. These correction factors are listed in Table 5 and are added to the maximum stress, which is present just prior to unloading, to give the $\sigma_{2}$ value defined in Figure 14a.

\section{Effect of Prior Heat Treatment and Prestrain}

The effect of initial heat treatment and pre-strain on the $400^{\circ} \mathrm{C}$ aging response of the Brush mediumiron material is evident in Table 6. It is apparent that the $\Delta$ values become more negative as the pre-strain increases, for all three initial heat conditions. Also, for a given pre-strain, the $\Delta$ values for the $\mathrm{B}$ - and $\mathrm{T}$-aged conditions are more negative than they are for the solutionized condition. Taken together, these two observations indicate 
that, for the $\mathrm{BM}$ material strain-aged at $400^{\circ} \mathrm{C}$, sof tening mechanisms predominate over hardening mechanisms, and that hardening is more of a factor for the solutionized than for the aged conditions.

In the aged condition, since precipitation should have been completed during the higher temperature aging treatments, softening is most likely caused by a recovery mechanism. The solutionized material, on the other hand, is supersaturated with solute, and precipitation during the strain-aging cycle is probable. By removing solute from the lattice,

Table 5. Correction Factors for Determining the Stress Present at a Strain $0.2 \%$ Greater Than the Strain Where Unloading Occurs.

\section{Correction Facror}

\begin{tabular}{|c|c|c|c|c|c|}
\hline \multirow[b]{2}{*}{ Material } & \multirow{2}{*}{$\begin{array}{l}\quad \text { Initial } \\
\text { Heat-Treat } \\
\text { Condition }\end{array}$} & \multicolumn{4}{|c|}{$\begin{array}{l}\text { Stress Increase for an Additional } \\
0.2 \% \text { Strain at Indicated Prestrain: } \\
\text { (ksi) }\end{array}$} \\
\hline & & $0.2 \%$ & $0.5 \%$ & $1.0 \%$ & $2.0 \%$ \\
\hline \multirow[t]{3}{*}{ BL } & $\mathbf{S}$ & 4.3 & 2.1 & - & - \\
\hline & B & 6.3 & 4.0 & - & - \\
\hline & $T$ & 4.4 & $2.8^{*}$ & - & - \\
\hline \multirow[t]{3}{*}{$\mathbf{B M}$} & $\mathbf{S}$ & 1.4 & 2.4 & 1.6 & 0.9 \\
\hline & B & 2.4 & 2.4 & 1.6 & 0.8 \\
\hline & $\mathbf{T}$ & 1.4 & 1.5 & 1.7 & 0.8 \\
\hline \multirow[t]{3}{*}{ BH } & $\mathbf{S}$ & 2.8 & 2.8 & - & - \\
\hline & B & 3.1 & 2.8 & - & - \\
\hline & $\mathbf{T}$ & 3.5 & 3.5 & - & - \\
\hline
\end{tabular}

$\overline{* E x t r a p o l a t e d ~ V a l u e ~}$ precipitation normally promotes softening. But in this case it is actually increasing the yield stress relative to the nonprecipitating aged material. Therefore a precipitation hardening mechanism is apparently operative, and in view of the rather small iron concentration, conventional coherentprecipitate hardening seems less likely than precipitation-pinning of dislocations. Unfortunately no yield drops were developed in this strain-aging cycle to corroborate this apparent pinning mechanism. It is possible that most mobile dislocations were not pinned; in which case a yield drop would not be expected, although slight hardening could still be observed. In this regard it is worth noting that all the aged tensile bars in this new test group exhibit yield drops and, as is evident in Table 6 , this results in an increased yield stress relative to the condition prior to aging, which is the solutionized condition. Thus, if pinning during strain aging were sufficiently general to cause a yield drop, then all the $\Delta$ values should be positive. As can be seen in Table 6, only the S-condition pre-strained $0.2 \%$ exhibits a positive $\Delta$. The 0.5 and $1.0 \%$ pre-strain levels produce more dislocations and obviously would require more precipitate to pin them all.

One final observation on the data in Table 6 is that regardless of pre-strain, the $400^{\circ} \mathrm{C}$ strain-aging cycle returned the material of the $\mathrm{T}$ condition to a yicld strcss vcry close to its initial value. Therefore, recovery, if it is the only mechanism operative, is quite complete for the aged material. 'The solutionized material on the other hand shows increases of

Table 6. Yield Stress Data for $400^{\circ} \mathrm{C}$ Strain-Aging of BM Material.

\begin{tabular}{|c|c|c|c|c|c|c|}
\hline $\begin{array}{l}\text { Initial Heat-Treat } \\
\text { Condition }\end{array}$ & No. of Bars & $\begin{array}{c}\text { Prestrain: } \\
\text { Plastic Strain } \\
\text { at Unloading } \\
(\%)\end{array}$ & $\begin{array}{l}\text { Initial Yield Stress } \\
(\mathrm{ksi})\end{array}$ & $\begin{array}{l}\text { Yield Stress on Reloading } \\
\text { (ksi) }\end{array}$ & $\begin{array}{c}\text { Yield Stress After Aging } \\
\text { (ksi) }\end{array}$ & $\underset{(\mathbf{k s i})}{\Delta \sigma_{2}^{\prime}-\sigma_{2}}$ \\
\hline $\mathbf{S}$ & $\begin{array}{l}3 \\
3 \\
1\end{array}$ & $\begin{array}{l}0.2 \\
0.5 \\
1.0\end{array}$ & $\begin{array}{l}42.8 \\
43.0 \\
43.7\end{array}$ & $\begin{array}{l}44.2 \\
48.8 \\
55.1\end{array}$ & $\begin{array}{l}44.6 \\
45.2 \\
49.3\end{array}$ & $\begin{array}{l}+0.4 \\
-3.6 \\
-5.8\end{array}$ \\
\hline B & $\begin{array}{l}1 \\
1\end{array}$ & $\begin{array}{l}0.5 \\
1.0\end{array}$ & $\begin{array}{l}43.7 y \\
42.5 y\end{array}$ & $\begin{array}{l}48.2 \\
52.9\end{array}$ & $\begin{array}{l}44.0 \\
44.8\end{array}$ & $\begin{array}{l}-4.2 \\
-8.1\end{array}$ \\
\hline $\mathbf{T}$ & $\begin{array}{l}3 \\
4 \\
1 \\
3\end{array}$ & $\begin{array}{l}0.2 \\
0.5 \\
1.0 \\
2.0\end{array}$ & $\begin{array}{l}44.4 \mathrm{y} \\
44.6 \mathrm{y} \\
44.7 \mathrm{y} \\
44.8 \mathrm{y}\end{array}$ & $\begin{array}{l}45.8 \\
47.5 \\
54.9 \\
57.8\end{array}$ & $\begin{array}{l}44.7 \\
44.0 \\
45.5 \\
46.4\end{array}$ & $\begin{array}{l}-1.1 \\
-3.5 \\
-9.4 \\
-11.4\end{array}$ \\
\hline
\end{tabular}

$\overline{y=y i e l d}$ drop present 
$1.8,2.2$, and $5.6 \mathrm{ksi}$ over the yield stress for the $0.2,0.5$, and $1.0 \%$ pre-strain levels; respectively. If one assumes for a first approximation that recovery processes are independent of initial heattreat condition, then the above stress increases are a measure of the magnitude of the precipitationhardening effect. Since these values increase with increasing strain, this provides the first indication that strain-enhanced precipitation is possibly occurring.

\section{Effect of Iron Content}

The data in Table 7 show the effect of iron content on the $400^{\circ} \mathrm{C}$ strain-aging behavior of powdersource beryllium. A typical load-extension trace for one of each of these alloys is given in Figure 15. Reloading immediately after unloading results in a return to the previous flow curve by the time the $0.2 \%$ yield stress is reached for all 3 alloys. But this is not true when reloading is preceded by aging at $400^{\circ} \mathrm{C}$, as can be seen in Figure 15.

Table 7. Yleld Stress Data for $400^{\circ} \mathrm{C}$ Strain-Aging of Iron Alloys. Data for BL and BH are for 1 bar only. Data for BM material are for 3 bars.

\begin{tabular}{|c|c|c|c|c|c|c|c|}
\hline $\begin{array}{c}\text { Initial } \\
\text { Condition }\end{array}$ & & 1 & & & & & I \\
\hline Pro-Strain & & $0.5 \%$ & $1.0 \%$ & $0.5 \%$ & $1.0 \%$ & $0.5 \%$ & $1.0 \%$ \\
\hline $\begin{array}{c}\text { BL } \\
\text { Fo-650 ppm } \\
\text { Al-370 ppm }\end{array}$ & $\begin{array}{l}\sigma_{1} \\
\sigma_{2} \\
\sigma_{2}^{\prime} \\
\Delta\end{array}$ & $\begin{array}{c}36.4 \\
.45 .7 \\
40.3 \\
-5.4\end{array}$ & $\begin{array}{l}38.9 \\
46.0 \mathrm{x} \\
- \\
-\end{array}$ & $\begin{array}{l}37.1 \\
46.7 \\
38.8 \\
-7.9\end{array}$ & $\begin{array}{l}34.0 \\
44.5 \mathrm{x} \\
- \\
-\end{array}$ & $\begin{array}{r}37.8 \\
46.5 \\
41.2 \\
-5.3\end{array}$ & $\begin{array}{c}36.3 \\
45.8 x \\
- \\
-\end{array}$ \\
\hline $\begin{array}{l}\text { BM } \\
\text { Fe-1750 ppm } \\
\text { Al } 440 \text { ppm }\end{array}$ & $\begin{array}{l}\sigma_{1} \\
\sigma_{2} \\
\sigma_{2}^{i} \\
\Delta\end{array}$ & $\begin{array}{l}43.0 \\
48.8 \\
45.2 \\
-3.6\end{array}$ & $\begin{array}{l}43.7 \\
55.1 \\
49.3 \\
-5.8\end{array}$ & $\begin{array}{l}43.7 y \\
48.2 \\
44.0 \\
-4.2\end{array}$ & $\begin{array}{l}42.5 y \\
52.9 \\
44.8 \\
-8.1\end{array}$ & $\begin{array}{l}44.6 y \\
47.5 \\
44.0 \\
-3.5\end{array}$ & $\begin{array}{l}44.7 y \\
54.9 \\
45.5 \\
-9.4\end{array}$ \\
\hline $\begin{array}{c}\text { BH } \\
\text { Fe-5800 ppm } \\
\text { Al-370 ppm }\end{array}$ & $\begin{array}{l}\sigma_{1} \\
\theta_{2} \\
\sigma_{2}^{\prime} \\
\Delta\end{array}$ & $\begin{array}{l}51.1 \\
58.4 \\
63.8 \mathrm{p} \\
+5.4\end{array}$ & $\begin{array}{l}50.7 \\
61.3 x \\
= \\
=\end{array}$ & $\begin{array}{l}46.7 \\
53.6 \\
53.0 \\
-0.6\end{array}$ & $\begin{array}{l}46.4 \\
58.2 x \\
- \\
-\end{array}$ & $\begin{array}{r}43.7 \\
52.6 \\
50.5 \\
-2.1\end{array}$ & $\begin{array}{l}42.6 \\
57.2 \\
52.6 \\
-4.6\end{array}$ \\
\hline
\end{tabular}

$\bar{x}$ - sample fractured

$y-$ yleld drop present

p - plateau present
Observations made above with reference to the BM material can be extended to include the $\mathrm{BH}$ material in Table 7. That is, the $\Delta$ values decrease with increasing strain and the $\Delta$ values for the aged conditions are more negative than for the solutionized condition. These generalizations cannot be extended to the BL material, however, because all BL tensile bars failed at $<1 \%$ strain and because the aged conditions are not significantly different than solutionized.

The effect of iron content on the $400^{\circ} \mathrm{C}$ strainaging behavior can be seen in Figure 16. The data for Figure 16 come from Table 7 for $0.5 \%$ prestrain in the S-condition. The iron for all four materials should be in solid solution prior to the aging treatment and, as Figure 16 shows, the amount of hardening resulting from the $400^{\circ} \mathrm{C}$ aging treatment is a strong function of the amount of solid-solution iron. The slope of the curve is $2.1 \mathrm{psi} / \mathrm{ppm}$. This result should not be confused with that given by. Figure 13. In that case the effect is simply solid-solution hardening, probably caused by increased Peierls stress. In this case the hardening is more likely a pinning mechanismeither solute or precipitate. This hardening actually competes with softening mechanisms such as removal of iron from solid solution, or recovery. The competing mechanisms would balance at about $3200-\mathrm{ppm}$ iron in solution prior to strain aging.

Figure 15. Load Extension Curve for Low (BL), Medium (BM), and High (BH) Iron Materials in the $760^{\circ}$ C-Aged Condition. Curve 1: Initial loading; Curve 2: immediate reloading; Curve 3: reload after 1 -hour age at $400^{\circ} \mathrm{C}$. Sample fracture indicated by $X$.

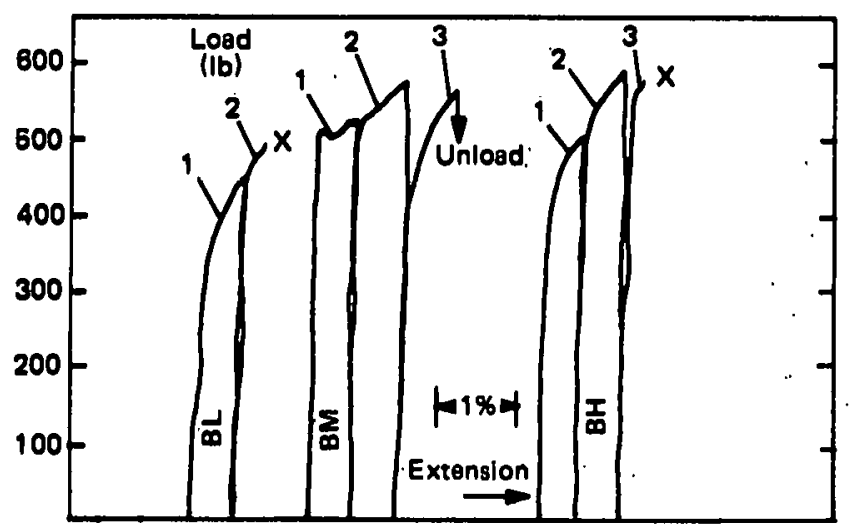


All three materials show more positive $\Delta$ values for the solutionized than for the aged precondition. Recalling that a positive $\Delta$ value indicates hardening, this might be considered to be evidence for solute pinning. But the apparent hardening could also be due to iron precipitation, which would show a stronger effect in the initially solutionized condition since there is more iron available for precipitation. These results must be considered ambivalent based on the data presently available.

One possibility raised, when discussing the $\mathrm{BM}$ results in Table 6 , is that of strain-induced precipitation. The evidence for BH material in Table 7 tends to support that hypothesis. Consider the yield stress in the solutionized condition, which

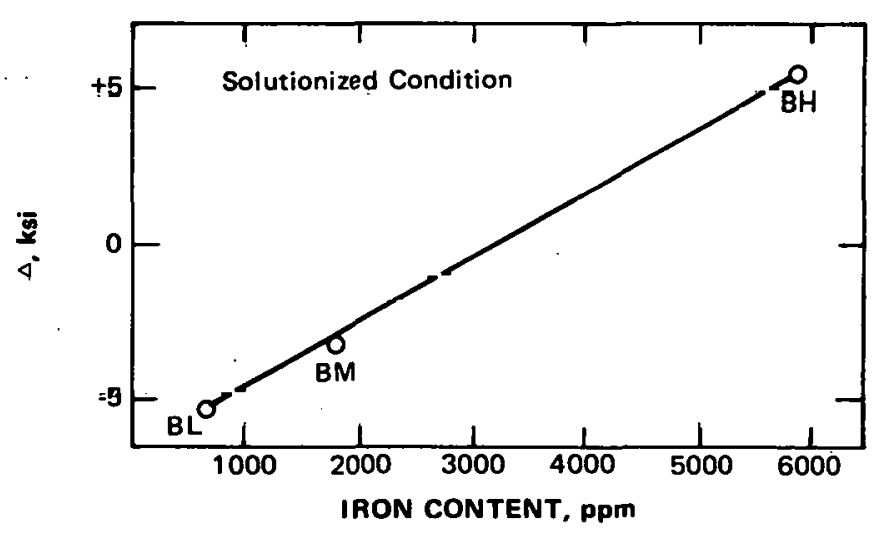

Figure 16. Dependence of the Parameter $\Delta$, Which Measures the Flow-Stress Change Caused by Strain Aging on the Amount of Iron Initially in Solid Solution. Data for the S-condition, $0.50 \%$ pre:strain. is $51.1 \mathrm{ksi}$. If this material is aged at $650^{\circ} \mathrm{C}$, the yield decreases to $46.7 \mathrm{ksi}$, and aging it at $760^{\circ} \mathrm{C}$ decreases it even further tn $4,7,7 \mathrm{ksi}$. But if the solutionized material is first strained $0.5 \%$, then aged at $400^{\circ} \mathrm{C}$, the yield stress becomes $63.8 \mathrm{ksi}$. Apparently the presence of pre-strain has greatly increased the yield stress, whereas when pre-strain is absent, aging lowers the yield stress.

To help establish this apparent strain-induced precipitation mechanism, a series of test results for material solutionized, then aged at $400^{\circ} \mathrm{C}$ without pre-strain is given in Table 8 , Column 2 . It can be seen in Column 3 of Table 8 that a slight decrease in yield occurs for this direct aging without prestrain, regardless of initial iron content. But if these alloys are first pre-strained then aged at $400^{\circ} \mathrm{C}$, the change in yield clearly becomès dependent on initial iron content as shown in rnlumn 6, Table 8. The strongest offoot is secn in the $\mathrm{BH}$ material, and the magnitude of the prestrain effect can be found by subtracting the aging effect from the strain-aging effect. These data, lister in Column 7, Table 8 are plotted as a function of initial iron content in Figure 17. These data points fit a straight line with a slope of $1: 9 \mathrm{psi}$ per p̈pm. This is a measure of the magnitude of the hardening effect, which appears to be one of strain-enhanced precipitation. The $\mathrm{FeBe}_{11}$ precipitate is probably responsible because, in the high-iron alloy, even if all the aluminum tied up the iron in the ternary compound $\mathrm{AlFeBe}_{4}$, there would be about $4500-\mathrm{ppm}$ iron in the binary precipitate and only about 750-ppm iron in the ternary. The difference between the slope of the

Table 8. Data Showing the Changes in the $0.2 \%$ Offset Yield Stress of Various Materials in the Solutionized Condition (Column 1) Caused by Aging at $400^{\circ} \mathrm{C}$ (Column 3) and Strain $(0.5 \%)-$ Aging $\left(400^{\circ} \mathrm{C}\right.$ ) (Column 6). The difference between the change in yield caused by strain-aging and the change in yield caused simply by aging shows the effect of pre-strain (column 7).

(1)

\begin{tabular}{ccc} 
S & S + 400 C Age & $\begin{array}{c}\text { Change in Yield } \\
\text { Caused by Aging } \\
(2)-(1)\end{array}$ \\
\hline BL 36.4 & 35.0 & -1.4 \\
BM 43.0 & 41.1 & -1.9 \\
BH 51.1 & 50.6 & -0.5
\end{tabular}

(4)

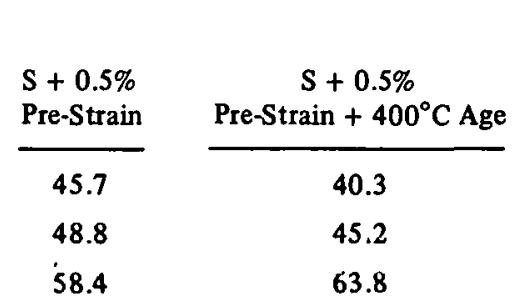

(6)

Change in Yield Caused by Strain-Aging (5) - (4)

$-5.4$

$-3.6$

$+5.4$
(7)

Change in Yield Caused by Pre-Strain (6) - (3)

$-1.7$

$+5.9$ 
RFP-2061

Table 9. Yield Data Comparing the Earlier Strain-Aging Result (BH-SA1) With the Results of Confirmation Tests (SA2-4).

\begin{tabular}{|c|c|c|c|c|c|}
\hline Test Bar No. & $\begin{array}{c}\sigma_{1} \\
\text { Yield As-Solutionized }\end{array}$ & Yield After $0.5 \%$ Pre-Strain & $\begin{array}{c}\sigma_{2}^{\prime} \\
\text { Yield After } 0.5 \% \text { Pre-Strain } \\
\text { and } 400^{\circ} \mathrm{C} \mathrm{Age}\end{array}$ & $\begin{array}{c}\Delta \\
\text { Change Caused by } \\
\text { Strain-Aging }\end{array}$ & $\begin{array}{c}\Delta \sigma \\
\text { Yield Drop }\end{array}$ \\
\hline BH-SA1 & 51.1 & 58.4 & $63.8 \mathrm{p}$ & +5.4 & - \\
\hline BH-SA2 & 53.1 & 59.2 & $64.1 y$ & +4.9 & 1.2 \\
\hline BH-SA3 & 50.6 & 56.6 & $61.1 y$ & +4.5 & 0.1 \\
\hline BH-SA4 & 51.1 & 56.2 & $62.9 y$ & +6.7 & 1.6 \\
\hline
\end{tabular}

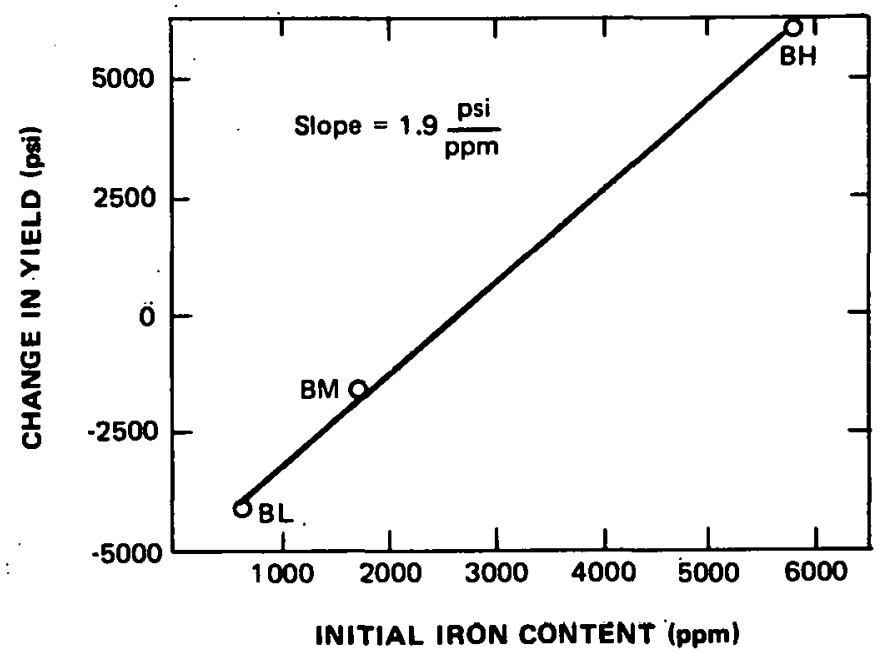

Figure 17. Change in Yield Resulting from the Presence of Pre-Strain as a Function of Iron Content.

curve in Figure 17 and the slopc in Figure 16, 0.2 psi per ppm, is a measure of the effect of aging at $400^{\circ} \mathrm{C}$ without pre-strain. Pre-strain then causes about a 10-fold increase in the amount of hardening. This seems clearly to be a case of strain-enhanced precipitation. For the $\mathrm{BH}$ material, the strengthening effect of the precipitates is greater than the softening of the lattice by solute depletion. The reverse is true for the other materials, possibly because the amount of iron is inadequate to completely pin once-mobile dislocations.

To lend further support to this strainenhanced precipitation mechanism, three more tensile bars of the BH material were given the same solutionize pre-strain age cycle as the one which is listed in Tables 7 and 8 . These results, shown in Table 9, reproduce the previous data well. More important, however, is that each of the three shows a yield drop. This is strong evidence that the precipitates

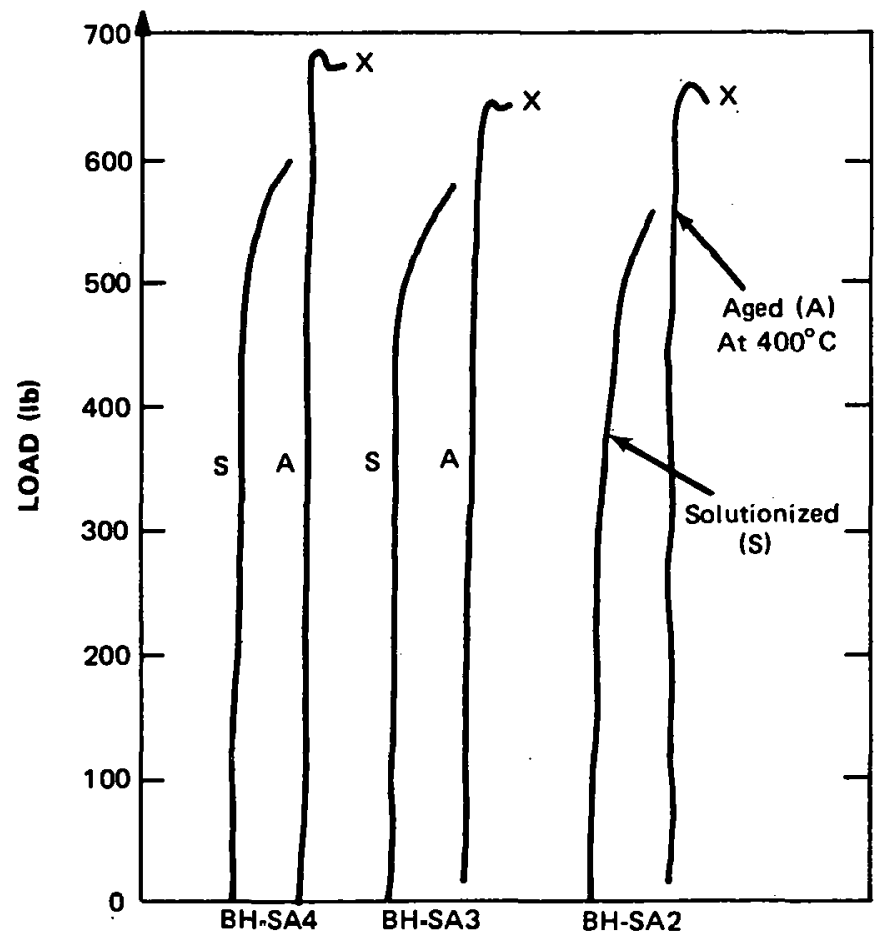

Figure 18. Load-Extension Curves from Which the Data in Table 9 are Obtained.

are strengthening by dislocation-pinning rather than coherency straining or providing obstacles to dislocation motion. The load-extension curves for these tests are plotted in Figure 18. Note that the reload curves subsequent to the $400^{\circ} \mathrm{C}$ aging treatment extend beyond the flow curve as-solutionized.

Effect of Temperature

The results of strain aging at $760^{\circ} \mathrm{C}$ rather than at $400^{\circ} \mathrm{C}$ are given in Table 10 , for the same three 
Table 10. Yield Stress Data for Beryllium Strain-Aged at $760^{\circ} \mathrm{C}$ After $0.5 \%$ Plastic Strain at $25^{\circ} \mathrm{C}$. One test bar per point. The $\Delta$ for $400^{\circ} \mathrm{C}$ strain aging of these materials is included for comparison.

\begin{tabular}{|c|c|c|c|c|c|c|}
\hline & & $\sigma_{1}$ & $\sigma_{2}$ & $\sigma_{2}^{\prime}$ & $\Delta_{760}$ & $\Delta_{400}$ \\
\hline \multirow{3}{*}{ BL } & S & 37.0 & 43.6 & 38.3 & -5.3 & -.5 .4 \\
\hline & B & 36.5 & 44.9 & 38.0 & -6.9 & -7.9 \\
\hline & $\mathbf{T}$ & 33.6 & 42.3 & 35.8 & -6.5 & -5.3 \\
\hline \multirow{3}{*}{$\mathbf{B M}$} & $\mathbf{S}$ & 42.9 & 48.5 & 39.1 & -9.4 & -3.6 \\
\hline & B & $45.5 y^{*}$ & 50.2 & 43.5 & -6.7 & -4.2 \\
\hline & $\mathbf{T}$ & $45.2 y$ & 48.3 & 43.2 & -5.1 & -3.5 \\
\hline \multirow{3}{*}{ BH } & $\mathbf{S}$ & 53.6 & 61.6 & 47.6 & -14.0 & +5.4 \\
\hline & B & 45.2 & 52.5 & 46.8 & -5.7 & -0.6 \\
\hline & $\mathbf{T}$ & 42.2 & 50.3 & 44.9 & -5.4 & -2.1 \\
\hline
\end{tabular}

$\overline{{ }^{*} \mathrm{y}=\text { yield }}$ drop present
Table 11. Yield Stress and Yield Drop (in parentheses if present) Data for Extruded Beryllium as a Function of Various Heat-Treat Conditions. Data are in ksi, and are averages of three tests.

\begin{tabular}{|c|c|c|c|c|c|}
\hline $\begin{array}{c}\text { Materials } \\
\text { Tested }\end{array}$ & Received & $\begin{array}{c}\text { Solu- } \\
\text { tionized } \\
\text { (S) }\end{array}$ & $\begin{array}{c}\text { Aged } \\
\left(400^{\circ} \mathrm{C}\right) \\
\text { (F) }\end{array}$ & $\begin{array}{c}\text { Aged } \\
\left(650^{\circ} \mathrm{C}\right) \\
\text { (B) }\end{array}$ & $\begin{array}{c}\text { Aged } \\
\left(760^{\circ} \mathrm{C}\right) \\
(\mathrm{T})\end{array}$ \\
\hline EF-L & $\begin{array}{l}62.5 \\
(0.2)\end{array}$ & 55.1 & 52.9 & $\begin{array}{l}65.1 \\
(1.5)\end{array}$ & $\begin{array}{l}62.5 \\
(0.7)\end{array}$ \\
\hline$E F-45$ & $\begin{array}{l}44.7 \\
(0.2)\end{array}$ & 38.9 & 37.9 & $\begin{array}{l}47.8 \\
(2.7)\end{array}$ & $\begin{array}{l}48.0 \\
(1.4)\end{array}$ \\
\hline BM & $\begin{array}{l}44.7 \\
(1.2)\end{array}$ & 43.2 & 41.1 & $\begin{array}{l}43.9 \\
(0.6)\end{array}$ & $\begin{array}{l}45.3 \\
(0.9)\end{array}$ \\
\hline
\end{tabular}

iron levels and heat-treat conditions as contained in Table 7. The BL material shows the same strainaging response as it did at $400^{\circ} \mathrm{C}$. Also the magnitudes of $\Delta$ values for the BL material do not vary significantly with initial heat-treat condition. This tends to corroborate earlier evidence that the iron level of the BL material is below the equilibrium solubility limit. Thus, the decrease in yield stress observed in Table 8 is due mostly to recovery effects and it is interesting to note that recovery is as complete after the $400^{\circ} \mathrm{C}$ strain-aging treatment as it is after the $760^{\circ} \mathrm{C}$ treatment. Also, the $\sim 6 \mathrm{ksi}$ decrease in yield caused by recovery can possibly be used as a baseline for separating impurity effects from dislocation-recovery effects for the $\mathrm{BM}$ and BH material.

In this regard, the $\Delta$ values for $760^{\circ} \mathrm{C}$ strain aging of both the BM and BH materials, given in Table 8, are about $6 \mathrm{ksi}$ for the aged preconditions. This suggests that recovery effects alone are responsible for the decrease in the yield stress from the prestrained condition if the materials are first aged. But if the materials are in the solutionized condition when pre-strained, then strain aging at $760^{\circ} \mathrm{C}$ causes a 9.4 and $14.0 \mathrm{ksi}$ decrease in the yield stress from the pre-strained level, for the BM and $\mathrm{BH}$ materials, respectively. This means, where $\sim 6 \mathrm{ksi}$ of the decrease may be due to recovery, $3.4 \mathrm{ksi}$ and $8 \mathrm{ksi}$ are due to solute depletion for the $\mathrm{BM}$ and $\mathrm{BH}$ materials, respectively.
It is surprising that neither the $\mathrm{BM}$ nor the $\mathrm{BH}$ material exhibits a yield drop on $760^{\circ} \mathrm{C}$ strain aging. The reasons for this are obscure and speculation is best delayed until the texture and grain size effects are discussed in the following two sections.

\section{Texture}

The data presented clearly indicate a strain-induced precipitation-pinning mechanism causing yield drops. The purpose of this section is to determine if this pinning is also a function of crystallographic orientation. For example, precipitates may restrict flow on basal planes more than on prism planes, or vice versa. To examine this question, tests run on extruded flat (EF) material oriented for basal (EF-45) and prism (EF-L) now are summarized in this section. The same solutionizing, aging, and strain-aging treatments used to obtain the results of the previous two sections are also given to the extruded material for comparison. Because the room temperature critical-resolved shear stress for basal slip is lower than for prism slip, the data in Table 11 show that the orientation favoring basal flow has a lower yield than does the orientation favoring prism flow. This provides confirmation that the expected texture (see Figure 5) is present. As is the case for the BM material, a yield drop exists in the as-received material and it is eliminated by solutionizing. Aging returns the yield drop for both orientations and the yield drops appear 
stronger subsequent to the low temperature B-aging treatment ( 1.5 versus 0.7 , and 2.7 versus 1.4 ). The net increase in yield strength accompanying the appearance of the yield drop is much greater for the extruded material in either orientation than it is for the BM material. The iron content for the extruded material is, from Table $2,1520 \mathrm{ppm}$ and the aluminum content is $370 \mathrm{ppm}$. These values are close to those for the BM material. The decrease in yield that would occur if the only mechanism were age softening, would be about $2 \mathrm{ksi}$ as shown in Figure 13 for a change in the amount of iron in solid solution from $1520 \mathrm{ppm}$ to $640 \mathrm{ppm}$. Therefore, the hardening that results from the aging treatments on the extruded materials is:

$$
\begin{gathered}
\text { EF-L: } \begin{array}{c}
2+(65.1-55.1) \text { or } ~ \\
\\
\text { condition }
\end{array} \\
\text { EF-L: } 2+(62.5-55.1) \text { or } \sim 9 \mathrm{ksi} \text { for the } \mathrm{B} \\
\quad \text { condition } \\
\text { EF-45: } 2+(47.8-38.9) \text { or } \sim 11 \mathrm{ksi} \text { for the B } \\
\text { condition } \\
\text { EF-45: } 2+(48.0-38.9) \text { or } \sim 11 \mathrm{ksi} \text { for the } \mathrm{T} \\
\text { condition }
\end{gathered}
$$
EF-45: $2+(48.0-38.9)$ or $\sim 11 \mathrm{ksi}$ for the $\mathrm{T}$ condition

These data might be summarized by stating that the net hardening on aging varies from 7 to 10 $\mathrm{ksi}$, depending upon aging temperature and orientation. Therefore, these data show that pinning can restrict flow on either basal or prism planes. Although the yield drop is about twice as great for basal pinning, the level of hardening of basalflow can be greater or lesser than for prism flow depending on the aging temperature.

Obviously, the effect of texture is a strong one. The net 7- to 10-ksi increase in yield strength for the textured EF material compares to an insignificant increase for the BM material. Localized variations of texture within a hot-pressed block can be expected to give rise to variations in yield drops; possibly causing them to be absent in some tensile bars and present in others.

The $400^{\circ} \mathrm{C}$ aging treatment does not promote a yield drop in any of the materials listed in Table 11 .

\begin{tabular}{|c|c|c|c|c|c|c|c|}
\hline & & \multicolumn{2}{|c|}{ S } & \multicolumn{2}{|c|}{ B } & \multicolumn{2}{|c|}{$\mathbf{T}$} \\
\hline & & 0.5 & 1.0 & 0.5 & 1.0 & 0.5 & 1.0 \\
\hline \multirow[t]{2}{*}{$\begin{array}{l}\text { EF-L } \\
\text { (Prism Flow) }\end{array}$} & $\begin{array}{l}\sigma_{1} \\
\sigma_{2}\end{array}$ & $\begin{array}{l}56.1 \\
62.8\end{array}$ & $\begin{array}{l}56.4 \\
69.5\end{array}$ & $\begin{array}{l}65.1 y \\
68.2\end{array}$ & $\begin{array}{l}64.3 y \\
73.5\end{array}$ & $\begin{array}{l}63.2 y \\
66.3\end{array}$ & $\begin{array}{l}62.4 y \\
71.3\end{array}$ \\
\hline & $\begin{array}{l}\sigma_{2}^{\prime} \\
\Delta\end{array}$ & $\begin{array}{c}59.1 \mathrm{i} \\
-3.7\end{array}$ & $\begin{array}{r}62.8 \\
-6.7\end{array}$ & $\begin{array}{c}63.3 \mathrm{i} \\
-4.9\end{array}$ & $\begin{array}{l}x \\
-\end{array}$ & $\begin{array}{l}63.4 \mathrm{i} \\
-3.9\end{array}$ & $\begin{array}{c}63.5 i \\
-7.8\end{array}$ \\
\hline \multirow[t]{2}{*}{$\begin{array}{l}\text { EF-45 } \\
\text { (Basal Flow) }\end{array}$} & $\begin{array}{l}\sigma_{1} \\
\sigma_{2}\end{array}$ & $\begin{array}{l}38.3 \\
42.0\end{array}$ & $\begin{array}{l}38.4 \\
46.4\end{array}$ & $\begin{array}{l}47.0 y \\
47.7\end{array}$ & $\begin{array}{l}47.3 y \\
50.3\end{array}$ & $\begin{array}{l}48.1 y \\
48.0\end{array}$ & $\begin{array}{l}48.4 y \\
51.7\end{array}$ \\
\hline & $\begin{array}{l}\sigma_{2}^{\prime} \\
\Delta\end{array}$ & $\begin{array}{r}40.7 \\
-1.3\end{array}$ & $\begin{array}{r}43.2 \\
-3.2\end{array}$ & $\begin{array}{l}45.4 p \\
-2.3\end{array}$ & $\begin{array}{l}46.5 p \\
-3.8\end{array}$ & $\begin{array}{c}48.0 \mathrm{i} \\
0\end{array}$ & $\begin{array}{l}47.3 \mathrm{i} \\
-4.4\end{array}$ \\
\hline \multirow[t]{2}{*}{$\mathbf{B M}$} & $\begin{array}{l}\sigma_{1} \\
\sigma_{2}\end{array}$ & $\begin{array}{l}43.0 \\
48.8\end{array}$ & $\begin{array}{l}43.7 \\
55.1\end{array}$ & $\begin{array}{l}43.7 y \\
48.2\end{array}$ & $\begin{array}{l}42.5 y \\
52.9\end{array}$ & $\begin{array}{l}44.6 y \\
47.5\end{array}$ & $\begin{array}{l}44.7 y \\
54.9\end{array}$ \\
\hline & $\begin{array}{l}\sigma_{2}^{\prime} \\
\Delta\end{array}$ & $\begin{array}{r}45.2 \\
-3.6\end{array}$ & $\begin{array}{r}59.3 \\
-5.8\end{array}$ & $\begin{array}{r}44.0 \\
-4.2\end{array}$ & $\begin{array}{r}44.8 \\
-8.1\end{array}$ & $\begin{array}{r}44.0 \\
-3.5\end{array}$ & $\begin{array}{r}45.5 \\
-9.4\end{array}$ \\
\hline \multicolumn{8}{|c|}{$\begin{array}{l}x \text { - sample broke } \\
y \text { - yield drop } \\
p \text { - plateau } \\
\text { i - inflection }\end{array}$} \\
\hline
\end{tabular}
Instead, each material has a slight decrease in yield, indicating a minor amount of solute depletion. Other investigators ${ }^{61}$ found yield drops in extruded
Table 12. Yield Stress Data for $400^{\circ} \mathrm{C}$ Strain Aging of Extruded-Flat Material Compared to BM Material.

material similarly aged. The discrepancy may be due to a cooling-rate effect, for they waterquenched from the solutionizing temperature, whereas rapid air cooling is used in this work.

Strain aging at $400^{\circ} \mathrm{C}$ does not develop a yield drop in the extruded material regardless of pre-strain, initial heat-treat condition, or orientation. This can be seen in Table 12. A comparison of the values for the strain-aging parameter, $\Delta$, reveals that the BM material behaves much like the extruded material oriented for prism flow.

The $\Delta$ value, caused by $400^{\circ} \mathrm{C}$ aging of solutionized extruded material without prior strain, is more. positive than it is for similar aging of solutionized, pre-straining material. The $\Delta$ values for $400^{\circ} \mathrm{C}$ aging without pre-straining are $-3.2 \mathrm{ksi}$ and $-0.4 \mathrm{ksi}$, for the prism and basal orientations, respectively.

Strain aging the extruded-flat material at $760^{\circ} \mathrm{C}$ after $0.5 \%$ room temperature pre-strain results in the return of a yield drop regardless of the initial heat-treat condition. This is evident from Table 13, where the BM results and the $\Delta$ value for the $400^{\circ} \mathrm{C}$ aging treatment are included for comparison. The presence of a yield drop on strain-aging 
Table 13. Effect of $760^{\circ} \mathrm{C}$ Strain Aging on the Yield Behavior of Extruded-Flat Material Oriented for Prism (EF-L) and Basal (EF-45) Flow. Results of $400^{\circ} \mathrm{C}$ strain aging and results for the standard hot-pressed beryllium (BM) are included for comparison. One test per datum point. Values are in ksi.

\begin{tabular}{|c|c|c|c|c|c|c|}
\hline Material & Heat-Treat Condition & $\begin{array}{c}\text { Initial Yield Stress } \\
\qquad \sigma_{1}\end{array}$ & $\begin{array}{l}\text { Unloading Flow Stress } \\
\qquad \sigma_{2}\end{array}$ & $\begin{array}{l}\text { Reloading Yield Stress } \\
\qquad \sigma_{2}^{\prime}\end{array}$ & $\frac{\text { Strain-Aging }}{760^{\circ} \mathrm{C}}$ & $\frac{\text { arameter, } \Delta}{400^{\circ} \mathrm{C}}$ \\
\hline EF-L & $\begin{array}{c}\text { Solutionized } \\
\text { Aged }-650^{\circ} \mathrm{C} \\
\text { Aged }-760^{\circ} \mathrm{C}\end{array}$ & $\begin{array}{l}52.8 \\
65.9 \\
62.0\end{array}$ & $\begin{array}{l}60.0 \\
67.8 \\
65.3\end{array}$ & $\begin{array}{c}63.0 \mathrm{i} \\
x \\
66.5 y\end{array}$ & $\begin{array}{c}+3.0 \\
- \\
+1.2\end{array}$ & $\begin{array}{l}-3.7 \\
-4.9 \\
-3.9\end{array}$ \\
\hline $\mathrm{EF}-45$ & $\begin{array}{c}\text { Solutionized } \\
\text { Aged }-650^{\circ} \mathrm{C} \\
\text { Aged }-760^{\circ} \mathrm{C}\end{array}$ & $\begin{array}{l}39.9 \\
49.1 \\
47.4\end{array}$ & $\begin{array}{l}43.1 \\
50.0 \\
48.7\end{array}$ & $\begin{array}{l}49.6 y \\
50.0 y \\
50.8 y\end{array}$ & $\begin{array}{c}+6.5 \\
0 \\
+2.1\end{array}$ & $\begin{array}{c}-1.3 \\
-2.3 \\
0\end{array}$ \\
\hline $\mathbf{B M}$ & $\begin{array}{c}\text { Solutionized } \\
\text { Aged }-650^{\circ} \mathrm{C} \\
\text { Aged }-760^{\circ} \mathrm{C}\end{array}$ & $\begin{array}{l}42.9 \\
45.5 \\
45.2\end{array}$ & $\begin{array}{l}48.5 \\
50.2 \\
48.3\end{array}$ & $\begin{array}{l}39.1 \\
43.5 \\
43.2\end{array}$ & $\begin{array}{l}-9.4 \\
-6.7 \\
-5.1\end{array}$ & $\begin{array}{l}-3.6 \\
-4.2 \\
-3.5\end{array}$ \\
\hline
\end{tabular}

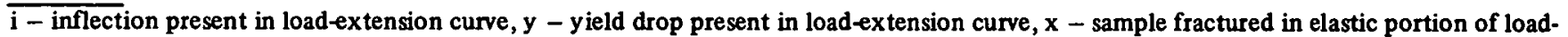
extension curve.

material previously solutionized is to be expected because direct aging without pre-strain at this temperature produces a yield-drop. It is surprising to observe that even material aged prior to prestraining exhibits a yield drop return. This is because precipitation must occur. to effect pinning and cause the yield drop; and, since the prior aging treatment presumably decreased the amount of iron in solid solution from $1520 \mathrm{ppm}$ to an equilibrium level presumed to be about $640 \mathrm{ppm}$, further precipitation seems unlikely. The explanation may involve strain-induced precipitation, which effectively lowers the solubility limit, but it must involve some other factor or the BM material would have shown a yield drop. That other factor might be texture, because texture is the most obvious difference between these materials.

Texture might allow a yield-drop return in previously aged material because it promotes more homogeneous deformation. Since these tests are done with $0.5 \%$ plastic pre-strain, the compatibility condition requires that the entire cross-sectional area deform a commensurate amount, or cracks will appear. Considering that some grains are oriented more favorably for slip than others, in randomly oriented material, they will flow first and build up stress concentrations at grain boundaries until flow commences in neighboring, less-favorably oriented grains. In textured material the stress build-up necessary to promote flow in neighboring grains is not as great, and the entire cross section will flow without such stress discontinuities. When subsequent strain aging is applied to each type of material, most of those dislocations in the textured material provide sites for hetrogeneous nucleation of pinning precipitates. Only the favorably oriented grains in the random material will have pinned dislocations within them; the dislocations in other grains being less suitable precipitation sites. Then on reloading, the mobile dislocation density of the textured material is low and yield drops appear. The randomly oriented material on the other hand does not show a yield drop because flow commences in those grains having unpinned dislocations.

Another possible way to explain the stronger tendency for yield drops in textured material is by Luders strain. Yield drops in textured material characteristically have a greater Luders strain or constant load plateau than random, hot-pressed material. This could be due to the progression of a Luders band down the gage length of the test bar if the amount of pre-strain is less than the Luders strain; then aging could pin the moving front requiring nucleation of a new front and the attendant yield drop.

\section{Grain Size}

Evidence presented thus far shows that the yield drop in beryllium is due to strain-induced precipitation, probably of the $\mathrm{FeBe}_{11}$ intermetallic 
phase. It has been also shown that yield drops are more easily obtained in textured material. The purpose of this section is to determine the effect of grain size on yield point behavior. Many nonferrous metals have an upper limit of grain size, beyond which yield drops do not occur. Possibly beryllium has a similar, upper grain-size limit. The observation that ingot sheet almost never has a yield drop, whereas powder-source beryllium with comparable impurity levels often has a yield drop certainly suggests that such a limit exists. This suggestion arises because ingot sheet normally has an average grain size of 35 microns and powdersource beryllium normally has an average grain size of 10 microns.

As mentioned, the means of obtaining a large grain size in this work is to conduct the solution anneal at $1150^{\circ} \mathrm{C}$ (G-anneal) instead of $1040^{\circ} \mathrm{C}$ (S-anneal). This higher temperature promotes grain growth. Rapid air cooling is used to retain iron in solid solution. Aging is then conducted at temperatures known to promote a yield drop in material solutionized at $1040^{\circ} \mathrm{C}$.

Results of such grain-growth treatments for the BM and EF-45 materials are given in Table 14. The grain-size values shown in Table 14 differ from those found in Figure 6 because the $1040^{\circ} \mathrm{C}$ solutionizing heat treatment(s) cause some grain growth. Tensile data included in Table 14 show that aging at $760^{\circ} \mathrm{C}$ subsequent to the grain-growth anneal (GT-heat treatment) does not promote a yield drop for either material. This same aging treatment causes yield drops if preceded by the normal $1040^{\circ} \mathrm{C}$ solution-anneal (T-heat treatment). Twenty of the twenty-two tests of the reference (BM) material show yield drops on T-aging, and all the extruded-flat (EF) material shows yield drops on T-aging.

The absence of yield drops in these two materials may be due to the increase in the average grain size. The increase is from 9.8 microns to 15.2 microns for the BM material, and from 8.1 microns to 11.5 microns for the EF material. Although this may seem to be a small increase in size, the pliotomicrographs in Figure 6 show the difference in size more dramatically. Also, it can easily be shown that the above increases in grain size
Table 14. Average Values for Yield and Yield Drop of Two Materials Given Grain Growth Anneals.

\begin{tabular}{|c|c|c|c|c|c|}
\hline Material & Condition & $\begin{array}{l}\text { No. } \\
\text { Tests }\end{array}$ & $\begin{array}{c}\text { Yield } \\
\text { Stress } \\
\text { (ksi) }\end{array}$ & $\begin{array}{c}\Delta a \\
\text { (ksi) }\end{array}$ & $\begin{array}{c}\text { Grain } \\
\text { Size } \\
\text { (microns) }\end{array}$ \\
\hline $\mathbf{B M}$ & $\begin{array}{l}S \\
T \\
\text { G } \\
\text { GT }\end{array}$ & $\begin{array}{r}18 \\
22 \\
3 \\
3\end{array}$ & $\begin{array}{l}42.4 \\
42.5 \\
33.0 \\
33.9\end{array}$ & $\begin{array}{l}- \\
1.4 \\
- \\
-\end{array}$ & $\begin{array}{r}9.8 \\
9.8 \\
15.2 \\
15.2\end{array}$ \\
\hline EF -45 & $\begin{array}{l}S \\
T \\
G^{*} \\
\text { GT }\end{array}$ & $\begin{array}{l}3 \\
3 \\
1 \\
3\end{array}$ & $\begin{array}{l}38.9 \\
48.0 \\
30.9 \\
32.9\end{array}$ & $\begin{array}{l}- \\
1.4 \\
- \\
-\end{array}$ & $\begin{array}{r}8.1 \\
8.1 \\
11.5 \\
11.5\end{array}$ \\
\hline
\end{tabular}

*This one test bar was also aged at $400^{\circ} \mathrm{C}$ for 1 hour and slow cooled prior to testing.

correspond to a rcduction of about $70 \%$ in the number of grains present in a given volume for each material type. This is a significant change, and is most likely the reason that the yield drop can no longer be obtained by aging.

The data in Table 14 is used to construct the HallPetch type of plot in Figure 19. Included in the plot is a linear curve, which is taken from Appendix $\mathrm{B}$, for typical hot-pressed beryllium (BY).

Appendix $B$ contains extensive analyses of the grain-growth method of studying the grain-size effect. As expected, the BM material in Figure 19 shows a decrease in yield strength resulting from an increased grain size. Since the slopes of the lines for the solutionized and aged condition are nearly parallel, the yield-point effect is not a strong one. Also the lines are closely parallel to that of another typical hot-pressed material (BY), showing that the decrease in yield accompanying grain growth is about the amount expected.

The results for the EF-45 material in Figure 19 do show a yield-point effect. The grain-size effect is typical of hot-pressed material if the EF-45 material is in the solutionized condition since the slope of the line is nearly parallel to the line for the BY material. But in the aged condition the EF-45 material exhibits a much greater difference in yield stress because of grain growth than would be predicted from the results of the BY material. Since a strong yield drop accompanies aging of the EF-45 material, which had been solutionized at $1040^{\circ} \mathrm{C}$, and whereas no yield drop accompanies aging after solutionizing at $1150^{\circ} \mathrm{C}$, the yield-point effect is 


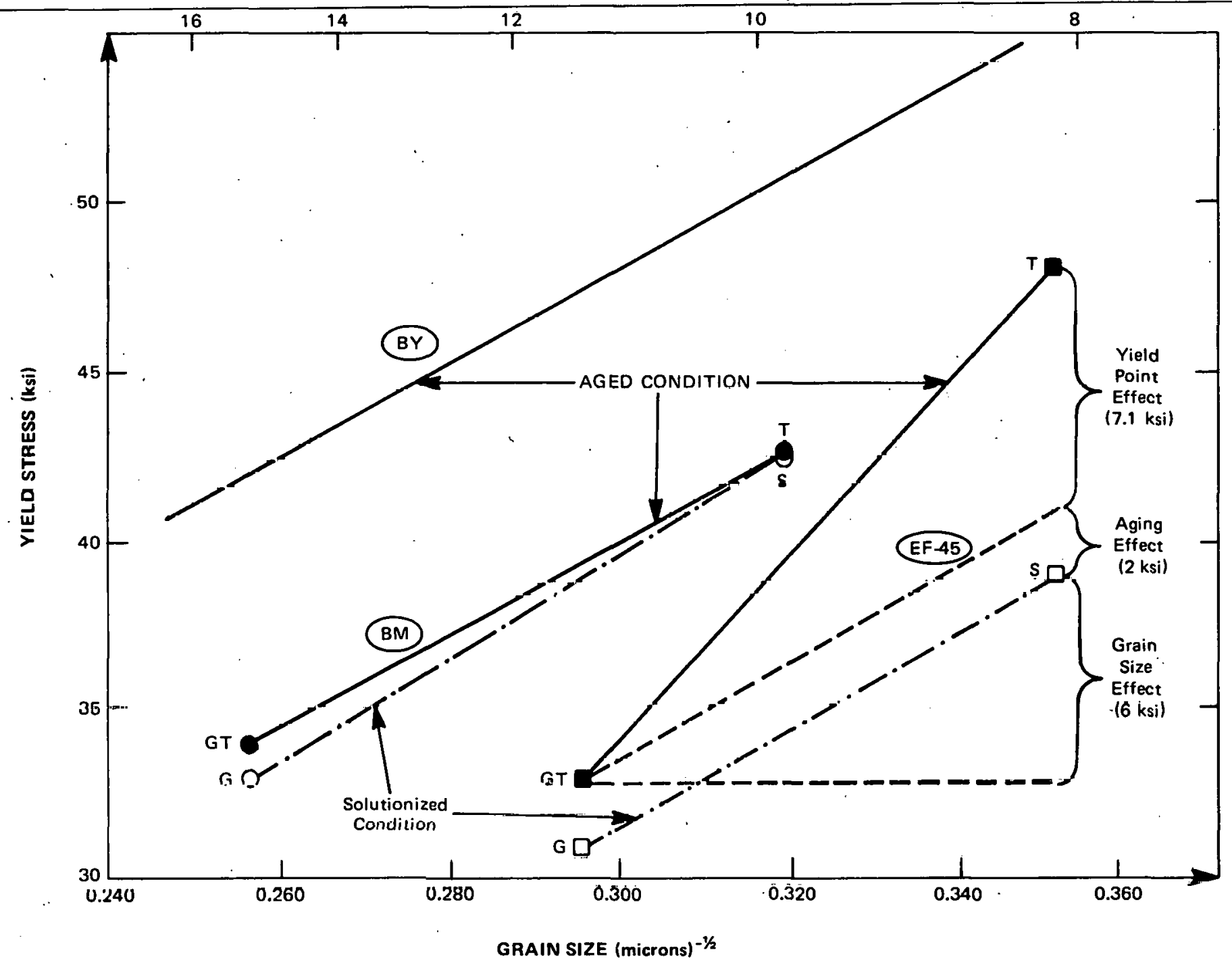

Figure 19. HallPetch Plot for Materials Given Grain Growth Anneals. Data points are averages of three tests. Circled letters are the materials and uncircled letters describe the heat treatments used.

probably the main reason for the observed difference. Part of the difference is due to aging $(2 \mathrm{ksi})$ and this would occur even if a yield drop did not appear. This can be seen in Figure 19 by the increased yield stress in the GT condition as compared to the G condition for the EF-45 material. Most of the difference is due to the yield point effect $(7.1 \mathrm{ksi})$ as shown by the braces in Figure 19. This $7.1 \mathrm{ksi}$ yield-point effect is not as great as would be predicted from the earlier results that showed the hardening that accompanies yield drops in this material is from 9 to $12 \mathrm{ksi}$. As a result, the evidence is not conclusive that the increased grain size is solely responsible for the removal of the yield drop. In fact, it even suggests that some other factor is possibly involved. This other factor could be a change in texture accompanying grain growth, although the results of Smigelskas and Barrett ${ }^{72}$ showing no change in texture during recrystallization of beryllium tend to minimize this possibility. Another, more likely, possibility is redistribution of impurities during grain growth. Aluminum, for example, when freed from the ternary phase $\mathrm{AlFeBe}_{4}$ will be swept up by the grain boundaries 
as they grow, and will be concentrated in the triplepoints of intersecting grains. This makes subsequent formation of the ternary phase more difficult owing to greater distances that the iron must diffuse to combine with aluminum.

Increasing the average grain size of beryllium is seen to eliminate yield drops. Apparently an average grain size of less than 10 microns is necessary to obtain yield drops.

Although the ingot-sheet material fabricated during this study by redundant forging and rolling does not have the desired 15-micron grain size, a few yield results are included in this section. The material tested is 0.060 -in. thick, having been rolled at $700^{\circ} \mathrm{C}$ from about 0.175 -in. thickness, using intermediate reheats at $760^{\circ} \mathrm{C}$. Two heat-treat conditions subsequent to the final $20 \%$ reduction in thickness are tested; $650^{\circ} \mathrm{C}$ and $760^{\circ} \mathrm{C}$ for one hour, followed by a slow cool. The yield values for two tests in each condition averaged 53.9 and $48.2 \mathrm{ksi}$, respectively. Although yield drops did not develop, a definite plateau is evident in one of the tests of the material heat treated at $760^{\circ} \mathrm{C}$, as shown in Figure 20. Also shown in Figure 20 is a load extension curve on some 0.1 -in.-thick ingot sheet made earlier and given a one-hour heat treat at $700^{\circ} \mathrm{C}$. In this case a yield drop is evident. Both optical and transmission electron microscopy reveal a finc cell-size substructure in this condition, resulting in an effective grain size that is finer than the one reported by conventional metallography, as in Figure 6. This provides further evidence that a fine grain size is a necessary condition for the occurrence of a yield drop.

Thus a fine grain size appears to be a necessary condition for the occurrence of a yield drop in beryllium. Results of this work indicate that an average grain size of less than 10 microns is required for a yield drop. Extruded-flat stock does not show a yield drop in material whose grain size has been increased by a grain growth anneal from 4.1 to 7.7 microns. Hot-pressed, high-iron material did show a yield drop upon strain aging at $400^{\circ} \mathrm{C}$ even though its average grain size is 12 microns. But its microstructure is duplex-many grains being about 5 microns in size-and the finer grains may have been responsible for the yield drop.

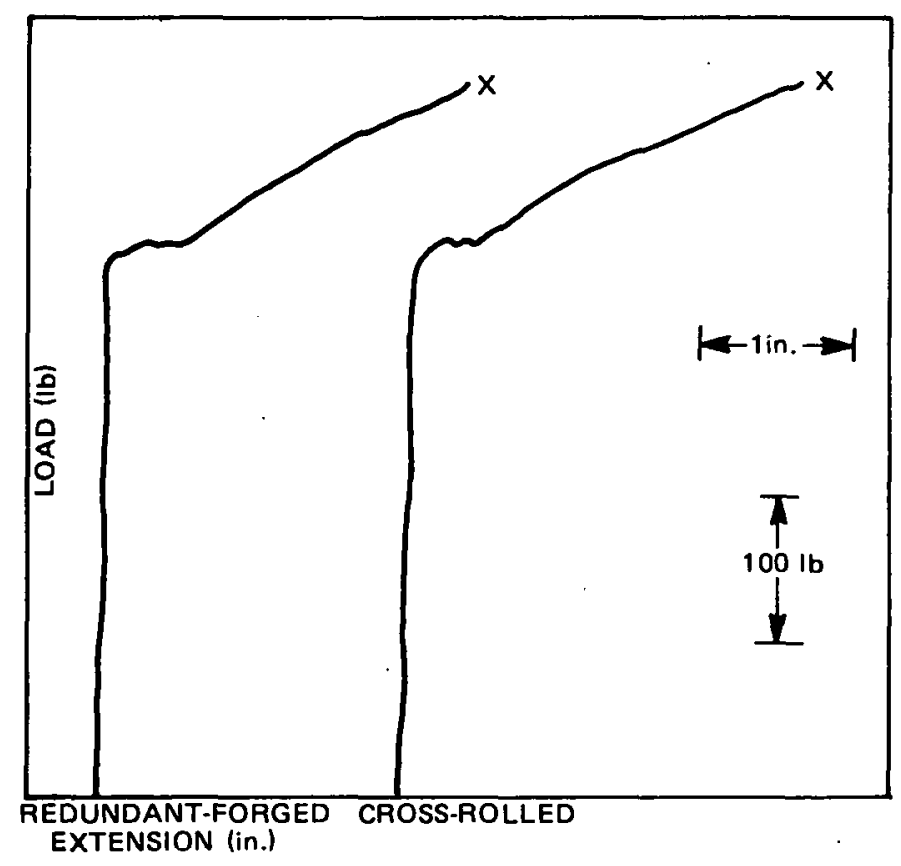

Figure 20. Load-Extension Curve for Ingot-Sheet Materials. Both the redundant-forged and cross-rolled materials are thought to have finer grain sizes than optical metallography predicts, because of substructure formation.

The extruded-flat microstructure is quite uniform, so the 7.7 micron upper limit is thought to be more reliable for uniform microstructures.

\section{Supplier}

As noted previously, material manufactured by Kawecki-Berylco Industries (KBI) does not show a yield drop as readily as does material made by Brush-Wellman Company. It is of interest to determine if the mechanism for the yield drop that is indicated by the work with Brush material, strain-enhanced precipitation pinning, can also be the cause of yield drops in KBI beryllium, or if another mechanism is operative in KBI material; perhaps it can be established by a study of similar heat treatments and strain-aging tests as used on Brush material in the preceding work.

The KBI material, selected for study because it had a slight yield plateau as-received, has an iron content of $2250 \mathrm{ppm}$ and an average grain size of 10 
Table 15. Comparison of Brush Medium Iron (BM) Material and Kawecki-Berylco-Industries Material (K) in Their Response to Solutionizing (S) and Aging (T) Treatments. Numbers of tests are shown in parentheses. Resulting data are in ksi.

\begin{tabular}{|c|c|c|c|c|}
\hline & \multicolumn{2}{|c|}{$s$} & \multicolumn{2}{|c|}{$T$} \\
\hline & \multicolumn{2}{|c|}{$\begin{array}{c}1040^{\circ} \mathrm{C}-6 \text { Hours } \\
\text { Rapid Air Cool }\end{array}$} & \multicolumn{2}{|c|}{$\begin{array}{l}\text { "S" Followed by } \\
760^{\circ} \mathrm{C}-6 \text { Hours } \\
\text { and Slow Cool }\end{array}$} \\
\hline & BM (5) & $K(6)$ & BM (9) & K (9) \\
\hline \multicolumn{5}{|l|}{ Yield } \\
\hline Mean & 42.9 & 38.7 & 44.7 & 36.1 \\
\hline Std. Dev & 0.1 & 0.9 & 0.5 & 1.5 \\
\hline Range & $42.8-43.0$ & $38.2-40.4$ & $44.1-45.5$ & $34.0-38.7$ \\
\hline \multicolumn{5}{|l|}{ Yield Drop } \\
\hline Mean & - & - & 1.5 & 0 \\
\hline Range & - & - & $0-2.8$ & $0-0.5$ \\
\hline
\end{tabular}

microns. A series of test results for KBI material (K) and Brush material (BM) given solutionizing ànd $760^{\circ} \mathrm{C}$ aging treatments are listed in Table 15. The standard deviation of the $\mathrm{K}$ material is seen to be greater than for the BM material for both heat-treat conditions. As expected, neither material has a yield drop as-solutionized. But, eight of the nine tests of BM material in the T-aged condition show a yield drop, whereas only one of nine tests of $\mathrm{K}$ material in this condition has a yield drop. This serves to emphasize the difference in yield-drop behavior between the two materials.

Further comparison of these two materials is given in Table 16, which lists their strain-aging response. The data for the BM material are taken from Table 7, and the strain-aging terminology is the same as defined in Figure 14. The value of the strain-aging parameter, $\Delta$, for the $\mathrm{K}$ material in the $S$ condition is seen in Table 16 to be more positive than for the BM material. This means that hardening is more prevalent in the $\mathrm{K}$ material. Such behavior is expected from the earlier strain-aging results for Brush material given in Figure 16, because of the higher iron content of the KBI material. In fact, the plot in Figure 16 predicts a $\Delta$ value of $-2 \mathrm{ksi}$, which is quite close to the observed value of $-1.6 \mathrm{ksi}$ for the $\mathrm{K}$ material with iron content of $2250 \mathrm{ppm}$. The hardening exhibited in Figure 16 is thought to be strain-induced precipitate-pinning and the preceding discussion shows that the $\mathrm{K}$ material exhibits such behavior.
Table 16. Results of $400^{\circ} \mathrm{C}$ Strain Aging of Brush and KBI Materials Initially in the Solutionized and T-Aged Conditions. Data are averages for three tests in each condition. Values are in ksi.

\begin{tabular}{|c|c|c|c|c|}
\hline \multirow[b]{2}{*}{ Matcrial } & \multirow{2}{*}{$\begin{array}{l}\text { Heat-Treat } \\
\text { Condition } \\
\text { Pre-Strain }\end{array}$} & \multirow{2}{*}{$\begin{array}{c}\begin{array}{c}\text { Solutionized } \\
(\mathrm{S})\end{array} \\
0.5 \%\end{array}$} & \multicolumn{2}{|r|}{$\begin{array}{l}- \\
\text { (T) }\end{array}$} \\
\hline & & & $0.5 \%$ & $1.0 \%$ \\
\hline \multirow[t]{2}{*}{$\mathbf{B M}$} & $\begin{array}{l}\sigma_{1} \\
\sigma_{2}\end{array}$ & $\begin{array}{l}43.0 \\
48.8\end{array}$ & $\begin{array}{l}44.6 y \\
47.5\end{array}$ & $\begin{array}{l}44.7 y \\
54.9\end{array}$ \\
\hline & $\begin{array}{l}\sigma_{2}^{\prime} \\
\Delta\end{array}$ & $\begin{array}{r}45.2 \\
-3.6\end{array}$ & $\begin{array}{r}44.0 \\
-3.5\end{array}$ & $\begin{array}{r}45.5 \\
-9.4\end{array}$ \\
\hline \multirow[t]{2}{*}{ K } & $\begin{array}{l}\sigma_{1} \\
\sigma_{2}\end{array}$ & $\begin{array}{l}38.2 \\
42.8\end{array}$ & $\begin{array}{l}34.4 \\
41.7\end{array}$ & $\begin{array}{l}36.4 \\
50.3\end{array}$ \\
\hline & $\begin{array}{l}\sigma_{2}^{\prime} \\
\Delta\end{array}$ & $\begin{array}{r}41.2 \\
-1.6\end{array}$ & $\begin{array}{r}36.4 \\
-5.3\end{array}$ & $\begin{array}{r}43.6 \\
-6.7\end{array}$ \\
\hline
\end{tabular}

Table 17. Results of Direct-Aging $B M$ and $K$ Materials at $760^{\circ} \mathrm{C}$ Without Prior Solution-Annealing.

\begin{tabular}{|c|c|c|c|c|c|}
\hline \multirow[b]{2}{*}{ Material } & \multirow{2}{*}{$\begin{array}{l}\text { No. } \\
\text { Tests }\end{array}$} & \multicolumn{2}{|c|}{$\begin{array}{c}0.2 \% \text { Offset Yield } \\
(\mathrm{ksi})\end{array}$} & \multicolumn{2}{|c|}{$\begin{array}{l}\text { Yield Irop } \\
\text { (ksi) }\end{array}$} \\
\hline & & Mean & Range & Mean & Range \\
\hline BM & 2 & 42.1 & $41.4-42.9$ & 0.25 & $\begin{array}{ll}0 & -0.5\end{array}$ \\
\hline $\mathbf{K}$ & 3 & 47.3 & $46.2-48.5$ & 4.3 & $3.9-4.7$ \\
\hline
\end{tabular}

A comparison of the response of the two materials initially in the $\mathrm{T}$-aged condition to strain aging at $400^{\circ} \mathrm{C}$ is less clear. At $0.5 \%$ pre-strain the BM material shows a more positive $\Delta$ value than the $\mathrm{K}$ material. At $1 \%$ pre-strain the reverse is true. No yield drops appear for either material upon strain aging at $400^{\circ} \mathrm{C}$.

To enhance the moderate yield drop present in both the BM and the $\mathrm{K}$ materials in the as hotpressed condition, three bars of each material were given the $\mathrm{T}$-aging treatment directly, without prior solutionizing. The results, summarized in Table 17, are the most surprising of this report. The $\mathrm{K}$ material develops very strong yield drops; the strongest thus far observed in this work. The BM material still exhibits a yield drop, but less strong than if the aging treatment had been preceded by a solution anneal.

The load-extension curves for the three tests of $\mathrm{K}$ material prove interesting and are reproduced in Figure 21. In the figure the stresses corresponding 


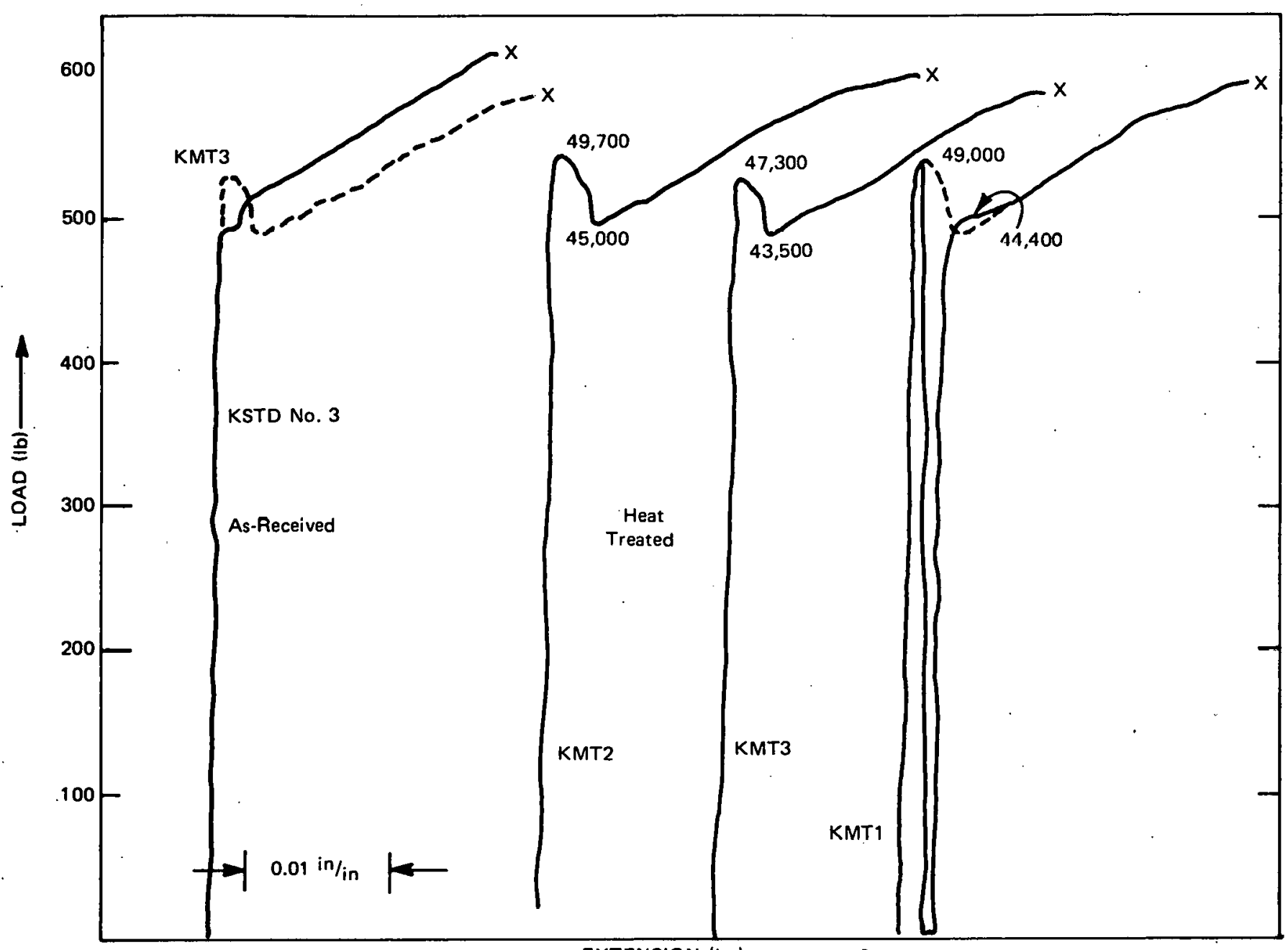

EXTENSION (in.)

Figure 21. Load-Extension Curves for K Material, Showing the Large Yield Drop Accompanying the MT Heat Treatment. Stresses at certain points are shown on the curves.

to certain points are given. Sample KMT 1 is especially interesting because the suddenness and magnitude of the yield drop triggered the samplefracture detector of the testing machine and thereby removed the load. The reload line is not as steep as the initial-load line above $\sim 400$ pounds, and the yield drop is absent. The dashed line is a trace taken from test KMT2, showing the path that might have been followed had the sample not been accidentally unloaded. Especially interesting is that all the strain that would have been taking place as the load was decreasing to the lower yield value is now apparently occurring in the 400- to 500-pound range during reloading. The reloading curve lonks like test results when no yield drop is observed, but a slight inflection is present. It serves to emphasize that once the yield drop is eliminated by over-stressing, it can not be expected to appear on reloading. Also shown in Figure 21 is a reproduction of a tensile test of this same material in the as-received condition. The introduction of a yield drop has caused a higher upper yield but a lower yield stress. The flow curves are closely parallel in both conditions.

To help explain this strong yield drop of $\mathrm{K}$ material upon direct aging, transmission electron microscopy is used. Thin sections, removed from the ends of the tensile bars of the $\mathrm{K}$ material in both the asreceived (KSTD) and "MT" (KMT) conditions, are thinned following methods described previously..$^{73}$ Although the abundance of impurities $(\mathrm{BeO}$, 
primarily) makes thinning more difficult, results of several useable films are presented in Figures 22a-f. A comparison of the distribution and size of the second-phase particles, shown in Figures 22a and b, reveals very little difference. These particles are principally $\mathrm{BeO}$ and they range from several microns to submicron sizes. The fines often appear in long stringers across grains.

The dislocation networks in the two conditions are revealed at a greater magnification in Figures 22c and $22 \mathrm{~d}$. The dislocations in the lower right corner of Figure $22 \mathrm{c}$ appear to be free, whereas those present in Figure $22 \mathrm{~d}$ show some evidence of being pinned. Notice the bowing-out near the center of Figure 22d. Also note the subboundary running along the right side of the photomicrograph. This is the most striking difference noticed between the two heattreat conditions. The dislocations in the as-received condition were randomly distributed whereas those in the MT condition had coalesced into subboundaries, producing a much finer effective grain size. A complex tangle of dislocations is seen in the grain boundary at the lower left of Figure 22e, indicating that the dislocations have migrated to the boundary. A few dislocations are evident in the matrix. Many of them have dark spots at one end that may be: precipitates, but are more probably the points where the dislocations intersect the film surface. Note the stringer of fines perpendicular to the grain boundary, which is thought to be mostly $\mathrm{BeO}$. Finally, Figure $22 \mathrm{f}$ shows a small grain that is nearly devoid of dislocations and contains an abundance of finely distributed, second-phase particles.

The transmission microscopy shows that the KMT material, which has the strong yield drop, differs from the as-received material chiefly by the presence of the well-developed substructure in the KMT material. This is related to the grain-size effect, discussed above in that the substructure produces an effective grain size much finer than is present in the as-received material. These subgrains are low in mobile dislocations, most dislocations having gone into the formation of the subgrains and a few apparently having been pinned. The dominant feature of the microstructure is the abundance of large and small second-phase particles. These can be the sources for free dislocations as the result of thermal expansion differences. Rapid cooling may not allow time for them to combine or form subboundaries, thereby eliminating the yield drop owing to the abundance of glissile dislocations. Slow cooling, on the other hand, may allow time for the dislocations to form this substructure of fine cell-size that has a low density of glissile dislocations, thereby promoting a yield drop.

The difference between the BM and the $\mathrm{K}$ materials in response to the direct-aging treatment may be caused by the presence of pre-strain in the as-received $\mathrm{K}$ material that is not present in the BM material. Aging at $760^{\circ} \mathrm{C}$ would then cause strain-enhanced precipitation in the $\mathrm{K}$ material as well as the substructure formation discussed above. Such a prestrain could be caused by differences in hot-pressing and cool-down practices between the two suppliers, and the solutionizing treatment eliminating these differences. To check out this possibility, the Brush-extruded flat stock, which probably has residual pre-strain owing to rapid cooling immediately after extrusion, was directly aged at $760^{\circ} \mathrm{C}$ without first solutionizing it. The sample chosen for this test was pre-strained $0.5 \%$, unloaded, immediately reloaded, and pre-strained an additional $0.5 \%$ at room temperature. Upon unloading, the sample was aged une hour at $760^{\wedge} \mathrm{C}$, slow-coooled, and reloaded. The resulting yield drop was the largest obtained in the course of this report-7400 psi. The load-extension curves for this sequence are shown in Figure 23. Earlier results, presented in Table 11, show that when the extruded-flat material of the same orientation is first solutionized and then given the $760^{\circ} \mathrm{C}$, one-hour aging treatment, the yield drop magnitude is only about $1000 \mathrm{psi}$ and the upper yield stress is about $51 \mathrm{ksi}$. In this case the upper yield stress reaches $60 \mathrm{ksi}$. The large difference must result from the structure present in the as-received extruded material that is altered during solutionizing.

These results indicate that the same explanation for the occurrence of yield drops in Brush material. can be used in KBI material; that is, in the presence of pre-strain, precipitation-pinning can occur. Apparently some difference in hot-pressing or cool-down practice between the two vendors causes a difference in pre-strain in the as-received condition; more being found in KBI material. 


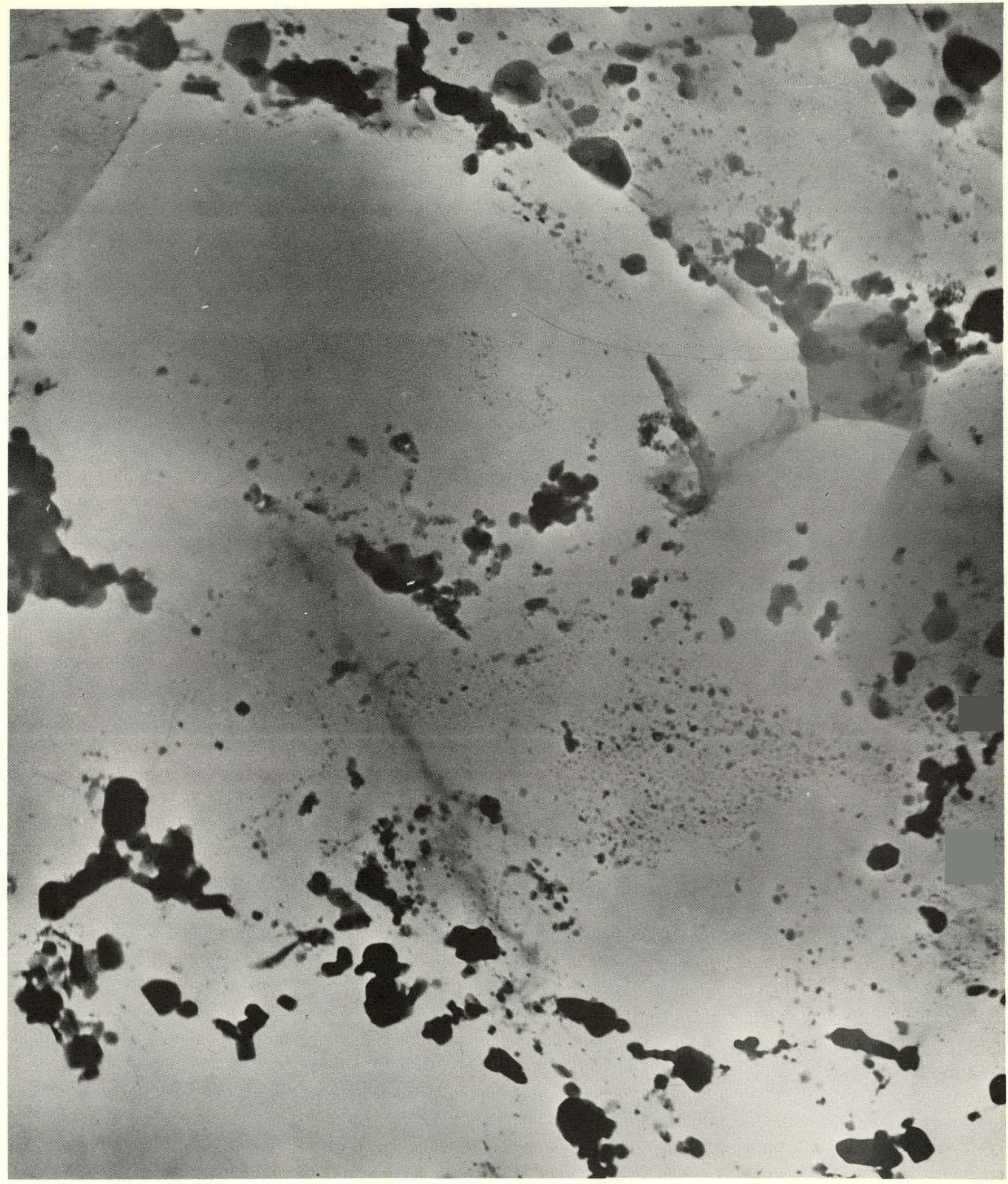

Figure 22a. Typical Microstructure of the KStd (As-Received) Material Showing the Size and Distribution of Second-Phase Particles in the Microstructure. $11,000 \mathrm{X}$. 


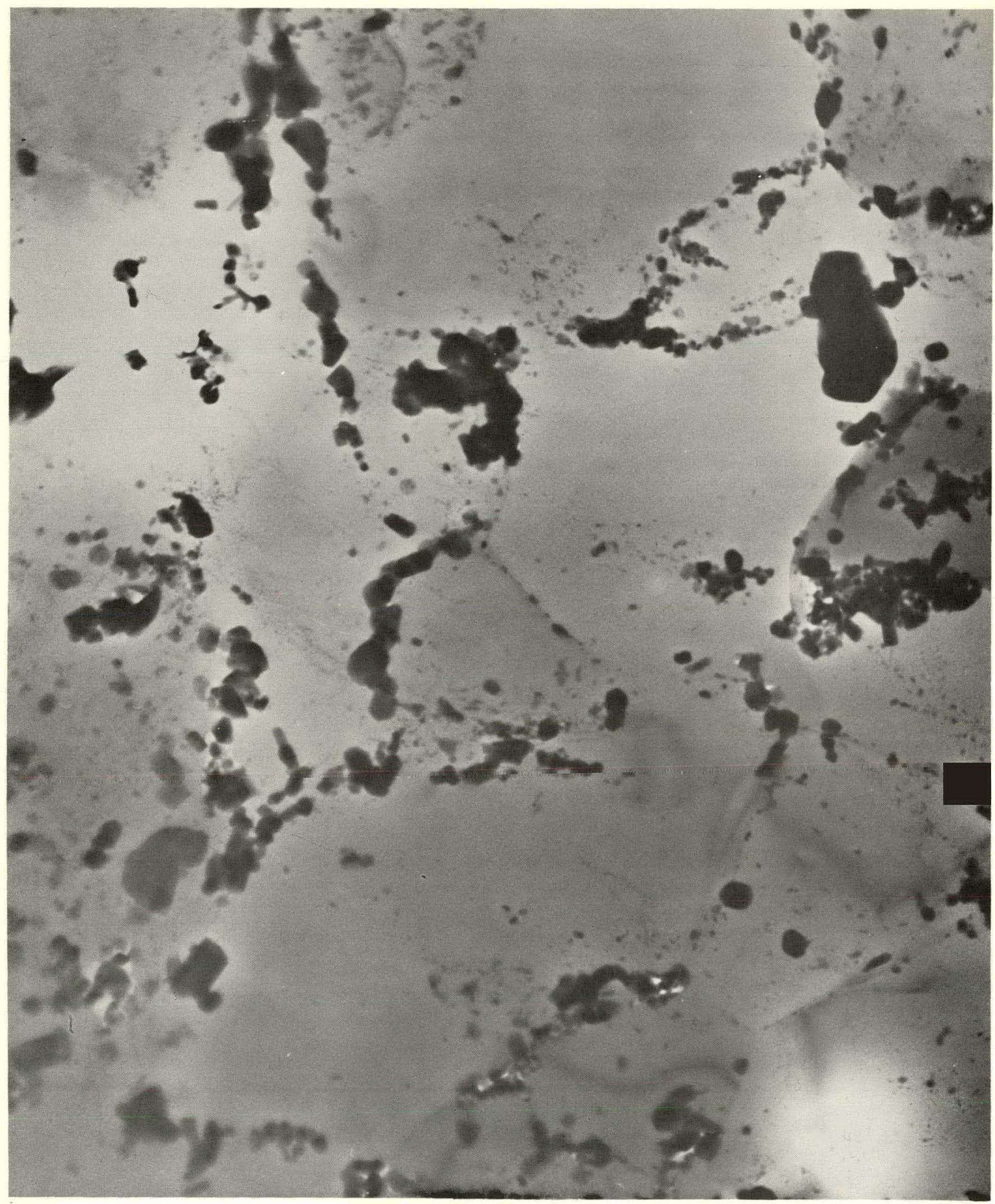

Figure 22b. Typical Microstructure of the KMT Material. Note the wide variation in size of the dark particles, most of which are BeO. $11,000 X$. 
RFP-2061

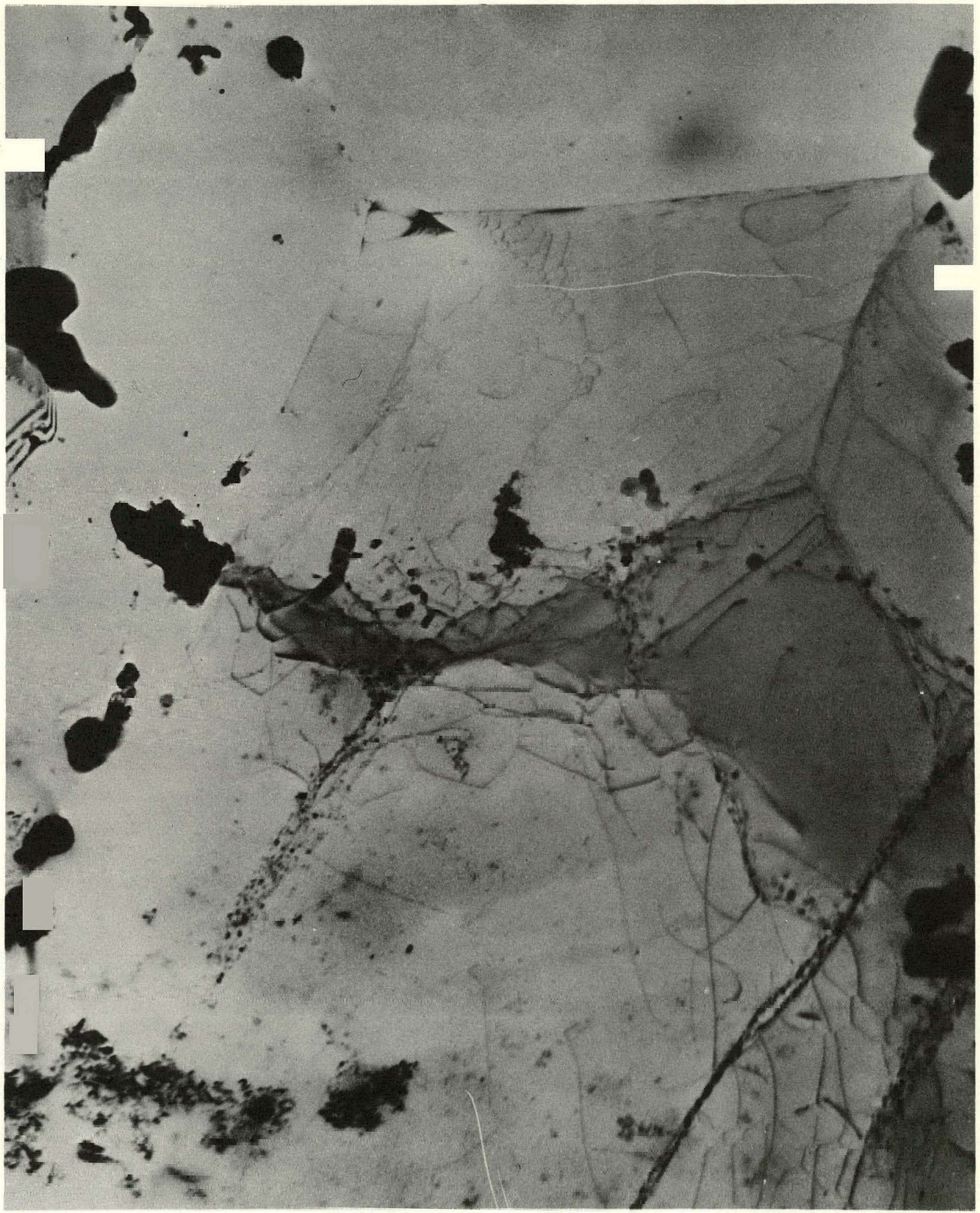

Figure 22c. Typical Dislocation Structure of the KStd Material. 25,000 X. 


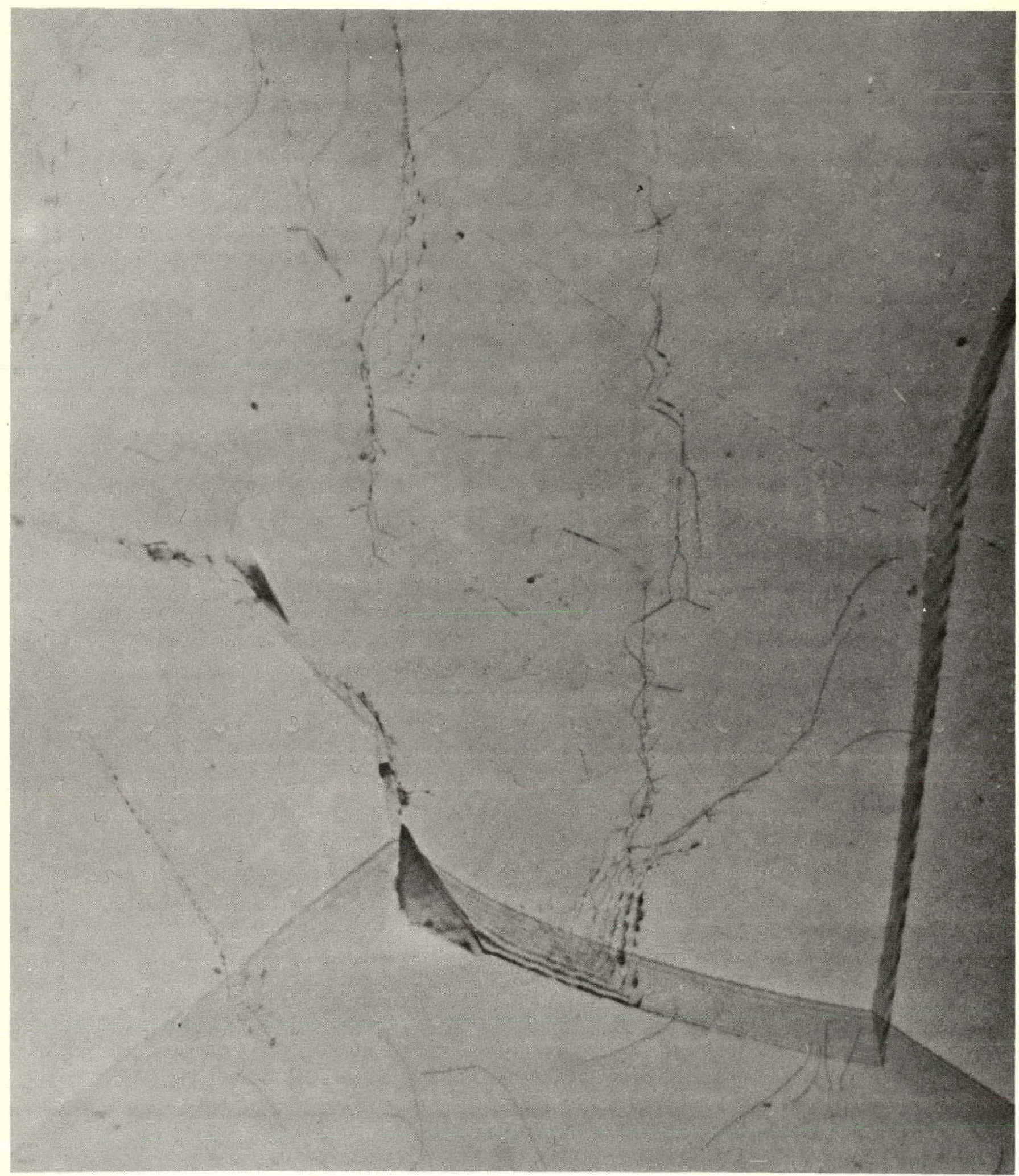

Figure 22d. Dislocation Structure of the KMT Material. Note the $90^{\circ}$ angle between the subgrain boundary running along the right edge and the larger grain boundary running left to right near the bottom of the photomicrograph. Some evidence of dislocations bowing out, as if pinned, also exists in the upper half of the photomicrograph. $25,000 x$. 


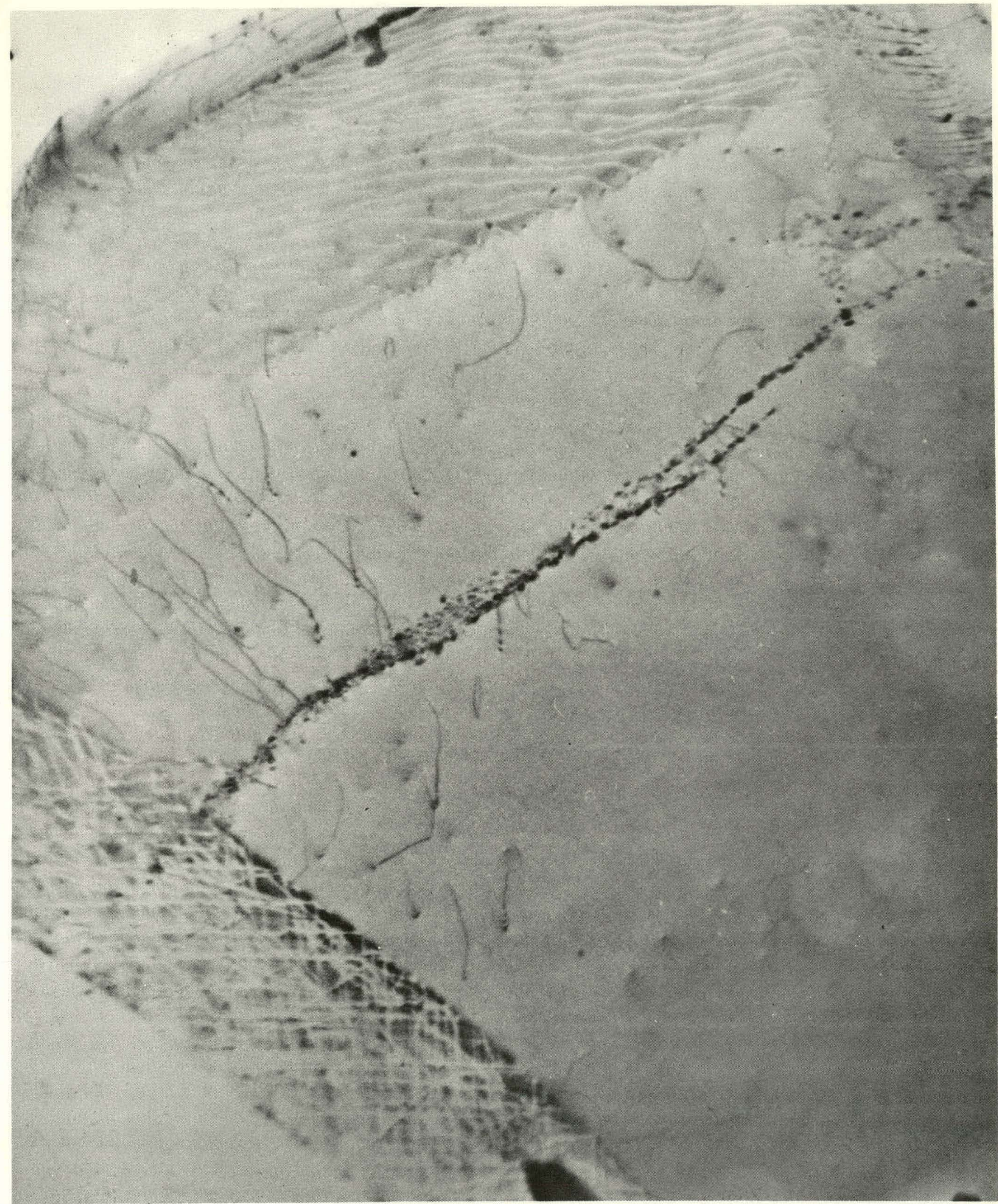

Figure 22e. Dislocation Tangles in the Grain Boundary in the Lower Left Corner of the Photomicrograph of KMT Material. These dislocations may have migrated during the $760^{\circ} \mathrm{C}$ anneal to the grain boundary. $25,000 \mathrm{X}$. 


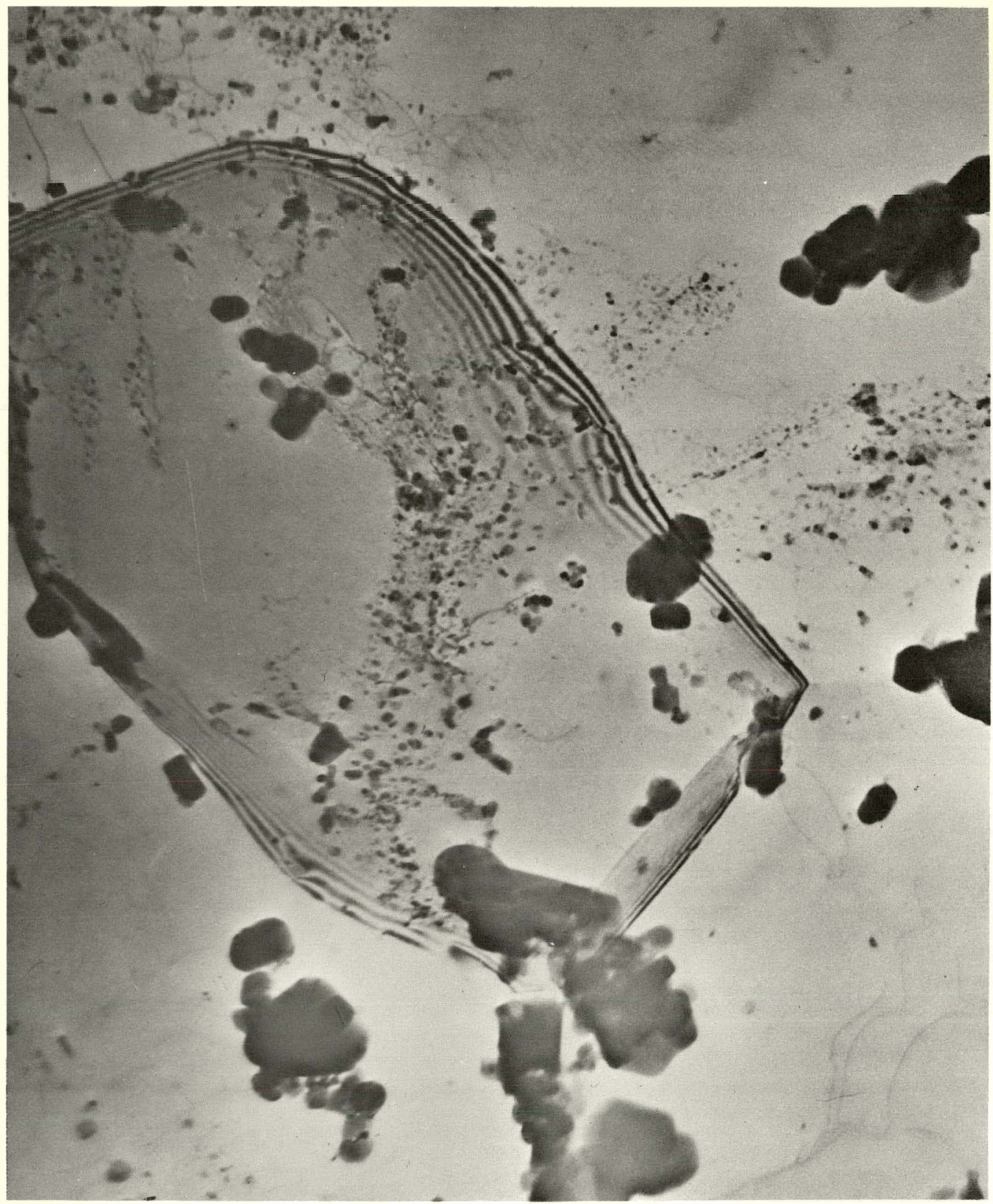

Figure 22f. Small Dislocation-Free Grain in the KMT Material. The low dislocation density in this grain, if extended over a large number of such grains, fulfills a necessary condition for the existence of a yield drop. 25,000 X. 


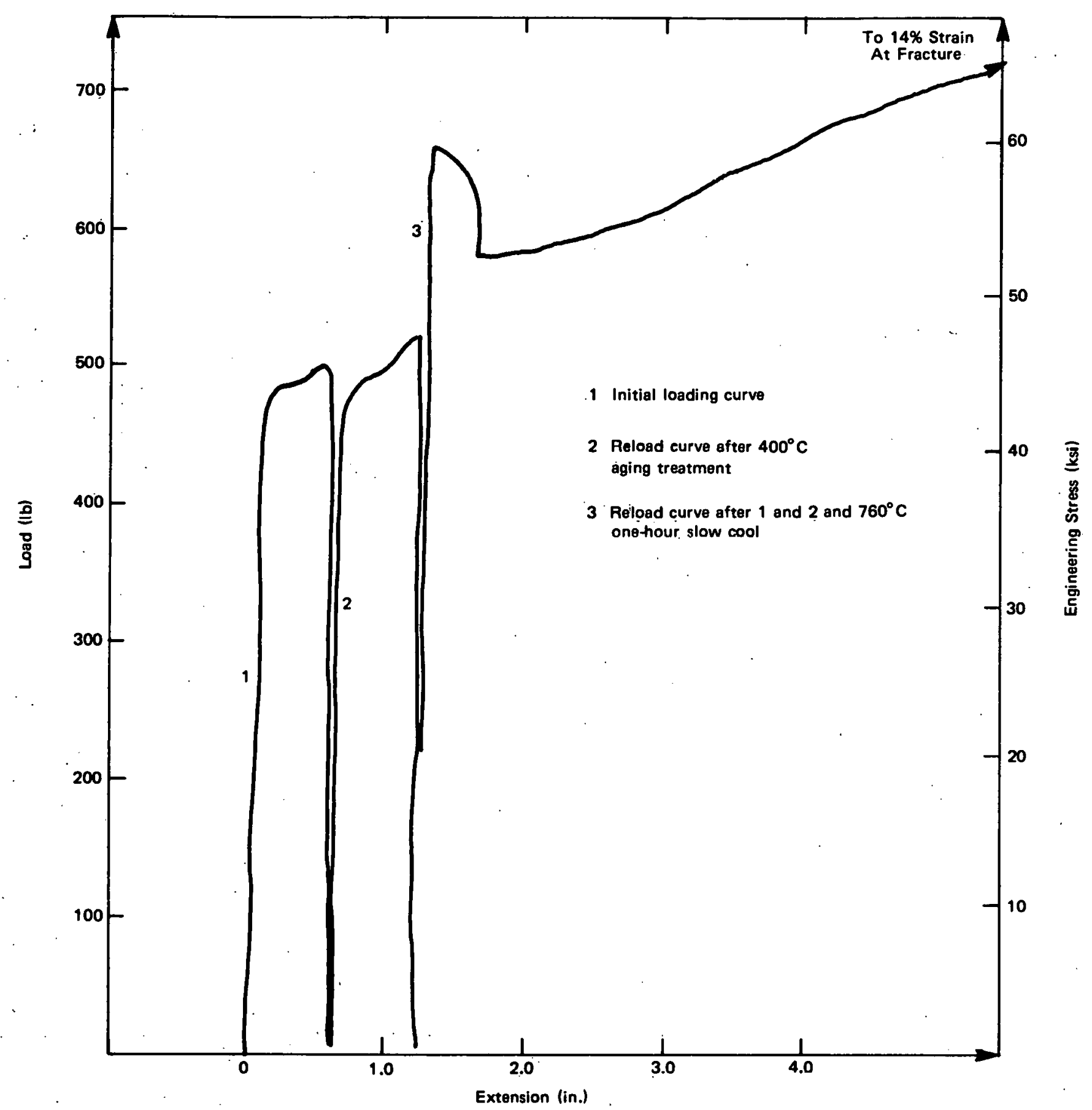

Figure 23. Load-Extension Curves for EF-45 Material in the As-Received Condition Showing Response to Two Aging Treatments.

Aging promotes a fine cell-size substructure in the $\mathrm{KBI}$ material, which is a necessary condition for a yield drop, and strain-nhanced precipitationpinning. Aging does not cause further pinning in the Brush material and may cause some breakup of substructure into a larger cell-size since the yield drop is less prominent after aging than as-received. Solutionizing prior to aging removes the pre-strain in the KBI material and may cause a redistribution of impurity elements making subsequent strain 
aging more difficult. It may be that the solutionizing treatment exposes the KBI material to a higher temperature than it received in hot pressing and hence irreversibly eliminates the yield drop by grain growth and solute distribution. At any rate, neither the pre-strain associated with rapid cooling from the solutionizing condition, nor even the tensile pre-strain at room temperature are able to induce precipitation on subsequent aging.

To establish which precipitate, the binary $\mathrm{FeBe}_{11}$ or the ternary $\mathrm{AlFeBe}_{4}$, is responsible for the pinning, a series of $x$-ray diffraction analyses has been run. The back ends of broken tensile bars were scanned and the relative magnitude of the major peaks for each precipitate is compared. Details are given in Appendix C. There is a strong correlation between the appearance of the ternary phase and a yield-drop occurrence. This result is surprising because the high-iron alloy is presumed to have a much higher amount of binary than ternary precipitate. If the ternary phase is responsible for pinning, this would help explain the infrequency of yield drops in KBI material, which normally has only half as much aluminum available to form the ternary as does Brush material.

\section{SUMMARY}

The objective of this work is to establish the mechanism for the yield drop commonly obtained in commercial beryllium products. The results show that the mechanism is one of straininduced precipitate-pinning. This conclusion is supported by the results of several independent experiments. A series of solutionizing and aging heat treatments is given to a typical lot of powdersource beryllium that shows a yield drop in the as-hot-pressed condition. Tests are run to establish statistical confidence limits for comparing changes in $0.2 \%$-offset yield stress caused by subsequent heat treatments. These tests also show that the yield drop is eliminated by the solution anneal and is returned by the aging treatment. This indicates that solute-pinning is not the mechanism for the yield drop because the amount of solute is greatest in the solutionized condition, and yield drops never occur in this condition. Furthermore, precipitatepinning is indicated because yield drops appear on heat treating at temperatures known to cause precipitation.

The same heat treatments are then given to alloys containing low and high levels of iron compared to the medium-iron material described. In the solutionized condition, the $0.2 \%$-offset yield stress of these iron alloys is seen to vary linearly with iron content. The slope is $2.3 \mathrm{psi}$ per ppm. Aging retains about $640 \mathrm{ppm}$ of iron in solid solution in all three alloys, but provides varying amounts of precipitate. The medium-iron alloy develops a yield drop and shows a rise in yield stress compared to the solutionized condition. The low-iron material shows no significant change upon similar aging. Since the main difference between these two is the presence of a precipitate in the one having the yield drop, precipitate-pinning is again the indicated mechanism.

Iron, when in solid solution, hardens because it has a large atomic size relative to beryllium. Removal of iron from solid solution has a softening effect. But the precipitate that forms will cause an increase In yield stress. This increase may result from pinning of dislocations by the precipitate, or the increase caused by the precipitate providing an obstacle to dislocation motion. In the case of the high iron alloy initially in the solutionized condition, the net effect of aging is to decrease the yield stress. This is because the 12 -ksi softening effect caused by depletion of iron from solid solution predominates over a 6-ksi precipitation-hardening effect. A yield drop does not accompany this aging treatment as it does with the typical material. Since more precipitate should result from aging the high iron material, some factor other than iron content must be required to promote a yield drop.

Strain-aging experiments reveal one such factorthe presence of pre-strain. When samples of the medium-iron alloy originally in the aged condition are pre-strained varying amounts, subsequent aging at $400^{\circ} \mathrm{C}$ causes the yield stress to return to its original value. But when the material is initially in the solutionized condition, the yield after strain aging is greater than its original value by an amount that increases with increasing strain. This is the first indication of strain-enhanced precipitation. When the strain-aging tests are extended to include 
the high-iron and low-iron material, the straininduced precipitation effect is seen to be linear with iron content and has a slope of 2.1 psi per ppm. Since this effect is similar to that obtained from solid-solution hardening with iron, this is evidence that the iron is active in the precipitationhardening effect.

Further confirmation of strain-induced precipitation is found by comparing results of direct aging at $400^{\circ} \mathrm{C}$ subsequent to solutionizing to those obtained by solutionizing, pre-straining, and aging. Direct aging causes slight decreases in yield compared to the solutionized condition, and these decreases are not consistent with iron content. But the yield stress as a result of aging following pre-strain is dependent on initial iron content. The change in yield stress, when compared to the maximum flow stress present during pre-straining, increases linearly with increasing iron content at a rate of $1.9 \mathrm{psi}$ per ppm.

The most compelling argument for strain-induced precipitate-pinning comes from results of three $400^{\circ} \mathrm{C}$ strain-aging tests of the high-iron alloy originally in the solutionized condition. These tests were run to confirm the apparent mechanism. Each of the three developed a yield drop in addition to confirming the magnitude of the strainaging effect. It might be argued that similar. hardening could arise from a mechanism of soluteiron atoms condensing around dislocation cores, pinning the dislocations. But if this were true, the dislocations present on solution-quenching should be similarly pinned and yield drops would be present on direct aging at $400^{\circ} \mathrm{C}$. None are observed. Also, yield drops are never observed in the solutionized condition where the solute available for pinning is at a maximum, and no tendency exists for increasing iron content to promote yield drops on solution-quenching, which would be expected for a solute-condensation mechanism. Precipitate-pinning is, on the other hand, an energetically favored mechanism, whcre the highly stressed regions of dislocation interactions caused by pre-straining can act as nucleation sites for precipitates that pin the dislocations.

Now that the yield drop can be explained, it is important to see how texture, grain-size, and supplier variables can alter yield-drop behavior.
The first of these is studied with extruded flat stock, of commercial purity, which can be oriented to get either prism or basal flow. Results show that the hardening accompanying the occurrence of a yield drop is 9 to $12 \mathrm{ksi}$, depending upon aging treatment and orientation. Hardening of commercial hot-pressed material, which also has a yield drop, is only 3 to $4 \mathrm{ksi}$. Thus, texture enhances the hardening effect indicating that pinning is more complete in textured material than in random material. Yield drops occur with equal facility for both prism and basal orientations. Yield drops return upon $760^{\circ} \mathrm{C}$ strain aging of textured material, whereas conventional hot-pressed material does not exhibit such a return of a yield drop. The uniform nature of deformation of the textured material may be the cause of this.

Grain-size experiments conducted on materials given grain-growth anneals result in a completc elimination of yield drops, even when aging treatments known to invoke yield drops in the same material prior to grain growth are used. An average grain size of less than 10 microns appears to be a necessary condition for the occurrence of a yield drop. Material that has a larger average grain size may show a yield drop if it has a duplex microstructure where a significant portion of the microstructure contains grains that are finer than 10 microns. If enough of these fine grains, with proper orientation, line up across the gage length, a yield drop can probably still occur.

Efforts to attain a grain size of less than 15 microns in ingot sheet were unsuccessful. But a yield plateau is developed in such material when a subgrain size of less than 10 microns is developed by a recovery-type anneal.

All the results described thus far in the summary are from material made by Brush-Wellman Co. To see if these results apply to Kawecki-Berylco Industries (KBI) material, the same solutionizing and aging treatments are given to samples from a hot-pressed block. No yield drops are observed upon aging or strain aging, although the amount of hardening on $400^{\circ} \mathrm{C}$ strain aging is consistent with results obtained with the Brush material. Direct aging at $760^{\circ} \mathrm{C}$ without prior solutionizing does develop a very strong yield drop $(\sim 4.7 \mathrm{ksi})$. 
Transmission electron microscopy suggests that a substructure with a finer cell-size than the asreceived 12-micron grain size is present in directly aged KBI material. This is a recovery effect and the prior strain that must have been present may have caused precipitation. Also the fine cell size favors yield drops. Solutionizing eliminates the cell structure and the pre-strain, thereby eliminating the yield drop.

This direct-aging treatment was then given to extruded material known to have retained prestrain from hot working, to see if the apparent strain-induced precipitation works for material from both suppliers. The strongest yield drop in this research, " $1400 \mathrm{psi}$, results.

These results show that the effect of texture is to increase the likelihood of observing a yield drop and to increase the magnitude of such yield drops. The effect of grain size is to provide a necessary condition for a yield drop to occur; namely, that the average grain size be less than 10 microns or that a substructure with a similarly fine cell-size exist. The finer grain size may also increase the magnitude of the yield drop. Finally, one reason for differences in the frequency of appearance of yield drops in materials made by the two major suppliers is because of residual strain differences. Assuming that texture, grain-size, and chemistry requirements for the occurrence of a yield drop are present, the material that has a yield drop as hotpressed, has one because of precipitate-pinning during slow cooling from the hot-pressing temperature. The other material does not have a yielddrop as hot-pressed because glissile dislocations are present. These dislocations may be present because they are not pinned during cool-down from hotpressing or because they are introduced during this cycle. At any rate, they can be pinned by direct aging without prior solutionizing, thereby producing a yield drop. The important implication of this is that the yield behavior of both materials can be altered, perhaps unintentionally, by the user. A yield drop, and corresponding higher yield stress, can be induced where one did not exist, by heating the material and slow cooling it. And a yield drop may be eliminated, and the yield lowered, by introducing glissile dislocations through rapid-cooling, machining loads, and pressurization.
Finally, x-ray diffraction results show a strong correlation of ternary phase, $\mathrm{AlFeBe}_{4}$, with the occurrence of a yield drop. This may be another reason why $\mathrm{KBI}$ material, with its characteristically low aluminum content, infrequently exhibits yield drop.

\section{Yield-Point Mechanism in Beryllium}

Results of this work suggest that strain-induced precipitation-pinning causes the yield-point behavior of beryllium. The pinning-precipitate appears to be the ternary phase, $\mathrm{AlFeBe}_{4}$, based upon results of $x$-ray diffraction analyses of tensile bars. The strain can be introduced by rapid couling from an elevated temperature, tensile loading at room temperature. or plastic straining at an elevated temperature.

Pinning and yield drops can occur in orientations favoring either basal or prism flow, and the presence of preferred crystallographic orientation increases the likelihood of a yield drop occurring. This may be due in part to the fine grain size that results from the metal working operation that induces the texture. Fine grain size is a necessary condition for the appearance of a yield drop, and increasing the average grain size above 10 microns by a graingrowth anneal irreversibly eliminates the yield drop.

The yield-point mechanism is not of the type described by Cottrell involving solute condensation at the dislocation core. Instead, the model proposed by Hahn for body-centered cubic metals, that is an extension of the model devised by Gilman and Johnson ${ }^{74}$ to explain the presence of yield drops in LiF crystals, most nearly fits these results. This model requires permanent locking of the dislocations, such as would be the case for precipitatepinning, followed by the generation of new dislocations at a higher stress level than that needed to sustain their flow. The higher level corresponds to the upper yield stress. The stress level at which these new glissile dislocations flow is the lower yield stress.

\section{CONCLUSIONS}

1. The cause of the yield-point phenomenon in commercial beryllium products is strain-induced 
precipitation-pinning. The precipitates, which are probably the ternary phase, $\mathrm{AlFeBe}_{4}$, pin dislocations permanently, reducing the number of glissile dislocations sufficiently to require new dislocations to be activated at a higher stress level than that required to sustain their motion. The model described by Hahn for bcc metals seems to apply to the yield-point behavior of beryllium.

2. Grain size is an important variable affecting yield strength. If it exceeds an average size of 10 microns, yield drops cannot be obtained. Slightly larger average grain sizes may still accompany a yield-drop occurrence, but in such a case a substructure exists having a size of less than 10 microns.

3. Crystallographic texture enhances the yielddrop behavior of beryllium, possibly because it occurs simultaneously with fine grain size. The increase in yield accompanying the yield drop is 9 to $12 \mathrm{ksi}$ for textured material compared to 3 to $4 \mathrm{ksi}$ for conventional hotpressed blocks.

4. Yield drops occur in orientations favoring either prism or basal flow, and no significant difference in magnitude of yield drops or response to aging and strain aging seems to exist.

5. Yield drops are not present upon solutionannealing, but can be returned by a suitable aging-heat treatment.

6. Prior strain eliminates yield drops. Subsequent aging can return the yield drops, regardless of initial heat-treat condition, providing that the texture and the grain size conditions are. suitable.

7. Differences in the frequency of yield-drop occurrences between vendors materials can be explained on the basis of prior strain and prior grain size. Yield drops are absent in the as-hot-pressed condition if numerous mobile dislocations are present because of rapid cooling or pre-straining at room temperature, or a slightly elevated temperature. The yield drop can be brought out in such cases by direct aging. If solutionizing precedes aging, yield drops will not appear because the strain is removed and the substructure is eliminated. If a yield drop is present in the as-hot-pressed condition, it can be removed by solutionizing at a high enough temperature to effect grain growth, or by introducing mobile dislocations by quenching or mechanically pre-straining.

8. The effect of grain size on yield stress, measured by the slope of the Hall-Petch plot of yield stress versus inverse square root of grain size is $136 \mathrm{ksi}-\mathrm{m}^{1 / 2}$.

9. The solid-solution hardening effect of iron on yield stress is linear for iron contents in the range 640 to $5800 \mathrm{ppm}$; its magnitude being 2.3 psi per ppm.

10. The solid solution effect of iron on strain aging at $400^{\circ} \mathrm{C}$ is linear with a magnitude of 2.1 psi per ppm. The effect ranges from a decrease in yield of $5.4 \mathrm{ksi}$ for material with $640 \mathrm{ppm}$ in solid solution, to an increase in yield of $5.4 \mathrm{ksi}$ for material with $5800-\mathrm{ppm}$ iron initially in solid solution.

11. A strong correlation exists between the appearance of the ternary phase as measured by $x$-ray diffraction and the occurrence of a yield drop.

\section{RECOMMENDATIONS FOR FUTURE WORK}

The results of this work indicate that the ternary phase, $\mathrm{AlFeBe}_{4}$, is associated with the occurrence of a yield drop. More information is needed to definitely establish that it causes the yield drop. Additional transmission electron microscopy work should be done to determine the size and distribution of precipitates and obtain more concrete evidence of pinning. Additional x-ray diffraction work could be used to confirm the present results and to determine the conditions needed to dissolve all binary and ternary phase.

Another way to help resolve which precipitate is responsible is to study the strain-aging behavior of 
a series of beryllium alloys with fixed iron content but variable aluminum content. In this way the amount of $\mathrm{AlFeBe}_{4}$ that could be formed is limited. A second way is to use $x$-ray diffraction to identify the phases present subsequent to the various heat treatments and to correlate these results with the yield-drop behavior. Electrical resistivity measurements could also be made to monitor precipitate reactions, but this would not help isolate the precipitate causing pinning.

Another aspect of future work that would be useful would be to extend the aging and strain-aging conditions to include longer times than used in this study, and use temperatures between 400 and $650^{\circ} \mathrm{C}$. This would allow a study of the kinetics of the precipitation process, including determination of activation energies. Similarly, the use of different solutionizing conditions should be explored. This should help differentiate between effects caused by impurity distribution and effects resulting from grain size.

A quantitative determination of texture would be a useful supplement to this work. The extrudedflat material is known to be highly textured, but basal and prism pole figures should be obtained fur both the solutionized and aged condition and the grain growth and aged condition. This would confirm or disprove the tacit assumption that texture does not change significantly during recrystallization and grain growth of beryllium.

\section{REFERENCES}

1. "The Metallurgy of Beryllium," Proceedings of an International Confeience hold in London, Oct. 16-18, 1961; Institute of Metals Monograph No. 28, Chapman and Hall, London, 1963.

2. "Beryllium Technology," Proceedinge of the Second International Conference, Philadolphla, Oct. 15-17, 1964; Volumes I and II, Gordon and Breach, Now York, 1966.

3. Conference Internationale sur la Metallurgie du Beryllium, Grenoble, May 17.20, 1965; Presses Universitoires de France, Paris, 1965.
4. A. N. Ashurst, H. D. Hanes, and R. J. Runck, "Summary of Beryllium Research and Development Programs (revised)," Defense Metals Information Center, DMIC-S-32, Columbus, Ohio, Fcb. 1971, p 38.

5. D. W. Lillie, "The Metal Beryllium," Chapter VI A, American Society of Metals, Metals Park, Ohio, 1955.

6. H. T. Lee and R. M. Brick, "Deformation of Beryllium Single Crystals at $25^{\circ}$ to $500^{\circ} \mathrm{C}$," Transactions of the American Society of Metals, Vol.48, 1956, pp 1003-1037.

7. H. D. Hanes, S. W. Porembka, J. B. Melehan, and P. J. Gripshover, "The Physical Metallurgy of Beryllium," Defense Metals Information Center, DMIC Report No. 230, Columbus, Ohio, June 24, 1966, p 30.

8. R. I. Garber, I. A. Gendin, V. S. Kogan, and B. G. Lararev, "Investigation of the Plastic Properties of Beryllium Single Crystals I," Fis. Metallov. $i$ Metallovendenie, Vol. 8, 1959, p 130.

9. D. F. Kaufman and L. R. Aronin, "The Effects of Purification and Realloying on the Mechanical Properties of Zone Refined Beryllium," Paper presented at the Second International Conference, Philadelphis (cf. Ref. 2).

10. B. $\bar{L}$. Averbach, "Nature of Interatomic Bonding in Beryllium," Technical Report of the Air Force Materials Laboratory, AFML-TR-70-15, January 1970, p 59.

11. S. Weissmann, "Study of the Deformation Mechanism of Beryllium Single Crystals," Technical Report of the Air Force Materials Laboratory, AFML-TR-70-166, July 1970.

12. R. E. Reed.Hill, "Physical Motallurgy Principles," Van Nostrand Reinhold Co., Now York, 1964, p 54.

13. M. Herman, "Metallurgy in Aerospace TechnologyBeryllium," The Franklin Inititute, Philadelphia, Pa., undated.

14. G. I. Taylor, Journal of Institute of Metals, Vol. 62, No. 307, 1936.

15. P. Pointu, L. Espagno, P. Axou, and P. Bastien, "Preclpitation in Low.Purity Beryllium," Compres rendus des scanes de l'Academie des Sciences, Vol. 250, 1967, pp 2365-2367. 
16. S. H. Gelles, J. J. Pickett, and A. Wolff, "Recent Advances in Beryllium Metallurgy," Jour. of Metals, Vol 12, Oct. 1960, pp 789-792.

17. H. P. Rooksby, "Intermetallic Phases in Commercial Beryllium," Jour. of Nuclear Materials, Vol. 7, No. 2, 1962, pp 205-211.

18. J. A. Carrabine, "Ternary AlMBe ${ }_{4}$ Phases in Commercially Pure Beryllium," Jour. of Nuclear Materials, Vol. 8, No. 2, 1963, pp 278-280.

19. F. J. Fraikor and V. K. Grotzky, Transactions AIME, Vol. 239, No. 12, 1967, p 2008.

20. A. Moore, F. Morrow, V. D. Scott, and D. A. Cheer, 'Precipitation-Aging and Improved Mechanical Properties in Commercially Pure Beryllium and Beryllium Alloys," paper presented at the International Conf. in London (cf. ref. 1, p 112).

21. S. H. Gelles, R. E. Ogilvie, and A. R. Kaufman, "The Solid Solubilities of Iron and Nickel in Beryllium," Transactions of the Metallurgical Society of ALME, Vol. 215, Aug. 1959, pp 695-702.

22. G. Donze, R. Le Hazif, F. Maurice, D. Dutilloy, and Y. Adda, "Diffusion and Solubility of Iron in Beryllium," Translated from Comp. Rend., Vol. 254, Aug. 1959, pp 2328-2330.

23. G. Donze, D. Dutilloy, R. Leltazif; and Y. Adda, "Morphology of an Aluminum Base Liquid Phase in the Grain Boundaries of Beryllium," Translated from Jour. of Nuclear Materials, Vol. 6, No. 1, 1962, pp 137-138.

24. P. Bastien and P. Pointu, "Microscopic Examination of Beryllium While Being Deformed in the Hot-Short Region," Jour. of Nuclear Materials, Vol. 10, No. 1, 1963 , pp 63-66.

25. M. Weisz, J. Mallen, and J. L. Varon, "Possibility of the Appearance of a Liquid Phase at $430^{\circ} \mathrm{C}$ in Commercial Beryllium," Jour. of Nuclear Materials, Vol. 10, No. 1, 1963, pp 56-59.

26. G. E. Darwin and J. H. Buddery, "Beryllium, Metallurgy of the Rarer Metals-7," Butterworth Scientific Publications, 1960, p 1.

27. D. R. Mash, "Aging Effects in Commercially Pure Beryllium," Transactions AIME, Jour. of Metals, Nov. 1955, pp 1235-1240.
28. J. A. Carrabine, D. H. Woodward, J. A. Stonehouse, and W.W. Beaver, "Effect of $\mathrm{AlFeBe}_{4}$ on the Mechanical Properties of Fabricated Polycrystalline Beryllium," Paper presented at the Philadelphia Conference (cf. ref. 2, p 239).

29. R. G. O'Rourke and W. W. Beaver, "A Study to Characterize a Fully Forgeable Grade of FineGrained High Strength Beryllium Powder," Air Force Materials Laboratory Technical Report AFML-TR-69. 61, Nov. 1969.

30. G. C. E. Olds, T. Raine, J. A. Robinson, and A. G. Todd, "High Temperature Ductility of Powder Fabricated Beryllium," (cf. Ref. 1, pp 166-176).

31. R. W. Fenn, Jr., D. D. Crooks, and W. C. Kinder, "Test Method for Evaluating Mechanical Properties of Anisotropic Material (Beryllium)," Report AFMLTR68-373, Lockheed Missiles and Space Co., Palo Alto, California, Feb. 1969. (Also AD 850909.)

32. A. F. Hayes, "Production of Forged Conical Beryllium Structural Shapes," AFML-TR-69-161, Lockheed Missiles and Space Co., Palo Alto, California, June 1969.

33. D. R. Floyd, ."Isotropic High Strength Beryllium," USAEC RFP-1831, Rocky Flats Division, Dow Chemical U.S.A., June 1972.

34. W. W. Beaver and K. G. Wikle, "Mechanical Properties of Beryllium Fabricated by Powder Metallurgy," Transactions of the American Institute for Mining and Metallurgical Engineers (ALME), Vol. 200, May 1954, pp 559-573.

35. C. I. Bort and A. Moore, "Grain Refinement of Ingot Sheet Beryllium by Warm Working and Annealing," in the (cf. Ref. 1 The Metallurgy of Beryllium, Chapman and Hall, 1963, pp 238-245).

36. J. E. J. Bunce and R: E. Evans, "A Study of the Effect of Grain Size, Texture, and Annealing Treatment on the Properties of Wrought Beryllium Ingot," in The Metallurgy of Beryllium, Chapman and Hall, 1963, (cf. Ref. 1, pp 246-263).

37. J. L. Frankeny and D. R. Floyd, "Ingot-Sheet Beryllium Fabrication," USAEC RFP-910, Rocky Flats Division, The Dow Chemical Company, 1969.

38. J. Greenspan, "Ductility in Beryllium Related to Grain Orientation and Grain Size," Transactions AIME, Vol. 215, Feb. 1959, pp 153-163. 
39. B. Allen and A. Moore, "The Ductile-Brittle Transition in Beryllium," paper presented at the London Conf. (cf. Ref. 1), pp 193-206.

40. I. I. Papirov and G. F. Tikhinskiy, "Mechanical Properties of Fine-Grain Deformed Beryllium," Fiz. Metal. Metalloved., Vol. 29, No. 5, 1970, pp 1057. 1060.

41: R. W. Armstrong, "The Influence of Polycrystal Grain Size on Several Mechanical Properties of Materials," Metallurgical Transactions, Vol. 1, May 1970, pp 1169-1176.

42. R. F. Bunshah and R. W. Armstrong, "The Dependence of Hardness of Beryllium on Grain Size," Materials Research Bulletin, Vol. 4, 1969, pp 239-250.

43. V. C. Kannon and S. Weissman, "Deformation Substructure in Beryllium after Prism Slip," Jour. of Applied Physics, Vol. 42, No. 7, June 1971, pp 26322638.

44. F. W. Cooke, V. V. Damiano, and.G. L. London, "Structure-Property Relations in Beryllium Sheet," Jour. of Materials, Vol. 6, No. 2, June 1971, pp 403421.

45. C. O. Matthews, M. I. Jacobson, W. E. Jahsman, and W. V. Ward, "Beryllium Crack Propagation and Effects of Surface Condition," WADD Technical Report No. 60-116, Wright Air.Development Division, July 1960, p 181.

46. S. Beitscher, "Tensile Properties of Rocky Flats Division Ingot Sheet Beryllium from Room Temperature to $250^{\circ} \mathrm{C}$," USAEC RFP-1205, Rocky Flats Division, The Dow Chemical Company, Dec. 11, 1968, p 11.

47. A. S. Martin and G. C. Ellis, "The Ductility Problem In Beryllium," Paper presented at the London Conf. (cf.Ref. 1, pp 1-31).

48. U. S. Lindholm and L. M. Yeakley, "Effect of Strain-Rate Temperature and Multiaxial Stress on the Strength and Ductility of S-200E Beryllium and 6Al-4V Titanium," Air Force Materials Labnratory Report AFML-TR-71-37, March 1971, p 68.

49. H. Conrad and F. W. Cooke, "The Effects of Temperature and Strain Rate on the Strength of Beryllium Sheet," Metallurgical Transactions, Vol. 2, May 1971,pp 1307-1313.
50. R. W. Armstrong and N. R. Borch, "Thermal Microstresses in Beryllium and Other HCP Materials," Met. Trans., Vol. 2, Nov. 1971, pp 307.3-3n77

51. R. E. Reed-Hill, loc cit, pp 231-234.

52. E. O. Hall, "Yield Point Phenomena in Metals and Alloys," Macmillan and Co., 1970, p 296.

53. G. T. Hahn, "A Model for Yielding with Special Reference to the Yield-Point Phenomena of Iron and Related BCC Metals," Acta. Met., 10, 1962, p 727.

54. W. G. Johnston and J. J. Gilman, Journal of Applied Physics, Vol. 30, No. 129, 1959.

55. H. Conrad and I. Perlmutter, "Beryllium as a Technological Material," Paper presented at the Grenoble Conf. (cf. Ref. 3, pp 319-372).

56. N. A. Hill, "The Effect of Various Treatments on the Tensile Properties of a Beryllium Sheet," (cf. Ref. 1, pp 84-97).

57. J. C. Guest and M. J. Hudson, "Tensile Properties of Hot-Extruded Beryllium Rod and Tube," (cf. Ref. 2,pp 182.192):

58. M. B. Hornak, E. M. Grala, R. G. O'Rourke, G. L. Mareh, and L. S. Busch, "Final Report un Rolling Improved Beryllium Sheet," ML-TDR-64-193, April 1964, p 215.

59. R. A, Foos. A. J. Stonehnuse, and K. A. Walsh, "Microalloying Relatiunships in Beryllium," Proceedings of the Beryllium Conf., March 23-25, 1970; National Materials Advisory Board, 272, July 1970, pp 127-147.

60. A. J. Stonehouse, private communication, Oct 26, 1971.

61. A. K. Wolff, S. H. Gelles, and L. R. Aronin, "Impurity Effects in Commercially Pure Beryllium Prepared from Powder," The Metallurgy of Beryllium, Chapman and Hall, (cf. Ref. 1) 1963, pp 150-166.

62. W. D. Bennett, "Brittle-Ductile and Yield Behavior of Extruded Beryllium," paper presented at the London Conf. (cf. Ref. 1, pp 33-46).

63. S. H. Gelles, P. R. Landon, J. Hauber, D. V. Miley, and D. R. Floyd, private communications from Battelle Columbus Labs, Lawrence Livermore Labs, and Rocky Flats Division, Dow Chemical U.S.A., 1972. 
64. S. H. Gelles, "Impurity Effects of Beryllium," Report MCIC-72-06, Battelle Columbus Laboratories, March 1972.

65. S. H. Gelles and J. H. Peterson, "Characteristics of Commercial Vacuum Hot-Pressed Beryllium," Report No. BMI-X-629, Battelle Columbus Laboratories, Sept. 1972.

66. National Materials Advisory Board, Evaluation Test Methods for Beryllium, National Academy of Sciences, National Research Council, Publication MAB-205-M, 1966, p 49.

67. American Society for Testing and Materials, Book of Standards, Part 31, Philadelphia, Pa., 1969, pp 202. 221.

68. E. O. Hall, cf. Ref 52, p 33.

69. P. R. Landon and J. R. Hauber, private communication.

70. H. Wiedersich, "Hardening Mechanisms and the Theory of Deformation," Journal of Metals, May 1964, pp 425-430.
71. R. A. Foos, private communication, Sept. 15, 1970.

72. A. Smigelskas and C. S. Barrett, "Preferred Orientation in Rolled and Recrystallized Beryllium," Metals Transactions, Feb. 1949, pp 145-148.

73. V. K. Grotsky and F. J. Fraikor, "Preparation of Be Foils for Transmission Electron Microscopy," Metallography, Vol. 1, 1969, pp 431439.

74. J. J. Gilman and W. G. Johnston, Jour. Appl. Phys., Vol. 30, 1959, p 1584.

75. V. G. Macres, "The Interdependence of Particle Size Microstructure and Orientation on the Ductility of Beryllium Rod and Sheet," M. S. Thesis, Massachusetts Inst. of Technology, 1953, p 66.

76. S. H. Gelles, V. Nerses, and R. Siergies, Materials Research Bulletin, 15, 1963, p 842.

77. M. I. Jacobson, "Metallurgical Factors Affecting the Ductile-Brittle Transition in Beryllium," Air Force Materials Laboratory Report ASD-TDR-62-509, Vol. V, Dayton, Ohio, July 1964. (Also AD604599.) 
RFP-2061 


\section{APPENDIX A. Strain-Hardening Program and Data.}

A program, in BASIC language, is used to compute the strain hardening constants $A$ and $\mathrm{m}$ from loadextension data. As written, the program requires the following input: elastic modulus, gage length, magnification factor used to record extension, the frequency of extension values at which data are obtained (every $0.2 \%$ is recommended), sample number, initial area, load at yield, total elongation, and load values at the regular extension values selected. The program converts the loads to true stress, the extensions to true strains, and obtains a least squares fit of these data to a straight line plot of $\ln \sigma$ versus $\ln \epsilon$. The slope of this line is the strain hardening exponent, $\mathrm{m}$, and the intercept is the stress corresponding to a strain of unity. The program uses only data beyond $0.6 \%$ extension, beyond the range of yield-point effects. It then extrapolates the flow curve back to the elastic loading line and obtains a rough measure of the magnitude of these yield-point effects, $\Delta S$, by taking the difference between the yield stress and the stress at the extrapolated intercept. Values of the strain-hardening constants for some of the materials studied in this report are given in Table 1-A.

Table 1-A. Strain-Hardening Parameters for Materials Examined in This Work. The coefficient $A$ is in ksi and $m$ is the strain-hardening exponent.

Heat Treat Condition

\begin{tabular}{|c|c|c|c|c|c|c|}
\hline Material & & Solutionized at $1040^{\circ} \mathrm{C}$ & Aged at $650^{\circ} \mathrm{C}$ & Aged at $760^{\circ} \mathrm{C}$ & Grain Growth at $1150^{\circ} \mathrm{C}$ & Grain Growth Plus $760^{\circ} \mathrm{C}$ Age \\
\hline \multirow[t]{2}{*}{ BL } & $\mathbf{A}$ & 106 & 108 & 112 & - & - \\
\hline & $\mathbf{m}$ & 0.172 & 0.175 & 0.182 & - & - \\
\hline \multirow[t]{2}{*}{$\mathbf{B M}$} & $\mathbf{A}$ & 127 & 122 & 117 & 116 & - \\
\hline & $\mathbf{m}$ & 0.200 & 0.204 & 0.192 & 0.211 & - \\
\hline \multirow[t]{2}{*}{ BH } & $\mathbf{A}$ & 120 & 104 & 118 & - & - \\
\hline & $\mathbf{m}$ & 0.158 & 0.130 & 0.169 & - & - \\
\hline \multirow[t]{2}{*}{ EF -43} & $\mathbf{A}$ & 74 & 49 & - & - & 133 \\
\hline & $\mathbf{m}$ & 0.107 & 0.041 & - & - & 0.232 \\
\hline \multirow[t]{2}{*}{ EF- $\dot{L}$} & $\mathbf{A}$ & 180 & 100 & 99 & - & - \\
\hline & $\mathrm{m}$ & 0.207 & 0.075 & 0.077 & - & - \\
\hline \multirow[t]{2}{*}{$\mathbf{K}$} & $\mathbf{A}$ & 100 & 88 & 86 & - & - \\
\hline & $\mathbf{m}$ & 0.166 & 0.147 & 0.152 & - & - \\
\hline
\end{tabular}


The program is as follows:

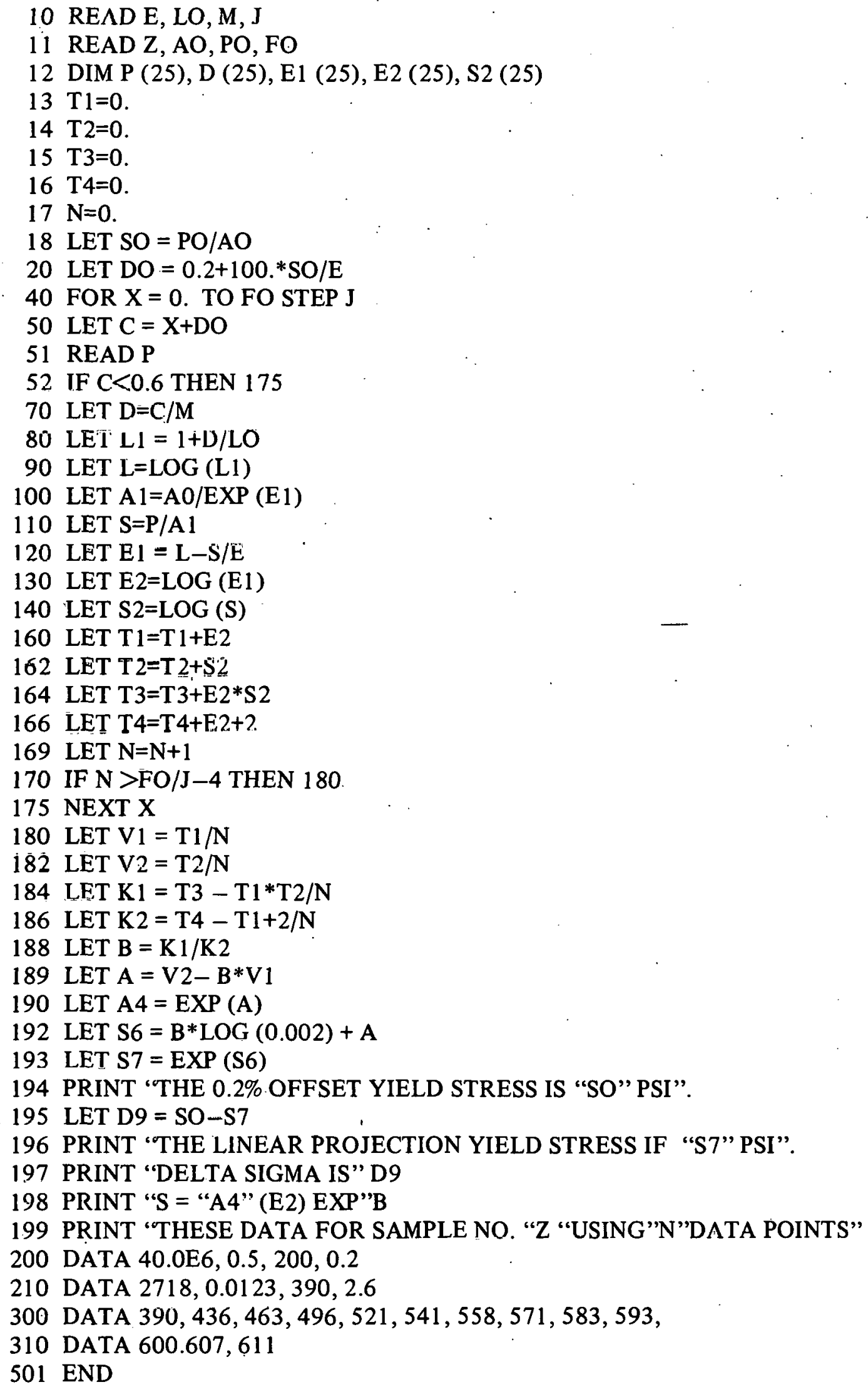




\section{APPENDIX B. Grain-Size Effect on Yield.}

Grain size is a key variable affecting yield, and most metals exhibiting yield points have an upper grain size limit beyond which yield drops are no longer observed. Therefore, the study of effects of grain size on yield and yield-point behavior of beryllium is essential to the stated objectives of this report.

Not a great deal of work has been done to quantitatively define the effect of grain size on yield in beryllium. The available data are clouded by the interaction of other variables affecting yield, such as fabrication method, chemistry, heat treatment, and texture. The earliest work, and still most commonly referenced work on grain size, was done by Macres in $1953 .{ }^{75}$ In this work the manner of varying grain size was to use input materials of different particle size. These materials ranged from coarse machine turnings to fine powder. The yicld stress-grain size data reported are really yield stress versus input particle size, since the grain sizes after fabrication of solid materials were not measured. Some recent authors have reduced Macres' data to fit the Hall-Petch relationship of yield stress being proportional to the inverse square root of grain size. ${ }^{42,76}$ Since Macres reports only his particle size and not his grain size, the constants obtained in such a plot may not be valid for predicting grain-size effects. Greenspan did a great deal of work with beryllium having varying grain sizes caused by different hot-working conditions. ${ }^{38}$ But his interests were in fracture behavior and he failed to report yield results. Jacobson, using beryllium powders of three different size ranges, obtained a linear yield stress versus inverse square root of grain size plot. ${ }^{77} \mathrm{He}$ did not determine the constants of the plot, and although he correctly measured grain size after fabrication, only one datum point was used for each grain size. Therefore confidence in his results is low.

In this work grain-size variations are brought about by grain-growth anneals. Two materials are used, both originating from large hot-pressings by Brush. One (BY) exhibits a yield drop and has a relatively high yield stress in the as-received condition. The other (BN) has no yield drop and a relatively low yield stress as-received. Chemical analyses given in Table 2 show that the iron contents are 1410 and $930 \mathrm{ppm}$ for the BY and BN materials; respectively. The corresponding aluminum contents are 800 and $400 \mathrm{ppm}$. Each of these materials is heat treated in high purity argon for 6 hours at temperatures of 800,1100 , and $1150^{\circ} \mathrm{C}$. Two different cooling rates are used: rapid (samples pulled from the hot zone to the cool end of the tube furnace while argon flows over them), and slow (programmed, $25^{\circ} \mathrm{C}$ per hour). Three tensile blanks are used for each combination of conditions.

The results are listed in Table 1-B. A grain size range of 10 to 35 microns is obtained for the $B Y$ material and a range of 20 to 45 microns for the $\mathrm{BN}$ material. The higher $\mathrm{BeO}$ content of the $\mathrm{BY}$ material ( $1.64 \%$ versus $1.20 \%)$ is probably responsible for its lower grain size subsequent to the 1100 and $1150^{\circ} \mathrm{C}$ anneals. A wide range in average yield stress is also seen in Table $1-B$, and the task is now to determine how much of the variation is from the change in grain size. The information in Figure 13 shows that the amount of iron in solid solution will have an effect on yield, and the two cooling rates used here should result in a variation in solid-solution iron. Before beginning this analysis, however, it is significant to note the data scatter in these tests. The range in values for a given heat treatment is narrowest for slow-cooled BN material, and broadest for fast-cooled BY material. This is most likely the result of variations in the amount of solid-solution iron resulting from varied cooling rates within a batch. With slow cooling, all test blanks cool uniformly; but, with rapid cooling, some blanks may cool more rapidly than others. The high iron and aluminum content of the BY material makes it more sensitive to such cooling variations because there is more iron available for precipitation.

There are two main effects responsible for the yield data in Table 1-B: grain size and iron distribution. Taking the iron effect first, note that the cooling 
Table 1-B. Grain Size and Yield Stress Data for Two Types of Hot-Pressed Beryllium, BY and BN, Given Various Heat Treatments (three tests per condition).

Heat Treatment

\begin{tabular}{cll}
\hline Temperature $\left({ }^{\circ} \mathrm{C}\right)$ & & Cooling Rate \\
800 & & Slow \\
& Fast \\
1100 & Slow \\
& Fast \\
1150 & Slow \\
& Fast
\end{tabular}

Average Grain Size (micruns)

$\frac{B Y}{10} \quad \frac{B N}{20}$

$20 \quad 35$

$35 \quad 45$
Yield Stress (ksi)

\begin{tabular}{|c|c|c|c|}
\hline Average BY & Range $B Y$ & Average $\mathrm{BN}$ & Range $B N$ \\
\hline 50.3 & $49.2-51.7$ & 33.0 & $32.7-33.0$ \\
\hline 50.8 & $50.6-51.3$ & 32.1 & $31.7-32.5$ \\
\hline 37.5 & $36.5-38.2$ & 28.9 & $28.8-29.3$ \\
\hline 43.6 & $41.4-45.6$ & 29.7 & $29.4-30.0$ \\
\hline 30.6 & $30.3-31.2$ & 23.2 & $22.8-23.6$ \\
\hline 35.6 & $34.4-38.6$ & 24.8 & $24.0-25.4$ \\
\hline
\end{tabular}

rate subsequent to the $800^{\circ} \mathrm{C}$ anneal does not affect the yield behavior of either material. This could be interpreted to mean that no further precipitation occurs on slow cooling from $800^{\circ} \mathrm{C}$, but the differences noted for the higher temperature anneals would then be hard to explain. More probably, the data for $800^{\circ} \mathrm{C}$ indicate that those. precipitates present in the as-received material as a result of slow cooling the large, production hotpressings are simply not dissolved by this $800^{\circ} \mathrm{C}$ treatment. Fast cooling subsequent to the $1100^{\circ} \mathrm{C}$ anneal results in a 6100 psi higher yield strength than does slow cooling for the BY material. And this difference is 5000 psi subsequent to the $1150^{\circ} \mathrm{C}$ anneal. The $\mathrm{BN}$ material on the other hand shows corresponding differences of 800 and 1600 psi. The reasons for differences in this effect at the twu temperaturès are obscure; probably resulting from experimental rather than micromechanistic considerations. But the reasons for the differences in this effect between materials is, at least in part, caused by solid-solution irnn. If the results for the two temperatures are averaged, then the magnitude of the effect is 5500 psi for the BY material and 1200 psi for the BN material.

These values are certainly in the direction predicted by Figure 13. In the case of the $\mathrm{RN}$ material, since its aluminum content is about the same as for the materials used to obtain Figure 13, the 2.3 psi per ppm solid-solution iron effect probably applies. Assuming, as before, that the solubility limit on slow cooling is $640 \mathrm{ppm}$ iron, then the change in iron content in solid solution as the result of rapid cooling is $290 \mathrm{ppm}$ (930 minus $640 \mathrm{ppm}$ ). This should result in a cooling-rate effect of about 700 psi for this change in iron content. The average figure observed for this effect is 1200 psi.
The BY material has an unusually high aluminum content and, as noted previously, the solubility for iron in beryllium is thought to decrease with increasing aluminum content ${ }^{64}$ Therefore the change in solid-solution iron content between fast and slow cooling should be around $1000 \mathrm{ppm}$, resulting in a cooling rate effecl of about $2.3 \mathrm{ksl}$. The observed effect is much higher, being about $5.5 \mathrm{ksi}$. The reason for this discrepancy is unclear.

Turning to the grain-size effect, the foregoing discussion indicates that the best measure of the grain-size effect comes by comparing rcsults in the slow-cooled condition. This is true because the solid solution iron content should remain constant for the different temperatures used and because the data scattcr is much lower in the slow-rooled condition. This grain-size effect can be deduced from the slope of the Hall-Petch type of plot shown in Figure 16. Note that the data, which extend over a 4.5 to 1 range of grain size, fit a straight-line quite wcll. The slope of these lines is constant at $136 \mathrm{ksi}-$ (microns) $^{1 / 2}$ and the intercepts, corresponding to an infinite grain size (i.e., a single crystal), vary depending upon couling rate and material. The fast-cooled high iron (BY) material has a singlc crystal fluw stress about 5000 psi higher than the slow-cooled BN material. This is caused by the solute-iron effect discussed above. The low-iron material (BN) has a single crystal flow stress 6000 psi lower than the BY material for the same slow-cooled condition. At first glance this result seems normal. In view of the higher iron content of the BY material, one would expect it to have a higher CRSS than the BN material. But in the slow-cooled condition the high-iron material should actually have less iron in solid 
solution than the low-iron material, as discussed above. Therefore another explanation is needed. The unknown texture differences between the two materials could account for some of the difference. Also the $0.4 \%$ difference in $\mathrm{BeO}$ content could contribute, since the BN material's yield stress should increase if its $\mathrm{BeO}$ content were raised to the level of the BY material, and the greater quantity of precipitates present in the BY material might be responsible. Results from the heat treatment section suggest that the effect of precipitates is at least $3.0 \mathrm{ksi}$, so the combined effect of $\mathrm{BeO}$ and texture is apparently no more than $3 \mathrm{ksi}$.

Again noting that these effects can not all be separated quantitatively, the significance of Figure 16 is that the slope for each curve is the same: $136 \mathrm{ksi}-(\text { microns })^{1 / 2}$. This means that the grainsize effect can be separated from other yield effects as follows. The change in grain size owing to a given treatment is measured and the stress change that should accompany that grain-size change is computed from the slope of the curve. This value is compared to the actual observed yield stress.

Any difference that is noted must result from something other than grain size. The stress intercept of the curve on the Hall-Petch plot is not necessary for such a computation. What the intercepts help emphasize in Figure 1-B is the major role that

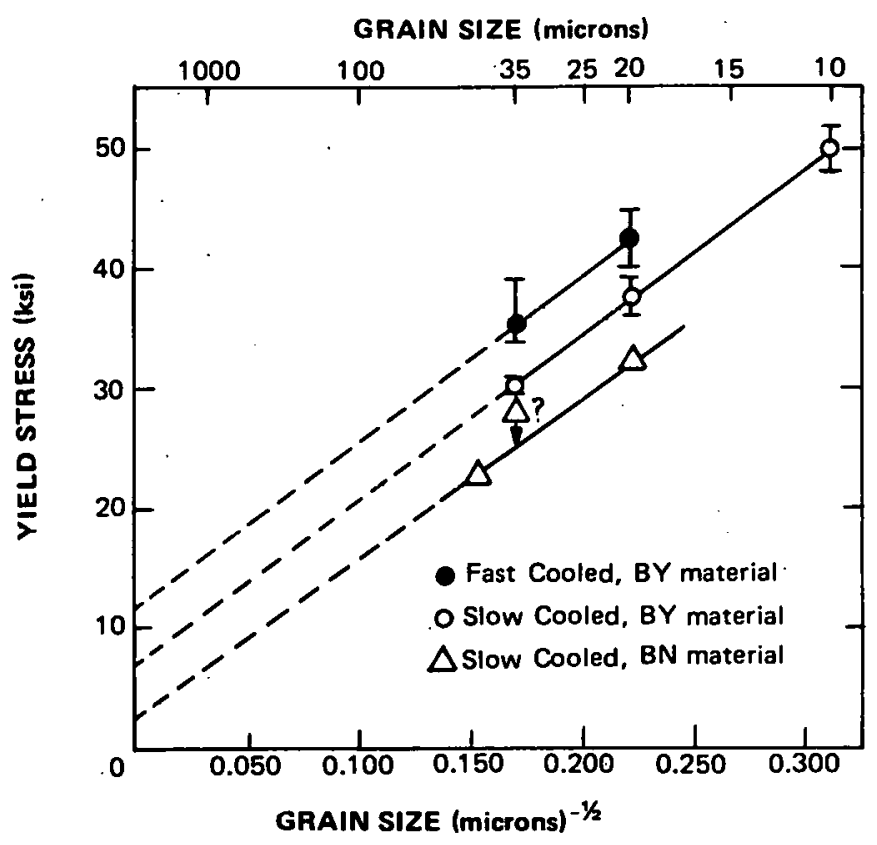

Figure 1-B. Plot of Vield Stress Versus Inverse SquareRoot of Grain Size for Hot Pressed Beryllium, BY-Material. Circles indicate the mean values and brackets the range for three tests.

texture and possibly $\mathrm{BeO}$ and other second phase impurities can play in determining the yield stress of beryllium. 
RFP-2061 


\section{APPENDIX C. X-Ray Diffraction Technique and Results.}

X-ray diffraction is used to identify the precipitates present in beryllium samples that are representative of different conditions of heat treatment and yield behavior. The experimental technique consists of traversing the two large ends of a fractured tensile bar with high voltage $(50 \mathrm{kV})$, high current $(40 \mathrm{~mA})$ copper $\mathrm{K}-a$ radiation. Complete scans, run on several samples, show the presence of two precipitates: the binary phase, $\mathrm{FeBe}_{11}$, and the ternary phase, $\mathrm{AlFeBe}_{4}$. Several peaks exist to establish the presence of these two phases, as shown in Figure 1-C. Fortunately, the major peak for each of these two phases occurs at nearly the same wavelength so only a short region of the spectrum need be scanned to see if these precipitates are present. Results of one such scan are shown in Figure 2-C. The height of each precipitate peak above the background level is measured to provide a comparison of the various materials and heat treatments as given in Table $1-C$. If the sample area scanned is constant from one sample to the next, as it is for all but one of the present samples, then the difference in peak heights is an indication of the relative amount of precipitates. For example,

Figure 1-C. Typical X-Ray Diffraction Pattern for a Beryllium Sample.






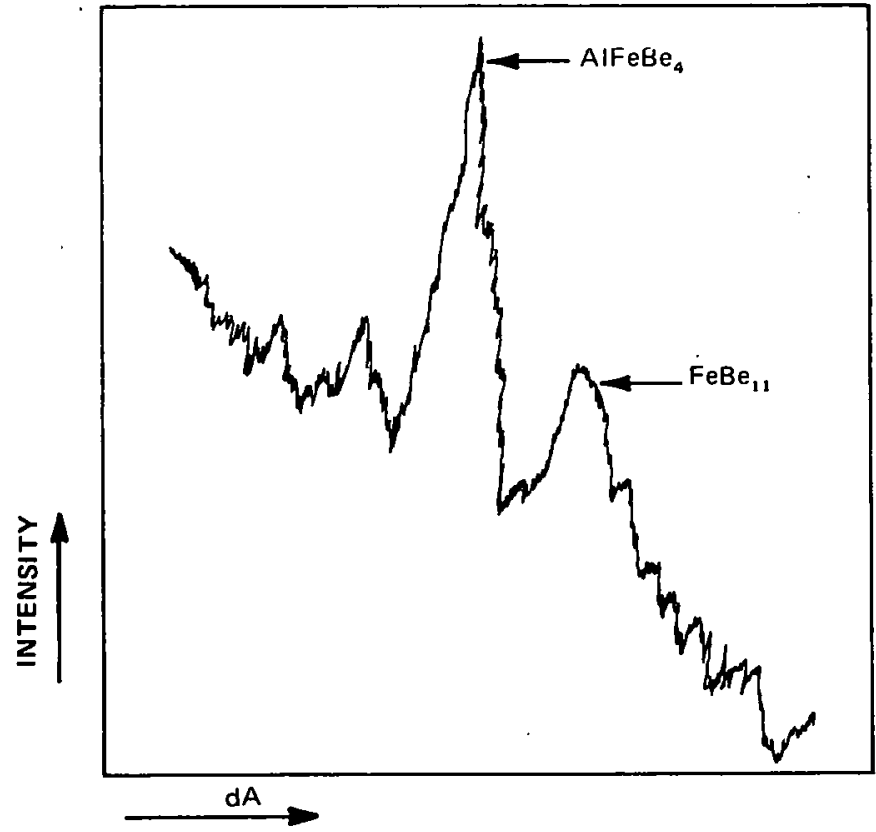

Figure 2-C, X-Ray Diffraction Pattern of the Highest Intensity Peaks for the Two Major Phases in Beryllium.

in Table 1-C, the BM material in the solutionized (S) condition shows peak heights of 5 scale divisions for each precipitate. When this material is aged at $650^{\circ} \mathrm{C}$ (B condition), this changes the peak heights to 7 scale divisions for the binary and 14 for the ternary. The technique is not sufficiently quantitative to conclude that an increase in peak height from 5 to 14 means that there is 2.8 times as much precipitate present after aging as was present in the solutionized condition. But it is reasonable to say that there is a significant increase in the amount of ternary precipitate as a result of the aging treatment, whereas there is not a significant increase in the amount of binary precipitate.

The heights of the binary and ternary peaks should not be compared to one another. If one has a height of 5 scale divisions and the other 7 , the one with the lesser height may, in fact, represent more precipitate. Also, the technique does not provide any information about the size or distribution of the precipitates. Therefore, it is possible that a few large precipitates of one phase will result in a larger amount of precipitate than many fine precipitates of another phase. But the finely dispersed
Table 1-C. Relative X-Ray Diffraction Peaks for Two Phases Present in Several Types of PowderSource Berylliım Given Various Hoat Treat ments.

\begin{tabular}{|c|c|c|c|c|}
\hline \multirow{2}{*}{$\begin{array}{c}\text { Material } \\
\text { Type }\end{array}$} & \multirow{2}{*}{$\begin{array}{l}\text { Heat Treat } \\
\text { Condition }\end{array}$} & \multicolumn{2}{|c|}{ Relative Peak Height: } & \multirow{2}{*}{$\begin{array}{c}\text { Yield Drop } \\
\text { Occurrence? }\end{array}$} \\
\hline & & $\mathrm{FeBe}_{11}$ & $\mathrm{AlFeBe}_{4}$ & \\
\hline BL & $\mathbf{S}$ & 5 & 4 & No \\
\hline BL & B & 10 & 8 & Nó \\
\hline BL & $\mathrm{T}$ & 10 & 6 & No \\
\hline BM & $\mathrm{AR}$ & 6 & 11 & Yes \\
\hline BM & $S$ & $s$ & 5 & No \\
\hline $\mathrm{BM}$ & B & 7 & 14 & Yes \\
\hline $\mathrm{BM}$ & $\mathrm{T}$ & 5 & 15 & Yes \\
\hline $\mathrm{BM}$ & MT & 3 & 21 & Yes \\
\hline BM & GT & 10 & 16 & No \\
\hline $\mathrm{BH}$ & AR & 26 & 15 & Nn \\
\hline $\mathrm{BH}$ & $\$$ & $(14)^{*}$ & $(0)$ & No \\
\hline BHI & B & (25) & $(10)$ & - \\
\hline $\mathrm{BH}$ & $\mathrm{T}$ & 15 & 3 & No \\
\hline BH & S.A.** & $7 * * *$ & $15 * * *$ & Yes \\
\hline$E F-45$ & $\mathrm{~S}$ & 12 & 9 & No \\
\hline$F F-45$ & $\mathbf{B}$ & 12 & 15 & Yes \\
\hline $\mathrm{EF}-45$ & $\mathbf{T}$ & 10 & 25 & Yes \\
\hline EF-45 & G & 10 & 4 & No \\
\hline$E F-45$ & GT & 15 & 24 & No \\
\hline K & $\mathbf{S}$ & $(10)^{* * *}$ & (n) & No \\
\hline K & MT & 9 & 20 & Yes \\
\hline $\mathbf{K}$ & B & (13) & (15) & No \\
\hline $\mathrm{K}$ & $\mathrm{T}$ & (12) & (20) & No \\
\hline
\end{tabular}

*Numbers in parcntheses are results from samples waterquenched from the solutionizing temperatures. All other results are from materials which were rapidly air-cooled.

**Strain-aged, solutionized initial condition, $1 / 2 \%$ pre-strain, $400^{\circ} \mathrm{C}$. age.

${ }^{*+*}$ Different sample size from rest of data.

phase will have the greater affect on yield behavior. A thorough understanding of the results of an $\mathrm{x}$-ray diffraction analysis such as this must include transmission electron microscopy (TEM) to help separate out this precipitate size effect. Such TEM support has nut been uone for the materials listed in Table $1-\mathrm{C}$.

Having noted the limitations of this $\mathrm{x}$-ray diffraction technique, it is useful to review the data in Table $1-\mathrm{C}$ as it relates to the yield-point behavior.

The reference material (BM) has a medium amount of iron present chemically (1720 ppm). In the asreceived condition, a yield drop occurs as noted in the right hand column of Tablc $1-\mathrm{C}$ and the binary 
and ternary precipitates are both present. The solutionizing treatment (S) dissolves the ternary phase (11* decreases to 5) without significantly changing the binary (6 decreases to 5 ). Solutionizing also eliminates the yield drop. Aging at $650^{\circ} \mathrm{C}(\mathrm{B})$ or $760^{\circ} \mathrm{C}(\mathrm{T})$ causes a return of the yield drop and a return of the ternary precipitate ( 5 increases to 14 and 15 for $B$ and $\mathrm{T}$, respectively). The binary precipitate does not change significantly for these same heat treatments. Since a yield drop returns with these same heat treatments, the pinning precipitates appear to be the ternary rather than the binary.

The low-iron material (BL) does not show a large change in the amount of precipitate on aging; although the amount of both precipitates increases compared to a solutionized condition. No yield drop is noted. The high-iron material is devoid of ternary precipitate in the solutionized condition. Aging causes some ternary precipitate to appear but no yield drop occurs. Strain aging, however, causes ternary precipitate to appear and, concurrently, a yield drop.

The extruded material also shows this association of ternary phase with yield drops. In the solutionized condition, the relative peak heights of binary and ternary phase are 12 and 9 scale divisions, respectively. Aging this material at $650^{\circ} \mathrm{C}$ causes a yield drop to occur, leaves the amount of binary phase the same (12), and increases the amount of ternary phase present ( 9 increases to 15 ). Aging at $.760^{\circ} \mathrm{C}$ again causes a yield drop, does not significantly alter the amount of binary phase, and still

\footnotetext{
*Numbers are taken from Table $1-C$ and refer to the relative magnitudes of the $x$-ray diffraction peaks.
}

increases the amount of ternary phase even more than the $650^{\circ} \mathrm{C}$ aging treatment (9 increases to 25 ).

The importance of cooling rate after solutionizing can be seen for the $\mathrm{K}$ material in the $\mathrm{S}$ condition. Water quenching leaves no ternary precipitate, whereas a significant amount is present in material quenched in air. Aging at $650^{\circ} \mathrm{C}$ and $760^{\circ} \mathrm{C}$ does not change the amount of binary phase significantly but does cause a significant increase in the amount of ternary phase. However, a yield drop does not develop. A yield drop does develop when the ashot-pressed material is directly aged at $760^{\circ} \mathrm{C}$ without prior solutionizing (MT condition). The amount of ternary phase present in this condition appears from Table 1-C to be quite high.

There is, therefore, substantial evidence that the precipitate responsible for the yield drop is not the binary phase, as is inferred by the heat-treat results for the high-iron material. Rather, $x$-ray diffraction results for the high-iron material and three other powder-source materials (BM, EF, K) indicate that the ternary phase $\mathrm{AlFeBe}_{4}$ is the pinning precipitate.

$\mathrm{X}$-ray diffraction results for material given the $1150^{\circ} \mathrm{F}, 6$-hour grain-growth anneal (G) followed by aging (GT) are included in Table $1-C$. These data, shown for the BM and EF materials, show that the presence of a large quantity of ternary phase ( 16 and 24 , respectively) is not sufficient to cause a yield drop. Apparently either the growth of large grains or the redistribution of the ternary phase accompanying grain growth has eliminated the yield drop. To establish which of these is responsible, additional TEM work is needed. 